NRTSC

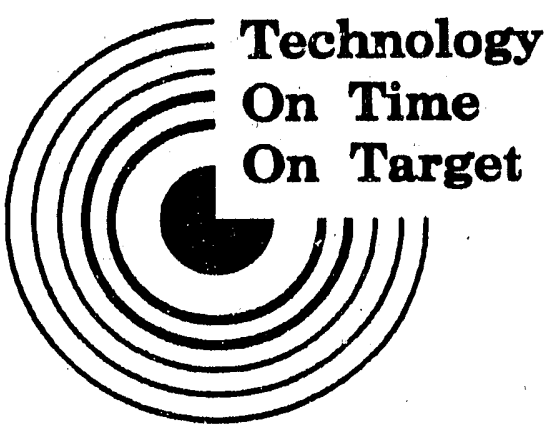

WSRC-TR-91-569

\title{
VALIDITY OF THE RULE-OF-FRACTIONS FOR ASSURING CRITICALITY SAFETY MARGINS (U)
}

October, 1991

C.s. Quarm 


\section{DISCLAIMER}

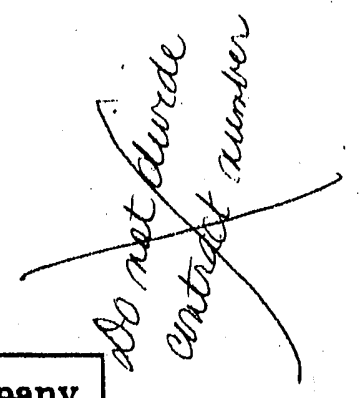

This report was prepared by Westinghouse Savannah River-Company (WSRC) for the United States Department of Energy under Contract DEAC09-89SR18035 and is an account of work performed under that contract. Netther the United States, the United States Department of Energy nor WSRC, nor any of their employees, makes any warranty, express or implied, or assumes any legal liability or responsibility for the accuracy, completeness, or usefulness of any information, apparatus, product, or process disclosed herein, or represents that its use will not infringe privately owned rights. Reference herein to any specific commercial product, process or service by trade name, mark, manufacturer, or otherwise does not necessarily constitute or imply endorsement, recommendation, or favoring of same by WSRC or by the United States Government or any agency thereof. The views and opinions of authors expressed herein do not necessarily state or reflect those of the United States Government or any agency thereof.

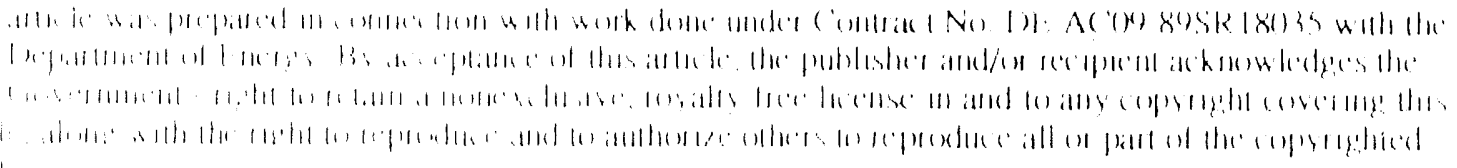


NUCLEAR REACTOR TECHNOLOGY AND SCIENTIFIC COMPUTATIONS

Key Words: Criticality Margins

Rule-Of-Fractions Method "B"

Mass Equivalents

Retention F'eriod: Lifetime

\section{VALIDITY OF THE RULE-OF-FIRACTIONS FOR ASSURING CRITICALITY SAFETY MARGINS (U) by}

Donald R. Finch and

Thomas G. Williamson

Issued: October, 1991
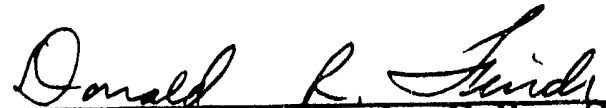

Donald R. Finch, Senior Fellow Scientist

J.G. Uill enso Thomas G. Williamson, Senior Consulting Scientist

SRL SAVANNAH RIVER LABORATORY, AIKEN, SC 29808 Westinghouse Savannah River Company

Prepared for the U. S. Department of Energy under Contract DE-AC09-88SR18035

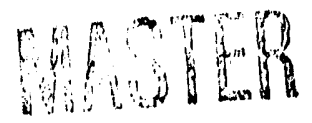




\section{PROJECT:}

DOCUMENT: $\quad$ WSRC-TR-91-569

TITLE: $\quad$ Validity Of The Rule-Of-Fractions For Assuring Criticality Safety Margins (U)

TASK:

\section{APPROVALS}

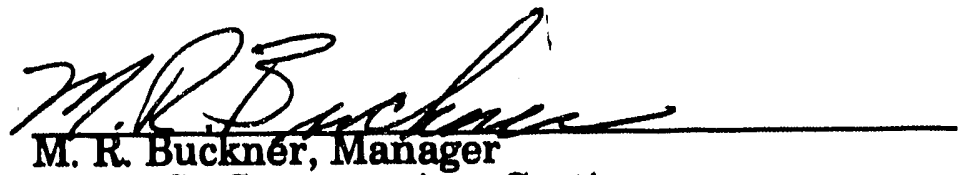

Scientific Computations Section

Date: $|P-2 z-q|$

C.S. Gyseusm
C.E.Apperson, Manager
Reactor Physics Group

Date: $10-15-91$

17

J. F Mincey, IAchnical Rqviewer

Date: $10 / 14 / 91$ 


\section{ABSTRACT}

A computational study was performed to determine the validity of the Rule-of Fractions for assuring criticality safety margins. The form of the Rile-ofFractions examined was the equation:

$$
\sum_{i} \frac{a_{i}}{A_{i}} \leq 1
$$

where $a_{i}$ is the quantity of fissile/fissionable nuciide present, and $A_{j}$ is the quantity of the same nuclide $i$ that corresponds to a known margin in $K_{e f f}$. The study considered binary mixtures of two nuclides that exactly satisfied the equality condition of the equation. Keff values of homogeneous and heterogeneous binary mixtures of fissile/fissionable nuclides in metal and solution form were considered in spherical geometry. Results were compared to Rule-of-Fraction predicted $K_{e f f}$ values using an assumed linear relationship. Calculations were performed with the ANI8N code with Hansen-Roach and ENDF/B-IV cross sections. The results of this study demonstrated that the Rule-of-Fractions in the above equation does not always maintain criticality safety margins in $k_{\text {eff }}$ for mixtures of nuclides. 
(Blank Page) 


\section{INTRODOCTION}

The Rule-of-Fractions has been used in many applicacions to assure a minimum margin in $K_{e f f}$ for various homogeneous and heterogeneous mixtures of fissile and fissionable isotopes. In its simplest form the rule of fractions may be stated as follows:

$$
\sum_{i} \frac{a_{i}}{A_{i}} \leq 1
$$

where $a_{i}$ is the actual amount of quantity $i$ present, and $A_{i}$ is an amount of quantity $i$ that corresponds to a specified margin in

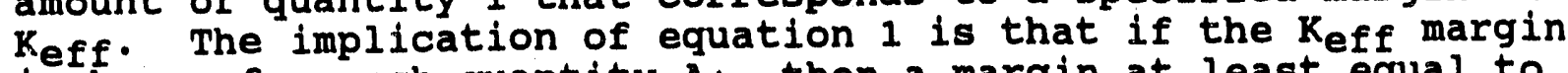
is known for each quantity $A_{i}$, then a margin at least equal to the smallest $K_{\text {eff }}$ margin for any $A_{f}$ is maintained when arbitrary amounts of quantities $i$ are intermixed, and the conditions of equation 1 are met.

The relationship in equation 1 is quoted in section 5.2 of the ANSI/ANS 8.15 standard for use with fissile isotopes. The statement is not a justification for the use of equation 1. Rather, it is a statement taken from some document in the public domain, although no reference is given in the standard.

Assurance of safe margins in $\mathrm{K}_{\text {eff }}$ based on equation 1 hass, been used in several applications at the Savannah River site 2,3 , although a full justification for equation 1 cannot now be found. The justification for a method (called Method "B") derived from equation 1 was questioned during a Technical safety Appraisal, and led to this study which was originally intended to provide the required justification.

\section{EXAYPLES OF THE RTLE-OF-RRACTIONS}

Three examples of the use of the Rule-Of-Fractions to assure a margin in $K_{\text {eff }}$ will be shown below. Each example is a documented use of the Rule-Of-Fractions at the Savannah River site to assure a justified margin of safety in $K_{e f f}$.

\section{A. Mixtures of Fissile Containers In Shipping Package}

A SRS shipping package ${ }^{2}$ is used to ship three types of fissile materials (referred to as Type A, Type B, and Type C respectively). The package contains up to five bottles of fissile material in a vertical column as shown in Figure 1.

The Rule-of-Fractions was used as a quick method to determine the Keff for mixtures of bottles of the three fissile materials. This was done by weighting the infinite array reactivity of each type of material by itself by the fractional 
number of bottles of that kind present. The calculated $\mathrm{K}_{\text {ef }} \mathrm{f}$ for each infinite array was as follows:

PACRAGE FIBgIIS CONYENT
5 bottles TYpe A
5 bottles Type B
5 bottles Type C

\author{
INFINITE ARRAY ReEE \\ $0.770 \pm 0.004$ \\ $0.583 \pm 0.004$ \\ $0.517 \pm 0.004$
}

The Rule-of-Fractions was checked by calculation for loadings of five bottles of two types of fissile material (Type A and Type B). For this case the Rule-of-Fractions $K_{e f f}$ is given by:

$$
\mathrm{K}_{\text {eff }}=\frac{\mathrm{N}_{\mathrm{A}}}{5} 0.770+\frac{\mathrm{N}_{\mathrm{B}}}{5} 0.583
$$

where $N_{A}$ and $N_{B}$ are the number of bottles of Type $A$ and Type $B$, and the calculated values of $K_{e f f}$ are shown in Table $I$ (the derivation of equation 2 will be shown later). A comparison between calculated $K_{\text {eff }}$ values and equation 2 is shown in Figure 2. These results show excellent agreement between the two methods, and provides reasonable assurance that a specified margin in $K_{\text {eff }}$ is preserved. This is an example of the use of the Rule-of-Fractions for heterogeneous mixtures of fissile materials in geometrically same containers. The good agreement between calculation and Rule-of-Fractions appears to be as much dependent on the geometry as on the fissile material content.

\section{B. Savannah River Laboratory Method "B"}

This particular method appeared in the SRL Criticality Control Procedure Manual ${ }^{3}$ as a method for maintaining criticality safety in mixtures of fissile/fissionable isotopes. The method starts by rewriting equation 1 in terms of a quantity $Q_{1}$ defined by:

$$
Q_{i}=1 / A_{i}
$$

equation 1 then becomes:

$$
\sum_{i} a_{i} a_{i} \leq 1
$$

A table of values of $Q_{i}$ are provided for each isotope $i$, hence satisfying equation $1 \mathrm{~A}$ assures criticaljty safety 1 The $Q_{i}$ are defined primarily from the ANSI/ANS 8.1 and 8.151 standards by taking the mass limits from the standards as the $A_{i}$ and rounding the resulting $Q_{i}$ upward. Table II shows the $Q_{i}$ defined in the Procedure Manual. 


\section{TABLE I}

\section{CALCULATIONB OF MIXTUREB OF TYPB A AND TYPE B FIB8ILE MATERIAL BOTTLEB IN INTINITE ARRAY OF BHIPPING PACKAGEB \\ (See Figure 1)}

\section{Position of Type B Bottles}

\section{Calculated Xere}

1 Bottle Type B - 4 Bottles Type A

$\begin{array}{ll}1 & 0.734 \pm 0.004 \\ 2 & 0.736 \pm 0.004 \\ 3 & 0.730 \pm 0.004 \\ \text { ation } 2 & 0.733 \pm 0.005 \\ \text { ation } & 0.733\end{array}$

2 Bottles Type B - 3 Bottles Type A
1,5
$0.694 \pm 0.004$
2,4
$0.701 \pm 0.004$
2,3
$0.698 \pm 0.004$
1,2
$0.695 \pm 0.004$
1,3
$0.686 \pm 0.004$
$0.695 \pm 0.005$
0.695

Average

Equation 2

3 Bottles Type B - 2 Bottles Type A
$2,3,4$
$1,4,5$
$0.655 \pm 0.004$
$1,3,5$
$0.662 \pm 0.004$
$3,4,5$
$0.656 \pm 0.004$
$2,4,5$
$0.663 \pm 0.004$
Average
$0.663 \pm 0.004$
Equation 2
$0.660 \pm 0.005$
0.658
4 Bottles Type B - 1 Bottle Type A
$1,2,4,5$
$0.615 \pm 0.004$
$1,3,4,5$
$0.617 \pm 0.004$
$2,3,4,5$
$0.618 \pm 0.004$
Average
$0.617 \pm 0.005$
Equation 2
0.620 


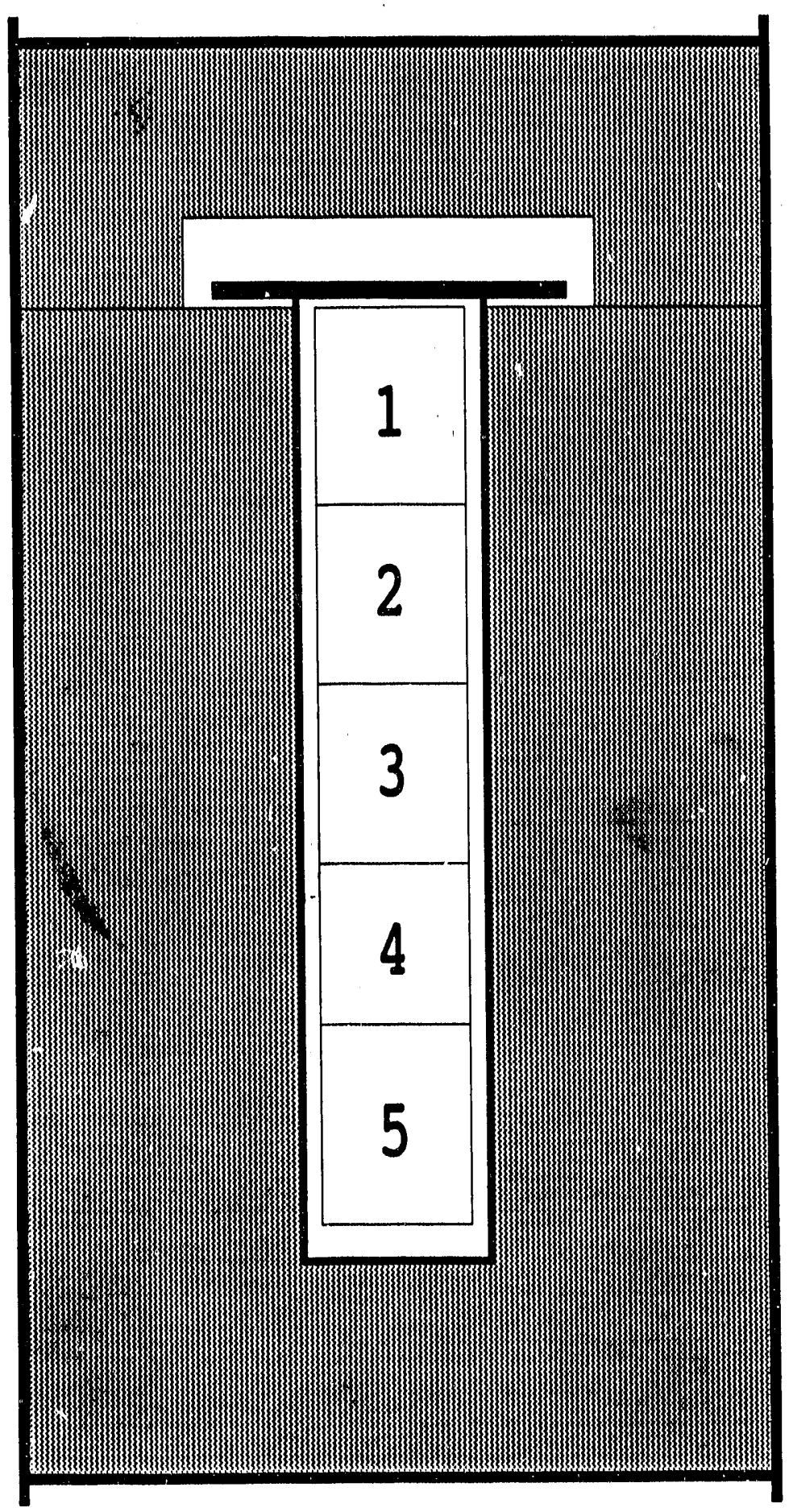

SHIPPING PACKAGE ARRANGEMENT FIGURE 1 


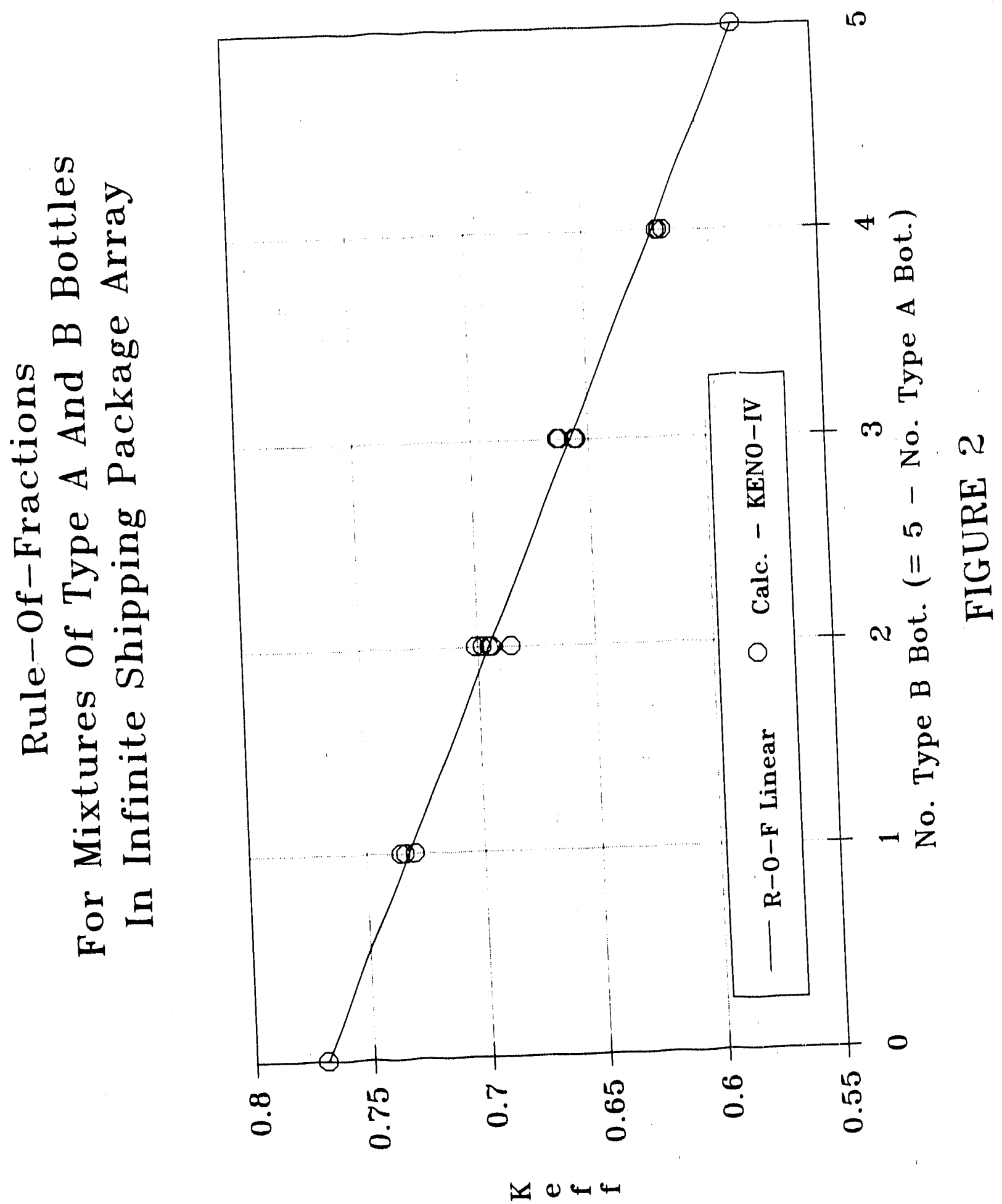




\section{ISOTOPIC EOUIVALENTS}

A variety of equivalency expressions abound in the literature that express quantities of fissile/fissionable isotopes that are critically equivalent to another fissile/fissionable isotope. Such expressions are very subject to the external conditions (eg., water reflection, concentration in solution, or bare metal) and many times are stated specifically for one condition only.

To express the coublined mass of several fissile isotopes as an equivalent amount of ${ }^{2.15} U$ one might proceed as follows. First write equation 1 as an equality because exact equivalency that assures a specified margin in Keff is the desired result. Define the $a_{f}$ as the actual quantity of isotope $i$ present and the $A_{i}$ as the IImiting quantities of isotope $i$ that assures a known margin

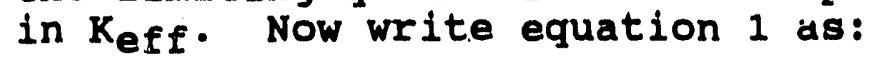

$$
\sum_{i}^{\prime} \frac{a_{i}}{A_{i}}=1-\frac{a_{235}}{A_{235}}=\frac{A_{235}-a_{235}}{A_{235}}
$$

where the prime on the summation indicates the ${ }^{235} \mathrm{U}$ term was removed. Multiplying by $A_{235}$ then yields the form:

$$
A_{235}-a_{235}=\sum_{i}^{\prime} a_{1} \frac{A_{235}}{A_{1}}
$$

The ration of $A_{235} / A_{1}$ can now be defined from accepted mass quantities that assure a specified $K_{\text {eff }}$ margin, or simply taken from ANSI/ANS $8.1^{4}$ or $8.15^{1}$. The statement that equation $4 \mathrm{~A}$ makes is that any quantity of $235 \mathrm{U}$ mass in a mixture not explicitly present is equivalent to the sum of masses of isotopes weighted by the terms on the right side of equation $4 \mathrm{~A}$. Another way to state this is that the equivalent mass of $235 \mathrm{U}$ represented by mass $a_{i}$ is defined by:

$$
\text { equivalent }{ }^{235} \mathrm{U} \text { mass }=a_{1} \frac{A_{235}}{A_{1}}
$$

Equation 5 more often appears with the summation from the right side of equation $4 \mathrm{~A}$ on its right side so that several isotopes may appear in the isotopic mixture.

The limitations of equivalency relationships in the form of equations $4 \mathrm{~A}$ or 5 are the following:

- All $A_{i}$ must be defined for the same environmental conditions.

- These equations assume that all isotopes behave the same no matter how the spectra is changed by the presence of other isotopes. 
TABLE II

quality ractors for Method "B"

"O" FACTOR

$7.5 \times 10^{-8}$

$1.5 \times 10^{-3}$

$2.3 \times 10^{-3}$

$1.0 \times 10^{-3}$

$1.4 \times 10^{-3}$

$5.3 \times 10^{-5}$

$2.1 \times 10^{-1}$

$1.7 \times 10^{-5}$

$2.1 \times 10^{-3}$

$7.0 \times 10^{-5}$

$1.5 \times 10^{-3}$

$3.5 \times 10^{-4}$

$2.3 \times 10^{-3}$

$7.0 \times 10^{-5}$

$5.3 \times 10^{-3}$

$2.6 \times 10^{-5}$

$6.6 \times 10^{-5}$

$8.1 \times 10^{-2}$

$4.2 \times 10^{-5}$

$1.2 \times 10^{-2}$

$3.5 \times 10^{-4}$

$3.5 \times 10^{-2}$

$1.2 \times 10^{-3}$
MATFRTAX

$1 / 0$ (arams) REF.

Normal uranium (<0.72\% Non- $238 \mathrm{U}) \quad 1.33 \times 10^{7}$

Enriched Urąjum (ex̧luding

Plutonium (
Americium (< $\left.10 \% 242 \mathrm{Am}+242 \mathrm{~m}_{\mathrm{Am}}\right)$

Americium $1<18 \%$
Curium $1<5 \%$

Neptunium, any isotopic

Californium, any isotopic

protactinium, any isotopic $233 \mathrm{U}$

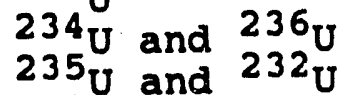

$238 \mathrm{Pu}$

$239 \mathrm{Pu}$

$240 \mathrm{Pu}$

$241 \mathrm{Pu}$

$242 \mathrm{Pu}$

$241 \mathrm{Am}$

$242 \mathrm{Am}$ and $242 \mathrm{~m}_{\mathrm{Am}}$

$243 \mathrm{Am}$

$243 \mathrm{~cm}$

$244 \mathrm{~cm}$

$245 \mathrm{~cm}$

$247 \mathrm{~cm}$
667

435

1000

714

18868

4.75

58824

476

14275

667

2857

435

14275

189

38462

15152

12.35

23810

83.3

2857

28.6

B33

Berkelium, Einsteinium, Fermium, etc.: No "Q" Factoris are assigned for isotopes of these elements. The handling of these materials will require special evaluation and approval. 


\section{BPECULATION ON THE K Ef MARGIN PREDICTED BY R-O-F}

The major unknown in specifying a mass limit or limiting condition using equation 1 is knowledge of the $K_{\text {eff }}$ value, hence Keff margin the equation predicts. A literature search has revealed very little of meaning in this regard. What appears here is the authors' speculation on the $K_{e f f}$ margin produced from the relation.

The shipping package in secision II will provide a first look at the question. In this example the following information was available:

- The Keff value of the empty package was 0.0 .

- The Keff value of the package with 5 Type A bottles was 0.77 .

- The Keff value of the package with 5 Type B bottles was 0.583 .

It would be natural to approximate the Keff behavior arsuming a linear relationship with the number of bottles as the independent variab? This yields:

$$
\begin{aligned}
& K_{\text {eff }}(\text { Type } A)=\frac{N_{A}}{5} 0.77 \\
& K_{\text {eff }}(\text { Type } B)=\frac{N_{B}}{5} 0.583
\end{aligned}
$$

Since the number of bottles $\left(N_{A}+N_{B}\right)$ always equals 5 , then:

$$
\mathrm{N}_{\mathrm{A}}=5-\mathrm{N}_{\mathrm{B}}
$$

and a superposition of equations 6 yields:

$$
K_{\text {eff }}\left(\text { Type } A+\text { Type } B \text { ) }=\frac{N_{A}}{5} 0.77+\frac{N_{B}}{5} 0.583\right.
$$

which is identical to equation 2 . Using the relationship between $\mathrm{N}_{\mathrm{A}}$ and $\mathrm{N}_{\mathrm{B}}$ in equation 7 yields:

$$
K_{\text {eff }}(\text { Type } A+\text { Type } B)=0.77-\frac{N_{B}}{5} 0.187
$$

which is the straight line shown in Figure 2. The validity of eriuation 9 depends completely on equations 6 . Calculations were performed with one to five Type $A$ bottles in the package and the results are shown in Figure 3 along with the first of equations 6 . The straight line approximation in equations 6 appears to be a resonable assumption, although none of the calculated points agree perfectly with equation 6 . 


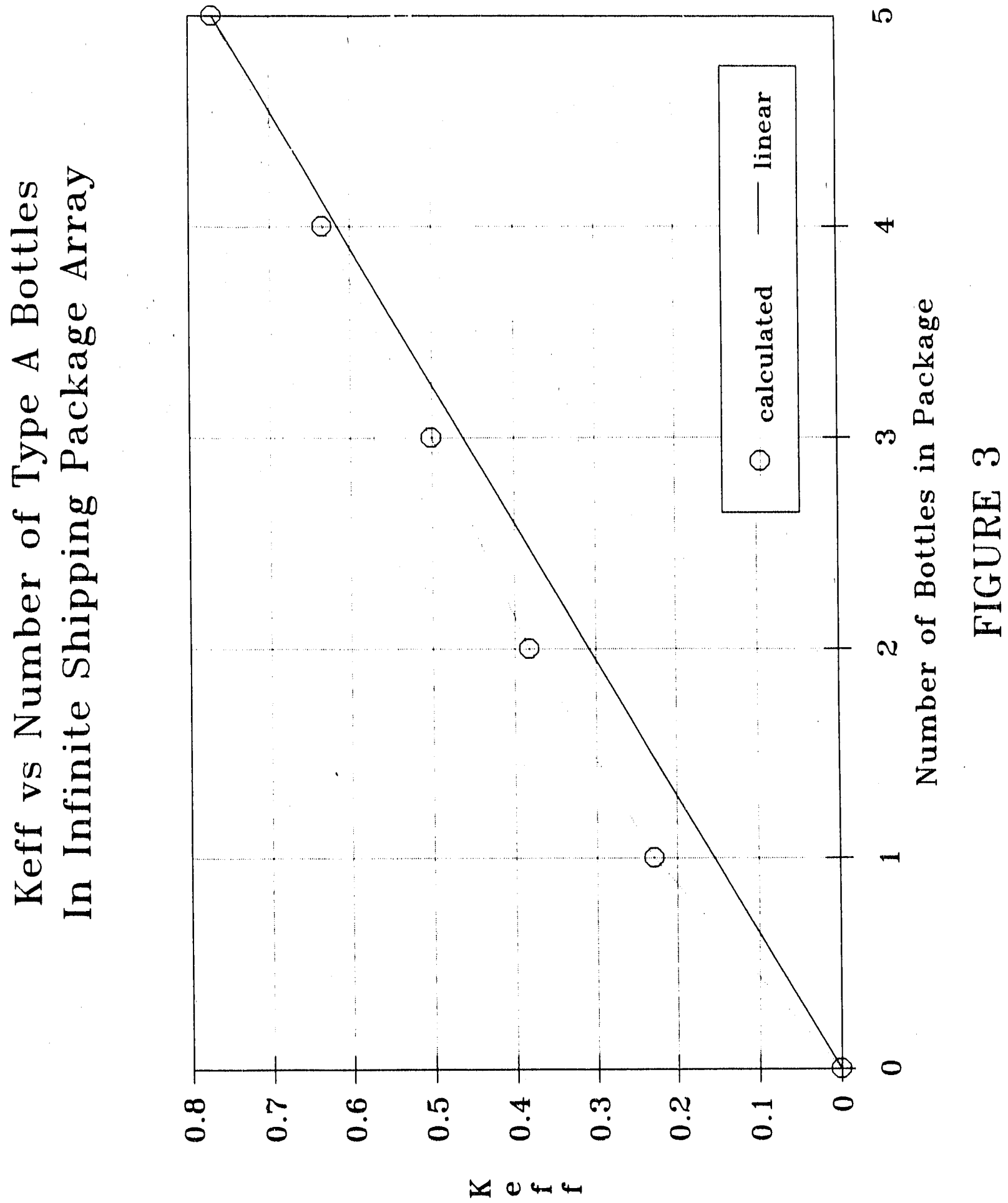


At this point it is convenient to define a term called the single Unit Mass as follows:

\section{single Unit Mass - A mass of fissile/fissionable material of known geometry that provides a known margin $\left(1-K_{e f f}\right)$ for specified conditions.}

Using this single unit mass (SUM), look now at the relationship between keff and SUM fraction for a homogeneous bare sphere of fissile material. Figure 4 shows this relationship for $23{ }^{\mathrm{U}},{ }^{239} \mathrm{Pu}$, and $240 \mathrm{Pu}$ derived from $\mathrm{s}_{16} \mathrm{P}_{1}$ NNI8N calculations using Hansen-Roach cross sections ${ }^{7}$. The sUM was chosen to produce a Keff of 0.95 and gaye calçulated massgs of $38.97 \mathrm{Kg}$., $8.28 \mathrm{Kg}$. , and $29.56 \mathrm{~kg}$. for ${ }^{235 \mathrm{U},}{ }^{2}{ }^{3} \mathrm{Pu}$, and $24 \mathrm{Pu}_{\mathrm{Pu}}$ respectively. Note how the curves for different isotopes almost reproduce each other. Also shown in Figure 4 is a straight line which is analogous to the linear assumption used for the shipping package above, however it does not represent the calculated results well.

Next, exgmine the changes in $\mathrm{K}$ ff $\mathrm{f}^{\mathrm{r}} \mathrm{r}$ homogeneous binary mixture of $23 \mathrm{~J}_{\mathrm{U}}$ and $240 \mathrm{Pu}$ as the $235_{\mathrm{U}} / 24{ }_{\mathrm{Pu}}$ ratio changes. The two isotopes are mixed so that the Rule-of-Fractions at equality is always satjisfied at a Keff of 0.95 ( 0.05 margin). That is:

$$
\frac{a_{235}}{A_{235}}+\frac{a_{240}}{A_{240}}=1
$$

The two ratios in equation 10 are simply the fractions of a single Unit Mass in both cases so that it is more easily written as:

or:

$$
F_{235}+F_{240}=1
$$

$$
F_{240}=1-F_{235}
$$

Using these single Unit Masses, Keff vs. 235U/240Pu mixture for a bare spherical homogeneous gegmetry is shown in Figure 5 . The isotopic mixtures vary from a $240 \mathrm{Pu}$ SUM at the left side to a 235 U SUM at the right side. Also shown in Figure 5 are curves and superpositions of the curves shown in Figure 4 for the two isotopes, and superposition of linear assumption curves for the two isotopes. Because the $K_{\text {eff }}$ values for the two single unit mass curves give 0.95 at the end points, it is reasonable to assume that the Rule-of-Fractions would predict that a margin of 0.05 is maintained through the entire range of mixtures. However, for this to be true requires use of the linear assumption curves from Figure 4. Superposition of the individual reactivity curves gives a $k_{\text {eff }}$ exceeding 1.0 by a large amount. Results of actual $K_{\text {eff }}$ calculations using ANISN $\left(S_{16} P_{1}\right)$ are also shown in Figure 5 and do not agree with either of the superposition curves. 


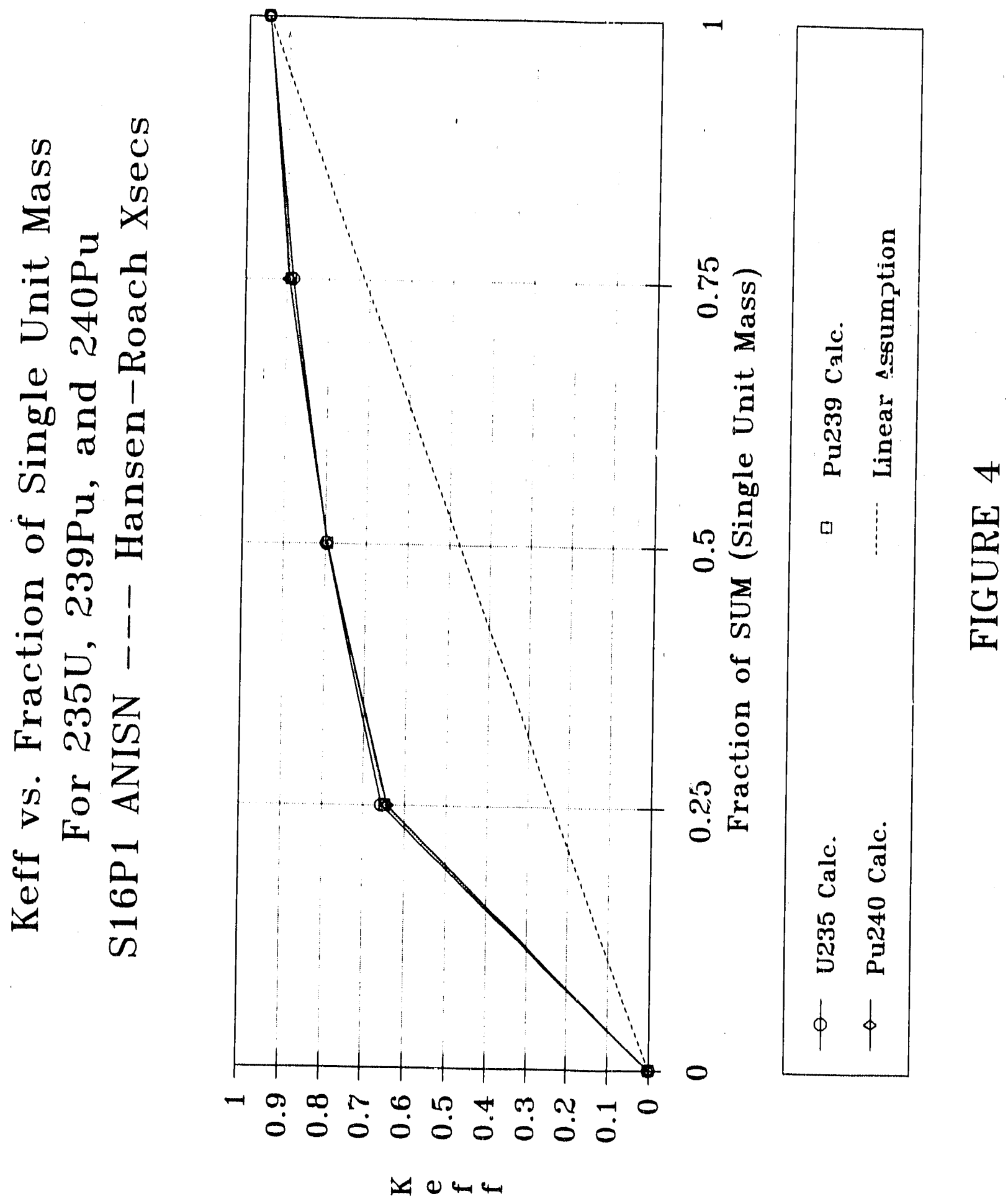




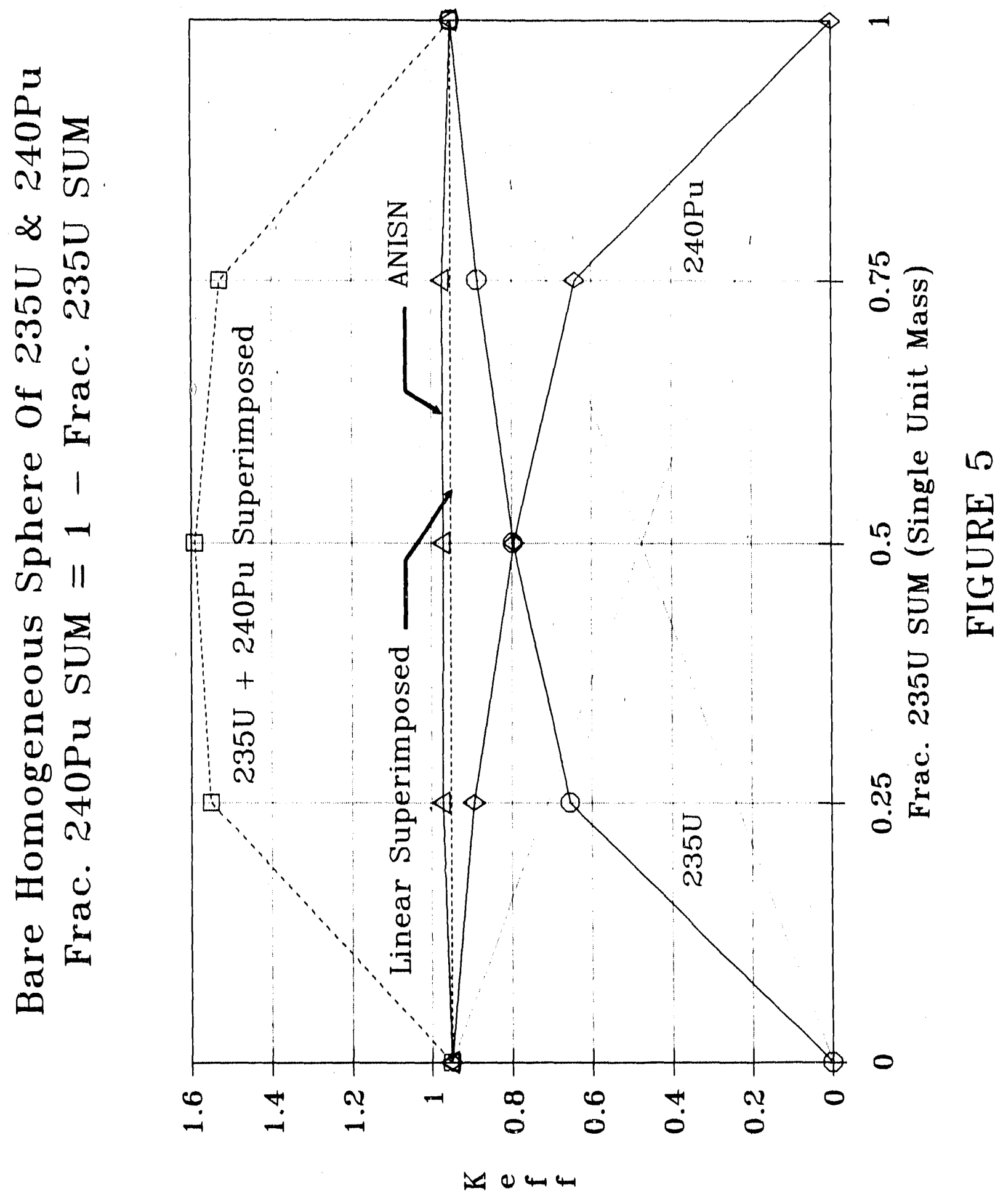


The result of the above exercise is confusion. It is logical to assume that $K_{e f f}$ (and its associated margin) is defined by a straight line connecting the 0.95 values at the end of the curves for the two isotopes, but this is not borne out by calculation. A more detailed picture of the calculations is shown in Figure 6 , and shows significant deviation from the straight line. The calculations demonstrate that a $K_{e f f}$ margin is not maintained, at least not one that is determined a priori.

These two examples, one that appears to confirm the Rule-ofFractions and another that does not, illustrate the problem of assuring a margin in $k_{e f f}$ with limits placed on physical entities like mass, geometry, and spacing. A well-defined relationship between $K_{e f f}$ and the controlled entities must exist to be assured that proper margins are maintained over a range of conditions. For the Rule-of-Fractions the question is whether a relationship exists, or whether agreement is fortuitous.

\section{Basis of computational Btudy}

Because of the mixed results shown in section III, a computational study of homogeneous and heterogeneous mixtures of fissile/fissionable isotopes was performed to find the general conditions under which the Rule-of-Fractions might be a vaild method for assuring criticality safety margins. The geometry for this study was chosen to be one-dimensional spheres surrounded by different reflectors. Within this geometry restriction examination of interaction effects between isotopes were accomplished, but geometrical effects like those in the shipping package discussed above could not be examined.

Any investigarion of interactions between isotopes involves detailed consideration of neutron spectrum and the factors that influence neutron spectrum. Multiple cross section sets should be used for each problem to elicit spectrum changes from that source. Where spectrum effects are important different cross sections always produce different answers.

\section{The study yas performed for two isotope (binary) mixtures of isotopes $235 \mathrm{U}, 238 \mathrm{Pu}, 23{ }^{\mathrm{Pu}}$, and $248 \mathrm{Pu}$ in metal form and solution form. Each mixture of isotopes was defined to meet the equality condition of the Rule-of-Fractions as was done in Equations 10 and 11. The isotopes were selected because good cross sections were available from the Hansen-Roach ${ }^{7}$ and ENDF/B-IV ${ }^{8}$ ibraries, and permitted examination of fissile-fissile, fissionable- fissionable, and fissile-fissionable mixtures of the four isotopes. $S_{n}$ transport calculations were performed using the ANI8N module in the Korg system ${ }^{9}$. Mixture cross sections were prepared using the HRXN 18 and GLAs8 11 modules in the roxo system. All $K_{\text {eff }}$ values were calculated for $s_{4}, s_{8}$, and $s_{16}$ quadrature and extrapolated to $S_{\infty}$.}

The question raised in section III - What is the $K_{e f f}$ predicted by the Rule-Of-Fractions? - is still unanswered. For 


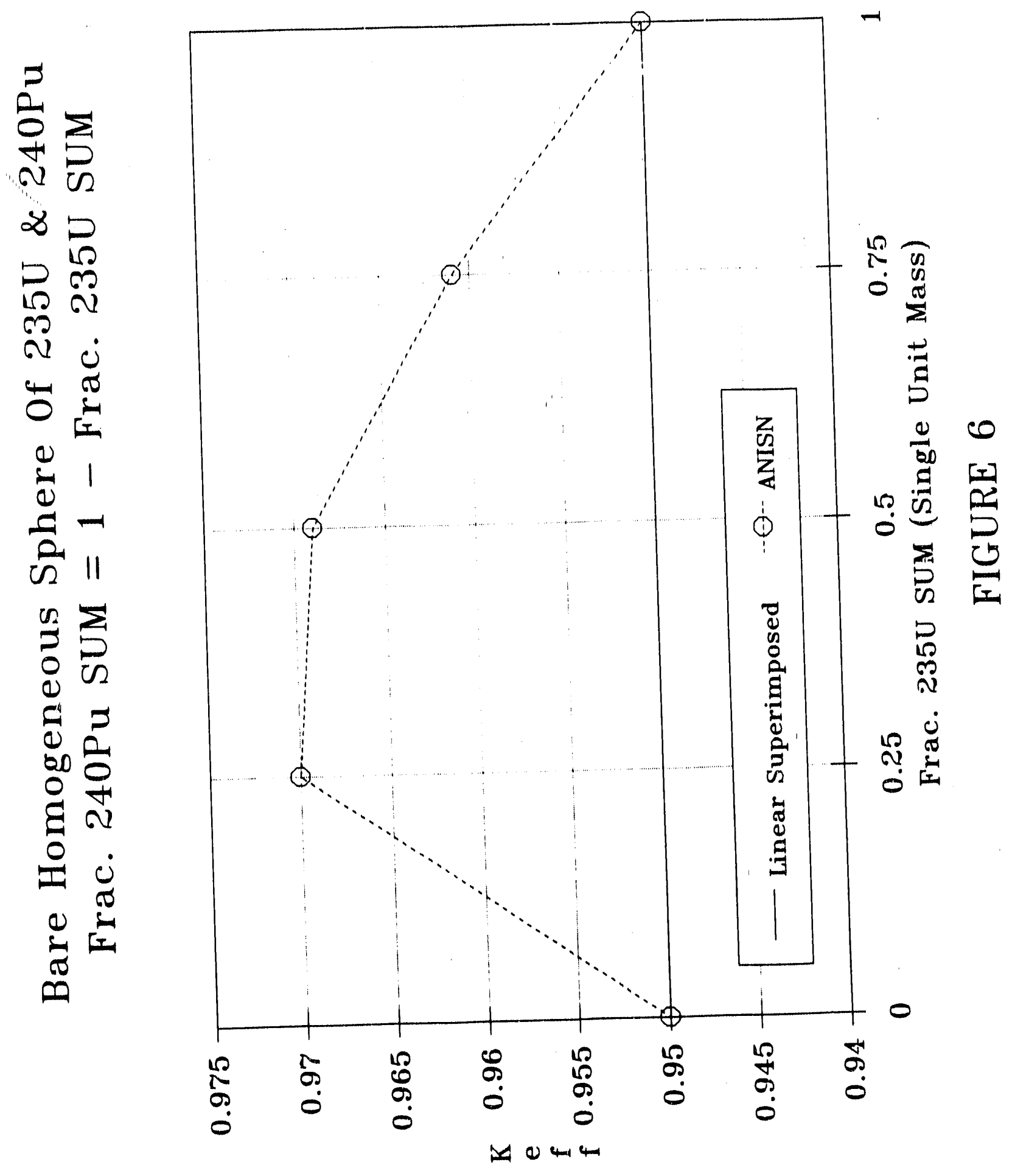


this study the logical approach was used; that is, a straight line between the $K_{e f f}$ values of the two single Unit Masses plotted as in Figure 6. Implied in this is the acceptance of the linear assumption curves shown in Figure 5 which are obviously incorrect. The justification for using this linear relationship between $K_{e f f}$ and fractions of single Unit Masses is that it appears closer to the presumed intent of the Rule-Of-Fractions (i.e., maintaining a known margin in $\mathrm{K}_{e f f}$ ) than any other assumption that might be made.

The study had four major divisions:

- Definition of Single Unit Masses (SUMs) for each isotope, cross section set, metal and solution form, and reflector (bare, water:, and steel).

- Calculations of binary Fissile-Fissile mixtures of isotopes.

- Calculations of binary Fissionable-Fissionable mixtures of isotopes.

- Calculations of binary Fissile-Fissionable mixtures of isotopes.

In each section of the study, all computations were performed by the AxI8x module of the roxo system using HansenRoach and ENDF/B-IV cross sections. Because the single Unit Mass Keff values used to define the Rule-Of-Fractions Keff values were derived from calculation using the same codes and cross sections, no correlated bias corrections were needed to enable comparison of results. The calculations were internally consistent so that results without bias correction were proper for comparison.

\section{v. Definition of 8ingle Onit kasses (sUxs)}

The Single Unit Mass for each isotope under each different condition was defined and the $k_{\text {eff }}$ value corresponding to this mass and condition defined as the starting point for the study. Selection of the Single Unit Masses was done as follows:

- Where a single parameter mass limit for an isotope existed in the ANSI/ANS 8.1 or 8.15 standard it was used.

- Where single parameter mass limits did not exist in standards the masses were defined from a $S_{\infty} P_{1}$ ANI8N calculation using Hansen-Roach cross sections for $K_{e f f}$ equal to 0.95 .

Single Unit Masses for metal spheres with different reflectors defined according to the above rules are shown in Table III. These units define the end points of the Rule-ofFractions values of $K_{e f f}$ as described above. Between these end points the variation of $K_{\text {eff }}$ is assumed to be linear. 
TABLE III

BIXGLE UAIT MAB8EB POR KETML BPHEREB

$$
{ }^{235} \mathrm{U} \text { (Density }=18.8 \mathrm{gm} / \mathrm{CC} \text { ) }
$$

Reflector Mass (Ka) Radius (Cm) Keff $S_{1-1}$

Bare

Water

Steel

Bare

Water

Steel

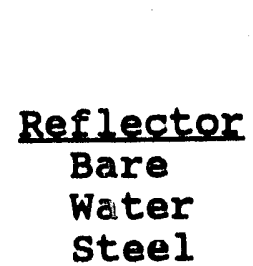

38.97
17.74

1.6 .39

7.910

6.085

5.926

0.950

0.950

0.950

$238 \mathrm{Pu}$ (Density $=19.74 \mathrm{gm} / \mathrm{CC}$ )

$S_{\infty} P_{1}$

Mass (Kg) Radius ( $\mathrm{Cm})$

8.35
4.00
3.00

4.657

3.644

3.311

Keff $\mathrm{H}-\mathrm{R}$

0.950

0.806

0.829
$239 \mathrm{Pu}$ (Density $=19.82 \mathrm{gm} / \mathrm{CC}$ )

Mass (Kg) Radius ( $\mathrm{Cm})$

$\begin{array}{ll}8.28 & 4.637 \\ 4.566 & 3.803 \\ 4.26 & 3.716\end{array}$

8.28

4.26

3.716

Keff $\frac{1}{H}-R$

0.950

0.950

0.950

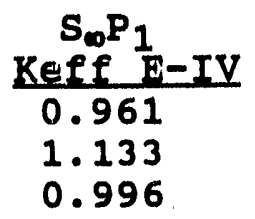

$\mathrm{S}_{\boldsymbol{\infty}} \mathrm{P}_{1}$

Keff 1 -IV

1.015

0.911

0.905

$$
24{ }^{\circ} \mathrm{Pu} \text { (Density }=19.90 \mathrm{gm} / \mathrm{CC} \text { ) }
$$

\begin{tabular}{|c|c|c|c|c|}
\hline $\begin{array}{l}\text { eflector } \\
\text { Bare } \\
\text { Water } \\
\text { Steel }\end{array}$ & $\begin{array}{c}\text { Mass }(\mathrm{Kg}) \\
29.58 \\
20.00 \\
15.00\end{array}$ & $\begin{array}{c}\text { Radius (Cm) } \\
7.080 \\
6.214 \\
5.646\end{array}$ & $\begin{array}{l}0.950 \\
0.878 \\
0.921\end{array}$ & $\begin{array}{l}0.913 \\
0.876 \\
0.890\end{array}$ \\
\hline
\end{tabular}

water reflector thickness $-30.48 \mathrm{~cm}$.

steel reflector thickness $-25.4 \mathrm{~cm}$.

H-R - Hansen-Roach Cross Sections

E-IV - ENDF/B-IV Cross Sections 
The steel reflector used in Table III was $25.4 \mathrm{~cm}$. This value is in line with the footnote to Table I in ANST/ANS 8.15 standard which suggests that $20 \mathrm{~cm}$. may be considered an infinite reflector. Steel reflector thickness was examined when leakage from the reflected spheres was too high in the Table III calculations. Results of this examination are shown in Figure 7 which suggests that a larger thickness of steel is necessary for some isotopes, and that ENDF/B-IV cross sections are more susceptible to the reflector thickness. Many of the calculations that appear in sections VI, VII, and VIII for steel reflected systems were completed before the thickness effects in Figure 7 were observed. The results of these calculations were included but must be considered somewhat suspect.

Single Unit Masses for solutions of fissile and fissionable isotopes were created by mixing nuclides in metal form uniformly with water in the proper spherical size to form a unit of acceptable Keff. The masses of fissiles were taken directly from the ANSI/ANS 8.1 standard; however, different concentrations were used for bare and reflected spheres to achieve a specified $K_{e f f}$ with minimum mass. A side study examined the concentration of fissiles that produced the minimum mass at $K_{e f f}=0.95$ for bare, water reflected, and steel reflected spheres separately. These results are incorporated into the final single Unit Masses for fissile isotopes in solution shown in Table IV. Another side study showed that the two fissionable nuclides achieve maximum $K_{e f f}$ when in metal form, and the presence of any quantity of water uniformly mixed will decrease the reactivity to almost zero. Figure 8 shows the reactivity results for mixtures of fissionable nuclides in water, with the upper limit of concentration of each fissionable nuclide the theoretical metal density limit. The final single Unit Masses for fissile/fissionable solutions are shown in Table IV.

\section{Hisile-Fisaile xixtures}

The first group of tests of the Rule-of-Fraction werger for homogeneous fissile-fissile binary mixtures of $235_{U}$ and $239 \mathrm{Pu}$. For convenience the single Unit Masses were divided into quarters so that mixtures consisting of $0.25 \mathrm{~A}+0.75 \mathrm{~B}, 0.5 \mathrm{~A}+0.5 \mathrm{~B}$, and $0.75 A+0.25 B$, where $A$ and $B$ are two fissile/fissionable isotope sUM values from Tables III and IV. The masses in proper proportion were mixed stochiometrically to form homogeneous mixtures for both metal and solution. Results of these calculations are shown in Table $\mathrm{V}$ and Figures 9, 10, and 11 . These results confirm that the Rule-of-Fractions, with the linear assumption, assures a minimum margin in $K_{e f f}$ for all mixtures and reflectors. The displacement of the results from calculations with ENDF/B-IV cross sections occurs because the single Unit Masses calculated using Hansen-Roach were used in the calculations. A second set of Single Unit Masses could have been determined for ENDF/B-IV cross sections, but no advantage was gained by doing so. The important thing is the results of calculation using both ENDF/B-IV and Hansen-Roach cross sections 


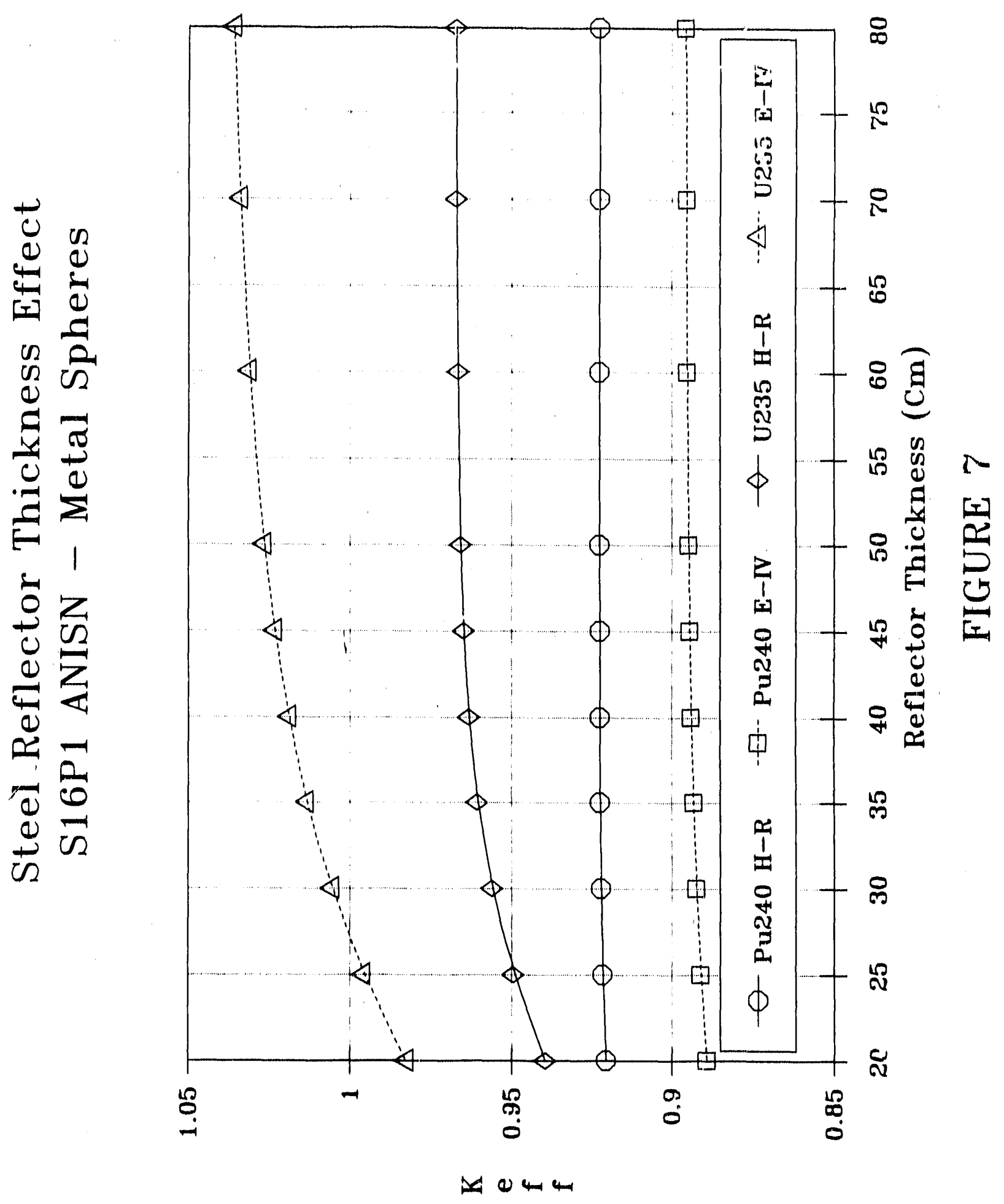




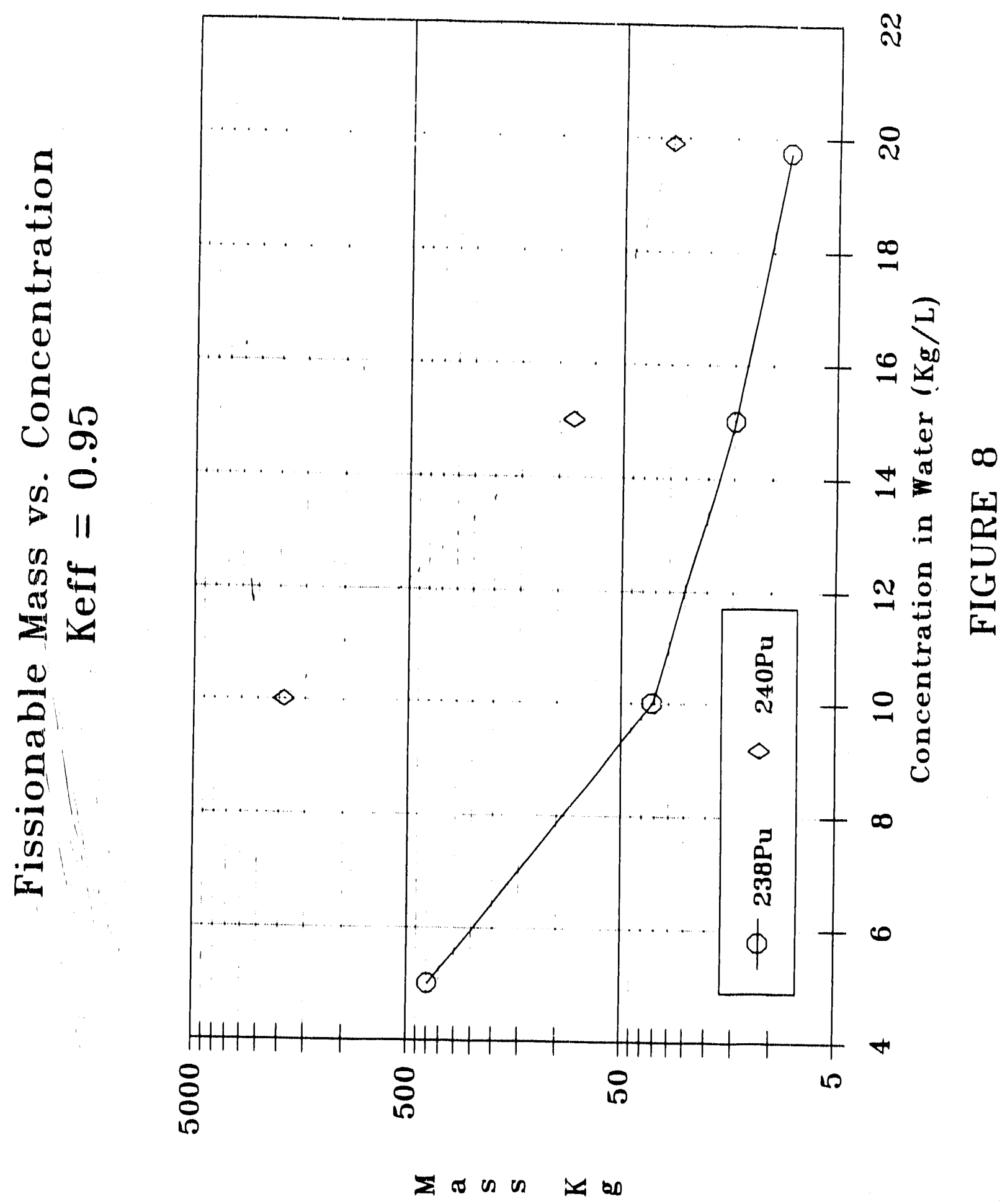


TABLE IV

\section{BIMOLE UNIT KABSEB FOR BOLUTIOY BPHERES}

$$
235_{\mathrm{U}} \text { (Density }=18.8 \mathrm{gm} / \mathrm{CC} \text { ) }
$$

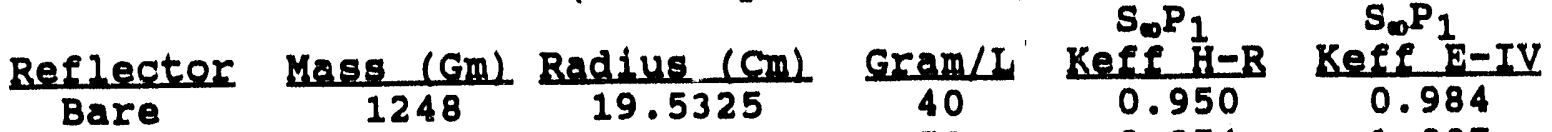

Water

Steel

760

568
15.3669

13.9426
50

50
0.974

0.950

1.007

1.006

\section{$238 \mathrm{Pu}$ (Density $=19.74 \mathrm{gm} / \mathrm{CC}$ ) \\ Metal Unit (Same as Table III)}

Reflector

Bare

Water

Steel

$$
\begin{aligned}
& 8.35 \\
& 4.00 \\
& 3.00
\end{aligned}
$$

$\mathrm{Kg} / \mathrm{L}$ $\frac{19 / 14}{19.74}$ 19.74 19.74

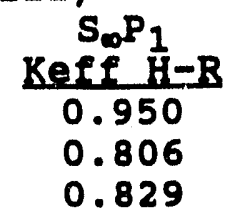

0.829

\section{${ }^{239} \mathrm{Pu}$ (Density $=19.82 \mathrm{gm} / \mathrm{CC}$ )}

$\mathrm{S}_{\infty} \mathrm{P}_{1}$

Reflector Bare

Water

steel

768
480
335

3. 644

\begin{tabular}{|c|c|c|c|c|c|}
\hline $\begin{array}{l}\text { erfector } \\
\text { Bare } \\
\text { Water } \\
\text { Steel }\end{array}$ & $\begin{array}{l}28.88 \text { (ng) } \\
29.58 \\
20.00 \\
15.00\end{array}$ & $\begin{array}{c}\text { agans } \\
7.080 \\
6.214 \\
5.646\end{array}$ & $\begin{array}{l}19.90 \\
19.90 \\
19.90\end{array}$ & $\begin{array}{l}0.950 \\
0.878 \\
0.921\end{array}$ & $\begin{array}{l}0.913 \\
0.876 \\
0.890\end{array}$ \\
\hline
\end{tabular}

3.311

\begin{tabular}{l}
$S_{\infty} P_{1}$ \\
Keff $1 \mathrm{E}-\mathrm{IV}$ \\
\hline 1.015 \\
0.911 \\
0.905
\end{tabular}

$240 \mathrm{Pu}$ (Density $=19.90 \mathrm{gm} / \mathrm{CC}$ )
Metal Unit (Same as Table III) 
TABLE V

CALCOLATIONB OF HONOGGENEOOS MIXTURES OP

$0.25235080 x+0.75239 P_{X}$ 80XX

Reflector Density (om/cc) Wt. $235 \mathrm{U}$ Wt. $239 \mathrm{Pu}$ Radius (cm)

$\begin{array}{lcccc}\text { Bare } & 19.184 & \frac{61.072}{38.928} & & 5.834 \\ \text { Water } & 19.231 & 56.429 & 43.571 & 4.604 \\ \text { Steel } & 19.234 & 56.188 & 43.812 & 4.490\end{array}$

\begin{tabular}{|c|c|c|c|c|}
\hline $\begin{array}{l}\text { eflector } \\
\text { Bare } \\
\text { Water } \\
\text { steel }\end{array}$ & $\begin{array}{c}\text { Volume (L) } \\
0.8317 \\
0.4088 \\
0.3792\end{array}$ & $\begin{array}{c}\operatorname{Mass}(\mathrm{Kg}) \\
15.95 \\
7.86 \\
7.29\end{array}$ & $\begin{array}{c}\text { Keff } H-R \\
0.895 \\
0.913 \\
0.907\end{array}$ & $\begin{array}{c}\text { Keff E-IV } \\
0.898 \\
1.080 \\
0.941\end{array}$ \\
\hline
\end{tabular}

\subsection{X $+0.5239 \mathrm{Pu}_{\mathrm{BOX}}$}

Reflector Density (am/cc) Wt. $235 \mathrm{U}$ Wt. $239 \mathrm{Pu}$ Radius (cm)

\begin{tabular}{|c|c|c|c|c|}
\hline $\begin{array}{l}\text { Bare } \\
\text { water } \\
\text { steel }\end{array}$ & $\begin{array}{l}18.971 \\
19.000 \\
19.002\end{array}$ & $\begin{array}{l}82.476 \\
79.530 \\
79.370\end{array}$ & $\begin{array}{l}17.524 \\
20.470 \\
20.630\end{array}$ & $\begin{array}{l}6.674 \\
5.194 \\
5.062\end{array}$ \\
\hline
\end{tabular}

\begin{tabular}{|c|c|c|c|c|}
\hline eflector & Volume (I) & Mass $(\mathrm{Kg})$ & $\begin{array}{l}S_{\infty} P_{1} \\
\text { Keff } \frac{H}{H}-R\end{array}$ & $\begin{array}{c}S_{\infty} P_{1} \\
\text { Keff } E-I V\end{array}$ \\
\hline $\begin{array}{l}\text { Bare } \\
\text { Water } \\
\text { Steel }\end{array}$ & $\begin{array}{l}1.2453 \\
0.5870 \\
0.5434\end{array}$ & $\begin{array}{l}23.62 \\
11.15 \\
10.33\end{array}$ & $\begin{array}{l}0.903 \\
0.917 \\
0.912\end{array}$ & $\begin{array}{l}0.911 \\
1.080 \\
0.951\end{array}$ \\
\hline
\end{tabular}

\section{$0.75235080 Y+0.25239 P_{Y} \mathrm{BOX}_{X}$}

Reflector Density (am/cc) Wt. $235 \mathrm{U}$ Wt.\% 239Pu Radius $(\mathrm{cm}$

\begin{tabular}{|c|c|c|c|}
\hline $\begin{array}{l}\text { Bare } \\
\text { Water } \\
\text { Steel }\end{array}$ & $\begin{array}{l}18.864 \\
18.877 \\
18.877\end{array}$ & $\begin{array}{l}93.386 \\
92.098 \\
92.027\end{array}$ & $\begin{array}{l}6.614 \\
7.902 \\
7.973\end{array}$ \\
\hline
\end{tabular}

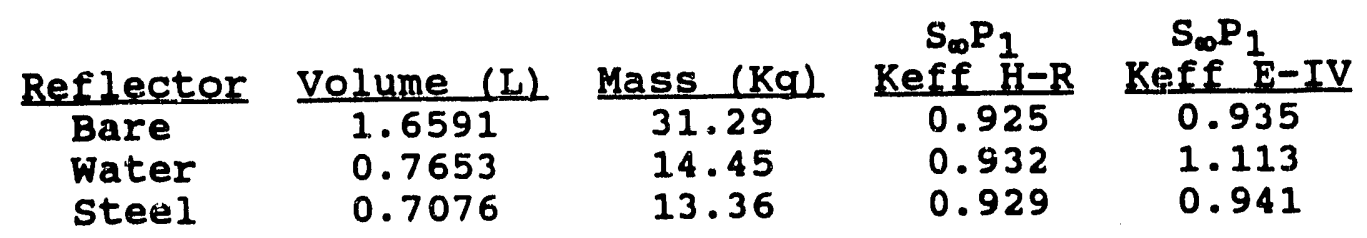

\footnotetext{
Water reflector thickness $-30.48 \mathrm{~cm}$.

steel reflector thickness $-25.4 \mathrm{~cm}$.

H-R - Hansen-Roach Cross Sections

E-IV - ENDF/B-IV Cross Sections
} 


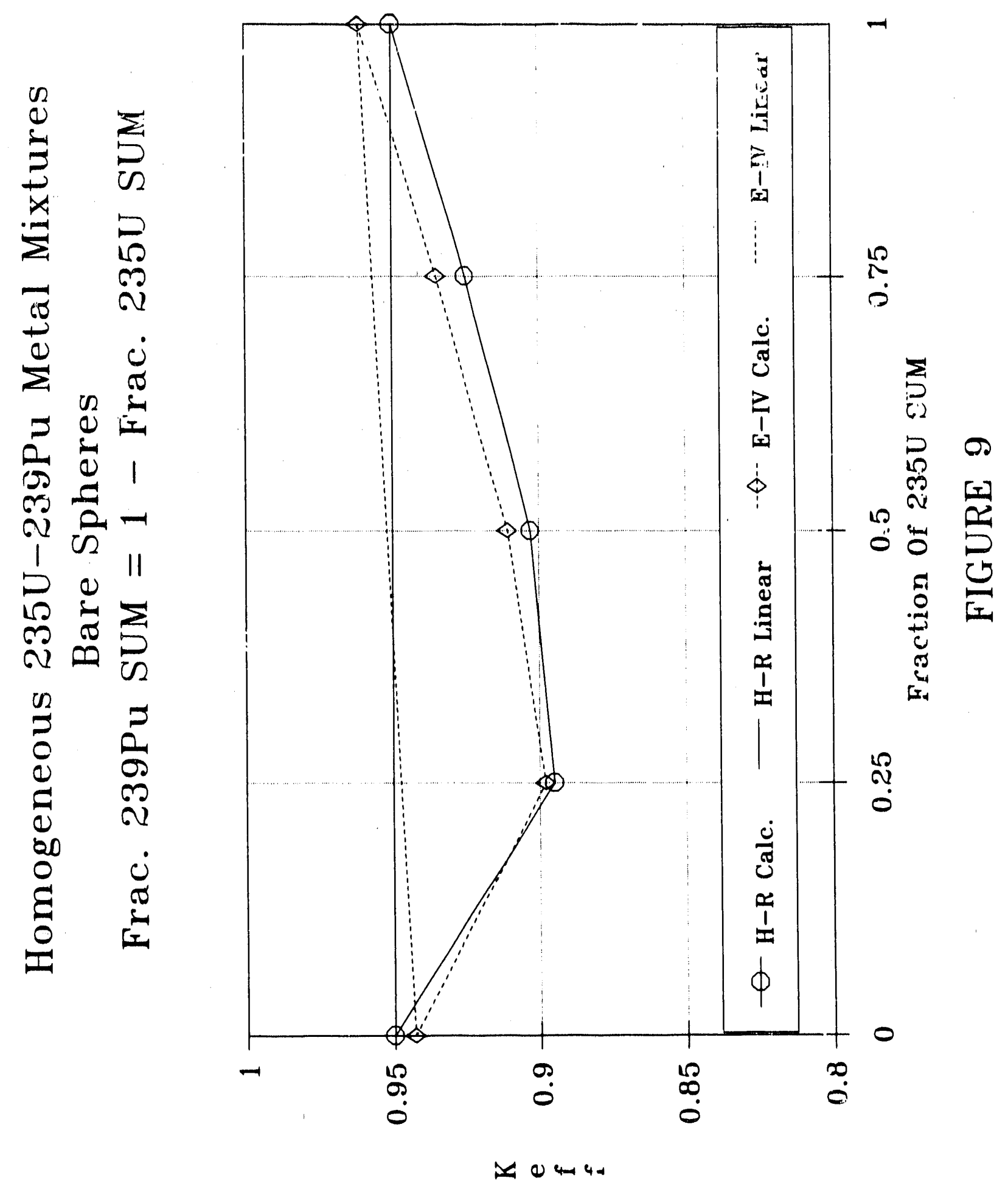




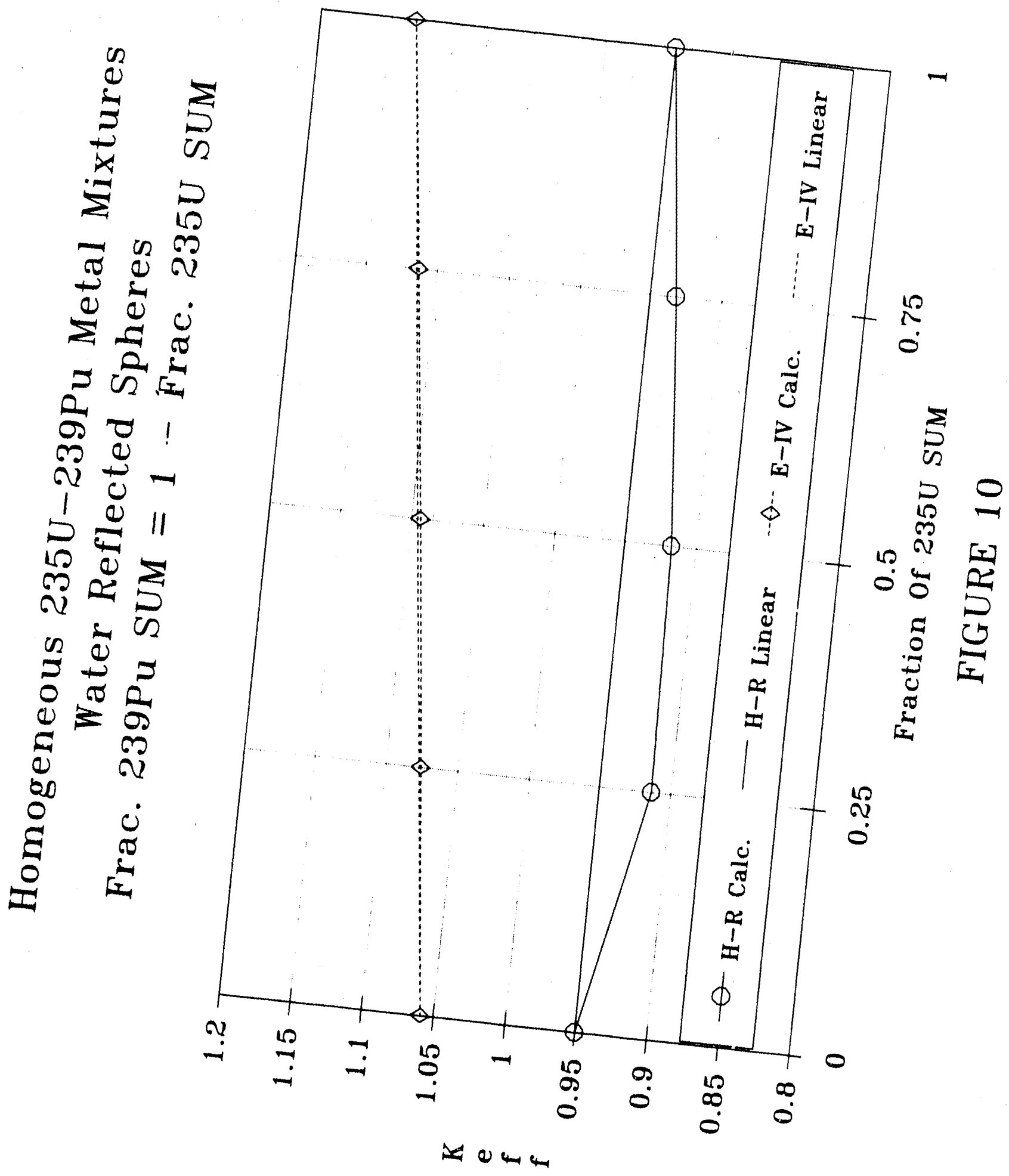


WBRC-TR-92-569

24

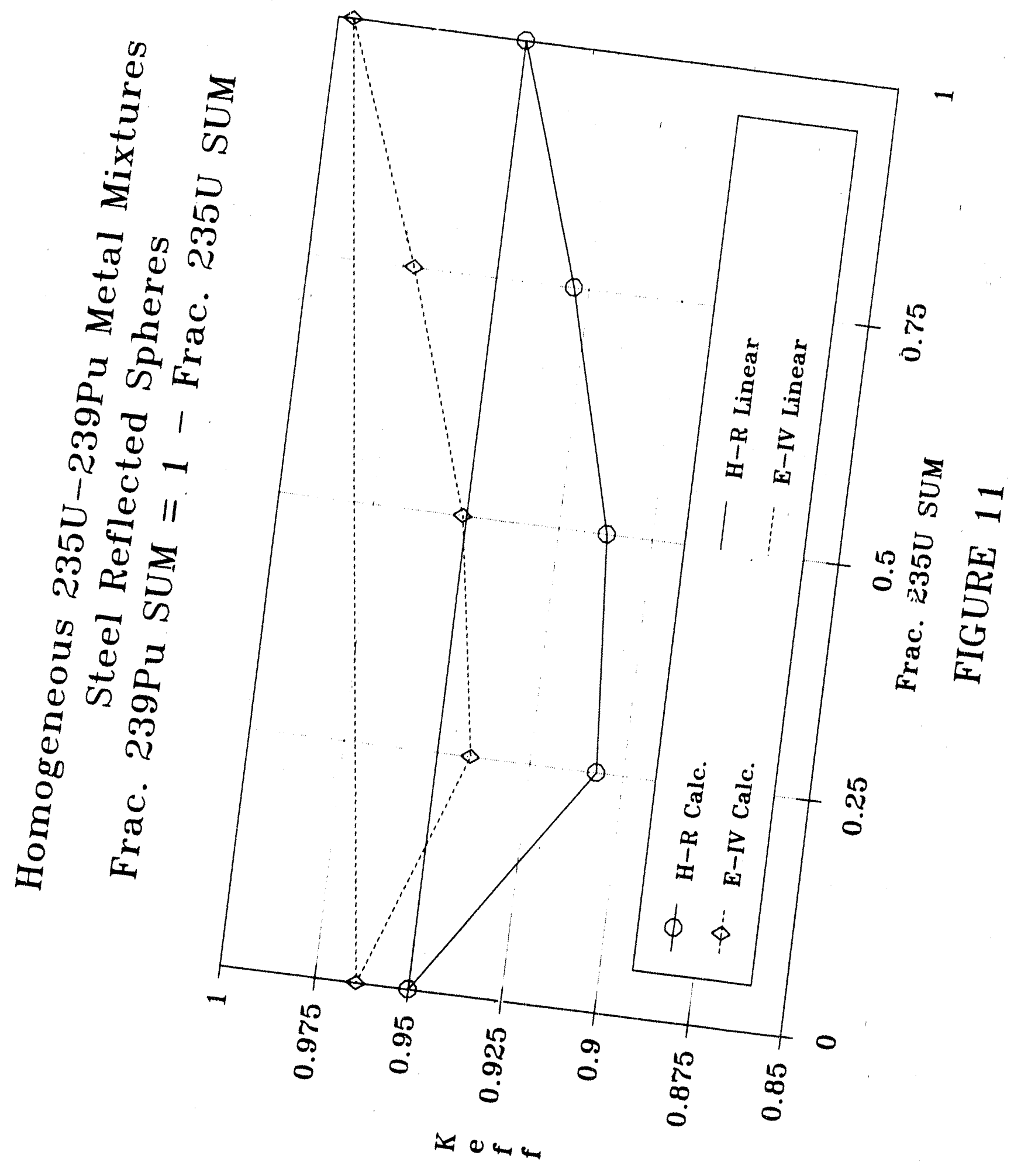


give the same behavior relative to the straight line for each individual set of cross sections.

The second set of calculations, yere for heterogeneous fissile-fissile binary mixtures of $235 \mathrm{U}$ and $239 \mathrm{Pu}$. The mixtures were combined as for the homogeneous cases in quarters of single Unit Masses, but the material was arranged with the two fissile materials segregated into a ball and shell. Calculationg yere done for both $235 \mathrm{U}$ in the ball (239 $\mathrm{Pu}$ in the shell) and $23 \% \mathrm{Pu}$ in the ball (235 $U$ in the shell). Results of these calculations are shown in Table VI and Figures 12,13 , and 14 . These results deserve comment.

The extremely high $K_{\text {eff }}$ values for the bare spheres are a direct outcome of the boundary condition. Table III shows that the 235 U Siggle Unit Mass for the steel reflector is less than half the $235_{U}$ single Unit Mass for the bare case. It comes as no surprise that a shell of ${ }^{2}{ }^{9} \mathrm{Pu}$, which is a better reflector than steel and fissions too, will produce an engrmous $K_{\text {eff }}$ value. Exactly the same condition is true of the ${ }^{239} \mathrm{Pu}$ ball geometry.

Complex spectral effects enter the picture for the water reflected spheres. The water reflector provides a more thermalized spectrum in the outer parts of the sphere, the overall effect being a thermal to intermediate ayerage spectrum. The ${ }^{239} \mathrm{Pu}$ mass is only about one fourth that of $235 \mathrm{U}$ which provides only a very thin shell permitting spectral effects to extend a significant distance inio the ball. The $235_{\mathrm{U}}$ shell is very thick in comparison and permits virtually no spectral changes in the ball. Both fissile metals are good reflectors, but $235_{\mathrm{U}}$ is significantly better than ${ }^{239} \mathrm{Pu}$. The overall effect is to give results that show the Rule-of-Fractions is valid when $239 \mathrm{Pu}$ is in the shell, and that the Rule-Of-Fractions is invalid when $235_{U}$ is in the shell. The spectral effects combine in a very complicated manner to produce these resuics. The major spectral effects are summarized in the following table.

SPECTRAL EFFECTS IN WNTER REFLECTED HETEROGENEOUS $235_{\mathrm{U}-239} \mathrm{PU}$ SPHERES

\begin{tabular}{|c|c|c|}
\hline GEOMETRY & SPECTRUM IN BALL & SPECTRUM IN SHELL \\
\hline $\begin{array}{l}235 \mathrm{U} \text { Ball } \\
239 \mathrm{Pu} \text { Shell }\end{array}$ & $\begin{array}{l}\text { Intermediate Energy in } \\
\text { outer region - fewer } \\
\text { fissions }\end{array}$ & $\begin{array}{l}\text { Intermediate Energy - } \\
\text { fewer fissions } \\
\text { Lower reflection }\end{array}$ \\
\hline $\begin{array}{l}239 \mathrm{Pu} \mathrm{Ball} \\
235_{\mathrm{U}} \text { Shell }\end{array}$ & $\begin{array}{l}\text { High energy spectrum - } \\
\text { more fissions }\end{array}$ & $\begin{array}{l}\text { Intermediate Energy - } \\
\text { slightly fewer fiss. } \\
\text { Higher reflection }\end{array}$ \\
\hline
\end{tabular}

The overall effect is to produce more fissions when ${ }^{239} \mathrm{Pu}$ is in the ball, and less when $235 \mathrm{U}$ is in the ball. An increase or decrease of fissions was determined relative to a weighted 
TABLE VI

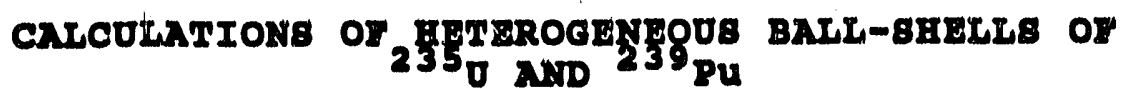

\section{$0.252350-\frac{94}{2}+0.25239 \mathrm{Pu}$.0X}

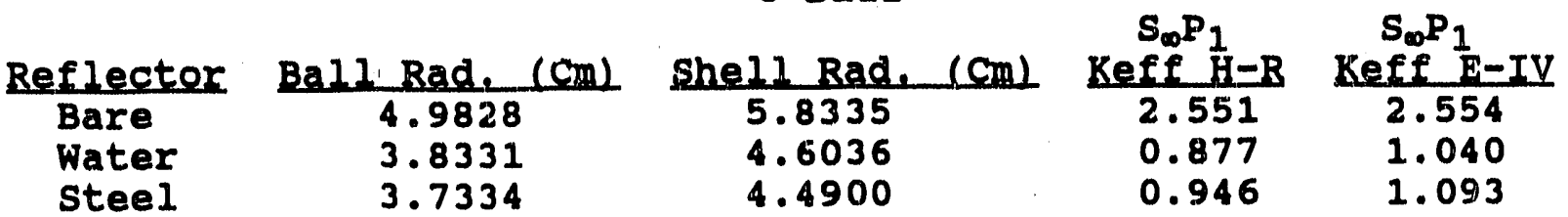

\section{$239 \mathrm{Pu} \mathrm{Ball}$}

Reflector

Bare

Water

Steel

Ball Rad. $(\mathrm{Cm})$
$\begin{aligned} & 4.2137 \\ & 3.4552 \\ & 3.3762\end{aligned}$

Shell Rad. (Cin)

5.8335

4.6036

4.4900

\begin{tabular}{cc}
$S_{\infty} P_{1}$ & $S_{\infty} P_{1}$ \\
$\operatorname{Keff} H$ & Keff $E-I V$ \\
\hline 2.561 & 2.567 \\
0.987 & 1.131 \\
1.063 & 1.191
\end{tabular}

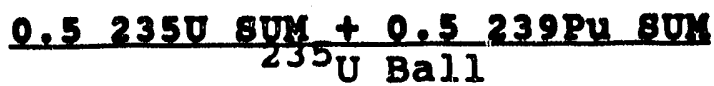

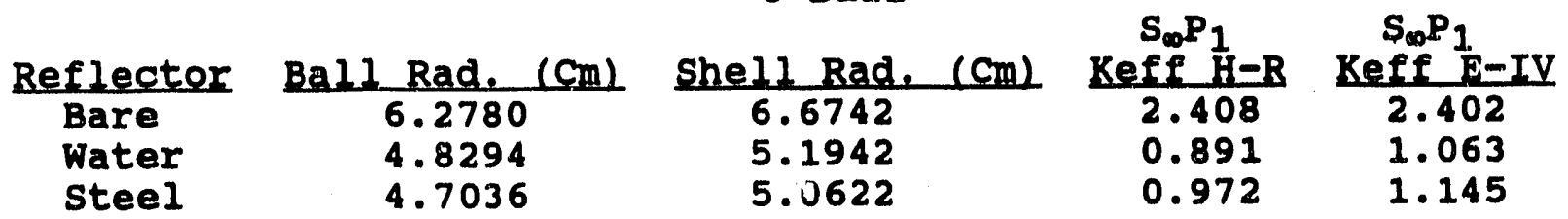

\section{$239 \mathrm{Pu} \mathrm{Ball}$}

$\begin{array}{cccccc}\text { Reflector } & \text { Ball Rad, (Cm) } & \text { Shell Rad. (Cm) } & \begin{array}{c}S_{\infty} P_{1} \\ \text { Keff H-R }\end{array} & \begin{array}{c}S_{\infty} P_{1} \\ \text { Keff }\end{array} \text {-IV } \\ \text { Bare } & 3.6807 & 6.6742 & 2.419 & 2.415 \\ \text { Water } & 3.0184 & 5.1942 & 0.987 & 1.141 \\ \text { Steel } & 2.9494 & 5.0622 & 1.073 & 1.222\end{array}$

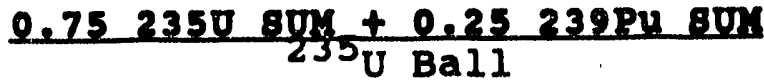

Reflector

Bare

Water

Steel

Ball Rad. (Cm) Shell Rad. (Cm)

7.1865

5.5283

5.3843
7.3439

5.6743

5.5280

$239 \mathrm{Pu} \mathrm{Ball}$

Reflector

Bare

Water

Steel
Ball Rad. (Cm) 2.9214

2.3957

2.3409
$S_{\infty} P_{1}$

Keff $\mathrm{H}-\mathrm{B}$

2.327

0.918

1.012
$S_{\infty} P$ eff $\overline{\mathrm{H}}-\mathrm{R}$

2.337

0.971

1.066

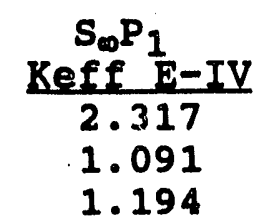

1.194 


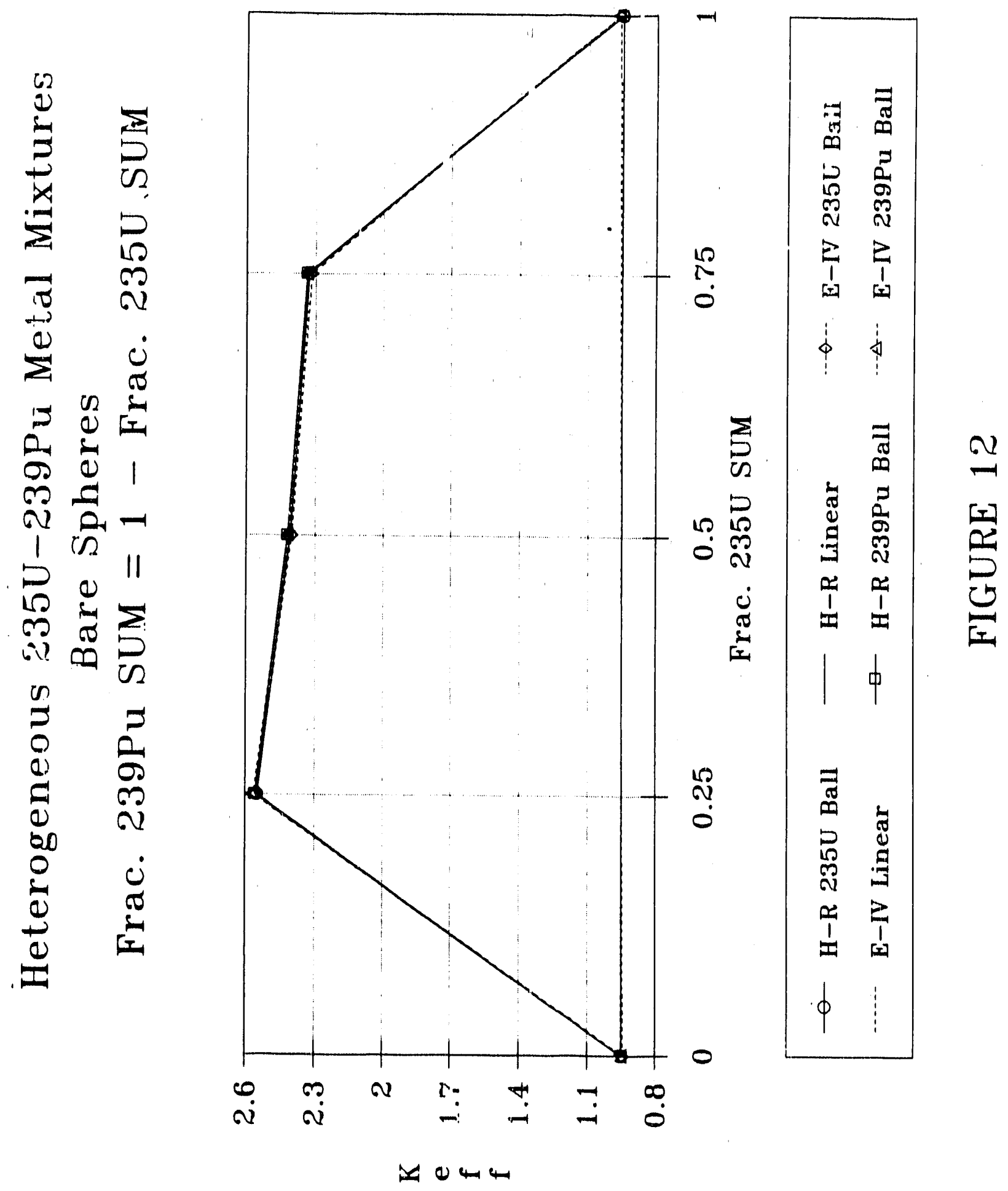


W8RC-TR-91-569

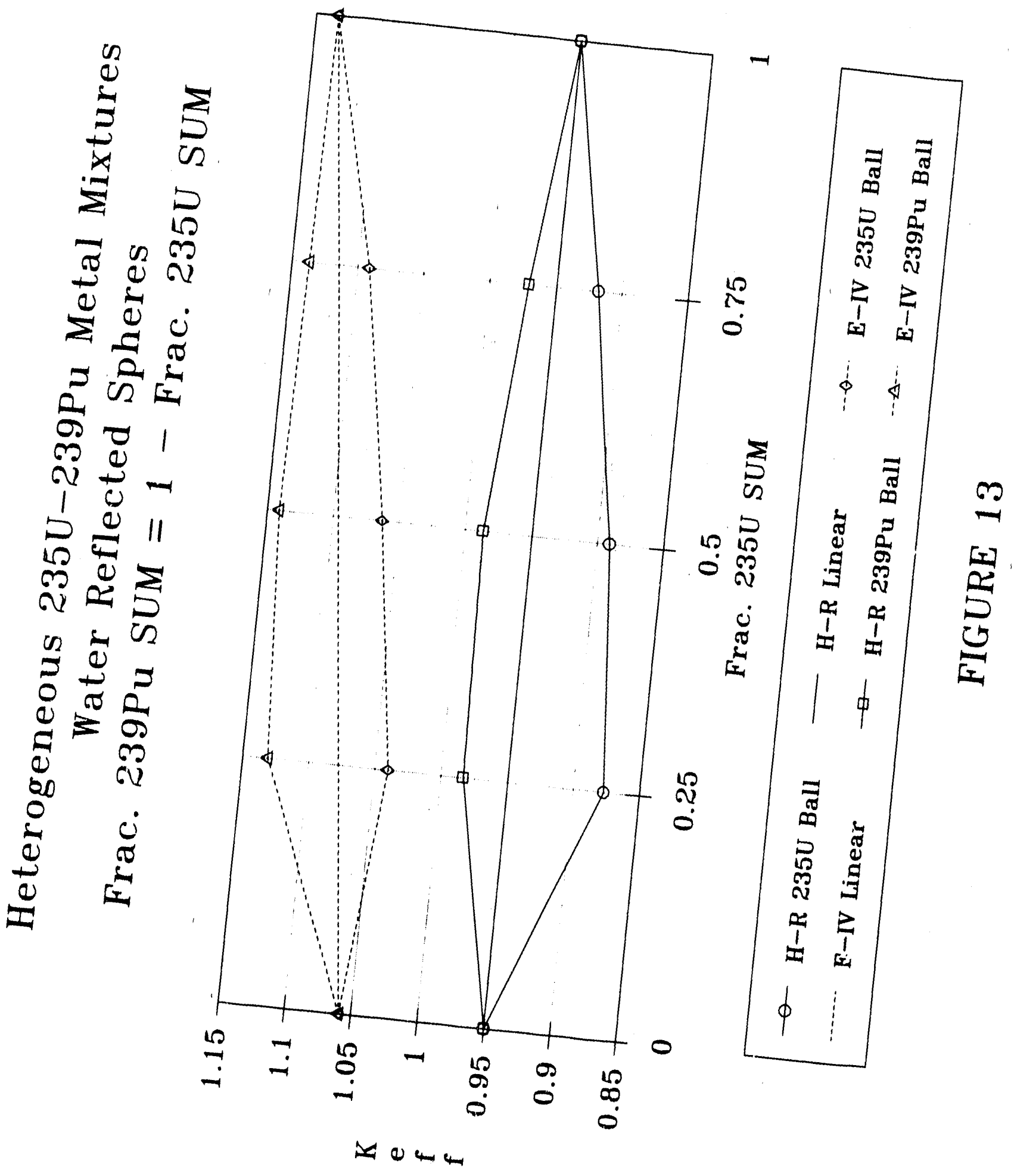



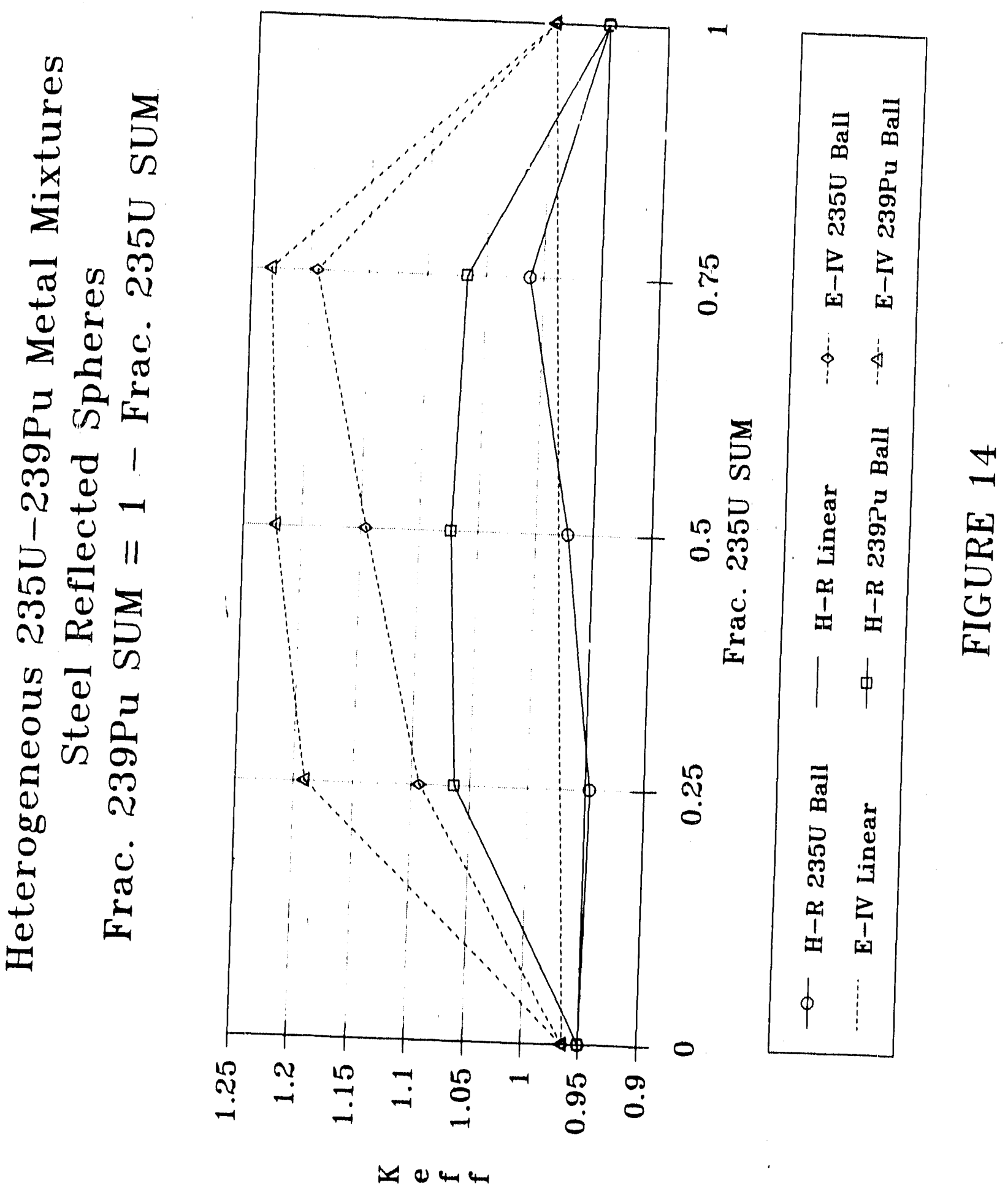
average of the fissions in the calculations of the single Unit. Masses that define the straight line

The steel reflected heterogeneous $235_{\mathrm{U}-239} \mathrm{Pu}$ spheres are somewhat simpler than the water reflected in that the spectrum is very high in energy throughout the sphere. The results shown in Figure 14 indicate that the ENDF/B-IV cross sections predict a bigger effect than Hansen-Roach, a result that appears to arise from differences in cross sections for the constituents of steel. Basically ENDF/B-IV cross sections provide more neutron reflection (less leakage) for a given thickness of steel reflector than Hansen-Roach cross liectlons. The reasons why $K_{e f f}$ increases for all heterogeneous ball-shell arrangements is based in the relative differences in fissions and scattering. The similarity in shape of the Hansen-Roach and ENDF/B-IV curves indicates the same mechanisms at work. The fissions peak is in group 2 of the sixteen group Hansen-Roach oross sections, and for that group the differences in fission and scattering oross sections are shown in the following table.

\begin{tabular}{|c|c|c|}
\hline CROSS SECTION & $\begin{array}{l}\text { RATIOS IN HAN } \\
\frac{235 U}{\text { Increasing }}\end{array}$ & $\begin{array}{l}\text { SEN-ROACH GROUP } 2 \\
\text { Neutron Production } \\
\frac{239 P 4}{\text { Production }}\end{array}$ \\
\hline$\nu \Sigma_{\mathbf{f}} / \Sigma_{\mathbf{a}}$ & 2.46 & 3.01 \\
\hline$\Sigma_{\mathbf{g}} / \Sigma_{\mathbf{a}}$ & 2.46 & 1.25 \\
\hline
\end{tabular}

Different meghanisms change the spectrum dependipg on whether $235_{U}$ or ${ }^{239} \mathrm{Pu}$ is in the ball. For a small $235 \mathrm{U}$ ball the effects arise from slightly increased fissions in the shell, higher reflection from the heavy metal shell, higher reflection from the ball surface, and slightly reduced fissions in the ball. The result is dependent on the magnitude of the changes and gives different results for the two cross section sets. As the ${ }^{2} 3 \mathrm{U}$ ball size increases, the reflection in both directions from the surface increases, yielding more total fissions overall. For the $239 \mathrm{pu}$ ball case the increased fissions occur primarily in the ball, and arise from adding a better reflector around the ball.

The last case to be considered was for mixtures of $235 \mathrm{U}-$ $239 \mathrm{pu}$ Single Unit Masses for solutions. Here only homogeneous mixtures were considered because heterogeneous geometries appeared very unlikely. The suMs were combined in quarter units as in the previous cases. Results of these calculations are shown in Table VII and Figures 15,16 , and 17 . These results show similar curve shapes for $K_{e f f}$ for both Hansen-Roach and ENDF/B-IV with Keff values that exceed the Rule-Of-Fractions linear values. ENDF/B-IV shows a larger effect than does HansenRoach which probably accrues from better treatment of the thermal and resonance region in ENDF/B-IV cross sections. 
TABLE VII

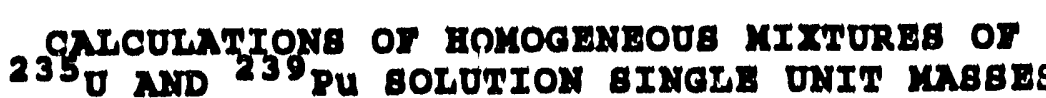

\section{$0.25235080 \mathrm{x}+0.7523924$ 80X}

$\begin{array}{ccccc}\text { Reflector } & \text { Density }(\mathrm{gm} / \mathrm{cc}) & \text { Wt.t235U } & \text { Wt.t 239PU } & \text { Radius }(\mathrm{cm}) \\ \text { Bare } & 1.0256 & 0.987 & 1.821 & 19.4540 \\ \text { Water } & 1.0312 & 1.166 & 2.209 & 15.5664 \\ \text { Steel } & 1.0315 & 1.228 & 2.172 & 13.8858\end{array}$

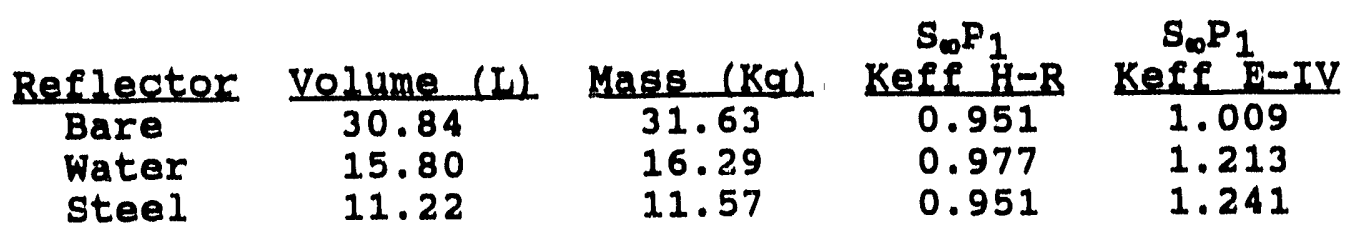

\section{$0.5235080 x+0.52392480 x$}

\begin{tabular}{|c|c|c|c|c|}
\hline $\begin{array}{l}\text { Reflector } \\
\text { Bare } \\
\text { Water } \\
\text { steel }\end{array}$ & $\begin{array}{c}\text { Density }(\mathrm{gm} / \mathrm{cc}) \\
1.0291 \\
1.0359 \\
1.0362\end{array}$ & $\begin{array}{c}\text { Wt.2.235U } \\
1.959 \\
2.351 \\
2.433\end{array}$ & $\begin{array}{c}\text { Wt. } 239 \mathrm{Pu} \\
1.205 \\
1.485 \\
1.435\end{array}$ & $\begin{array}{c}\text { Radiug (Cm } \\
19.4792 \\
15.5005 \\
13.9057\end{array}$ \\
\hline
\end{tabular}

\begin{tabular}{|c|c|c|c|c|}
\hline eflecto & Volume (I) & Mass $(\mathrm{Kq})$ & $\operatorname{Keff}_{\mathrm{H}}^{S_{\infty} \mathrm{P}_{1}}$ & $\begin{array}{l}S_{\infty} P_{1} \\
\text { Keff }{ }_{E}-I V\end{array}$ \\
\hline $\begin{array}{l}\text { Bare } \\
\text { Water } \\
\text { Steel }\end{array}$ & $\begin{array}{l}30.96 \\
15.60 \\
11.26\end{array}$ & $\begin{array}{l}31.86 \\
16.16 \\
11.67\end{array}$ & $\begin{array}{l}0.952 \\
0.977 \\
0.952\end{array}$ & $\begin{array}{l}1.035 \\
1.323 \\
1.338\end{array}$ \\
\hline
\end{tabular}

\subsection{X +0.2523984 80X}

Reflector Density (am/cc) Wt.t235

$\begin{array}{lcccc}\text { Bare } & 1.0326 & 2.916 & 0.598 & 19.5043 \\ \text { Water } & 1.0407 & 3.557 & 0.749 & 15.4340 \\ \text { Steel } & 1.0409 & 3.618 & 0.711 & 13.9256\end{array}$

Reflector Volume (I) Mass (Ka).

$\begin{array}{ll}\text { Bare } & 31.08 \\ \text { Water } & 15.40 \\ \text { Steel } & 11.31\end{array}$

32.09
16.03
11.77

$\operatorname{Keff}_{\infty} P_{1}-B$
0.951
0.976
0.951
$\operatorname{Kefe}_{\infty} P_{1-T V}$

1.038

1.320

1.340

Water reflector thickness - $30.48 \mathrm{~cm}$.

steel reflector thickness - $25.4 \mathrm{~cm}$.

$H-R$ - Hansen-Roach Cross sections

E-IV - ENDF/B-IV Cross sections 


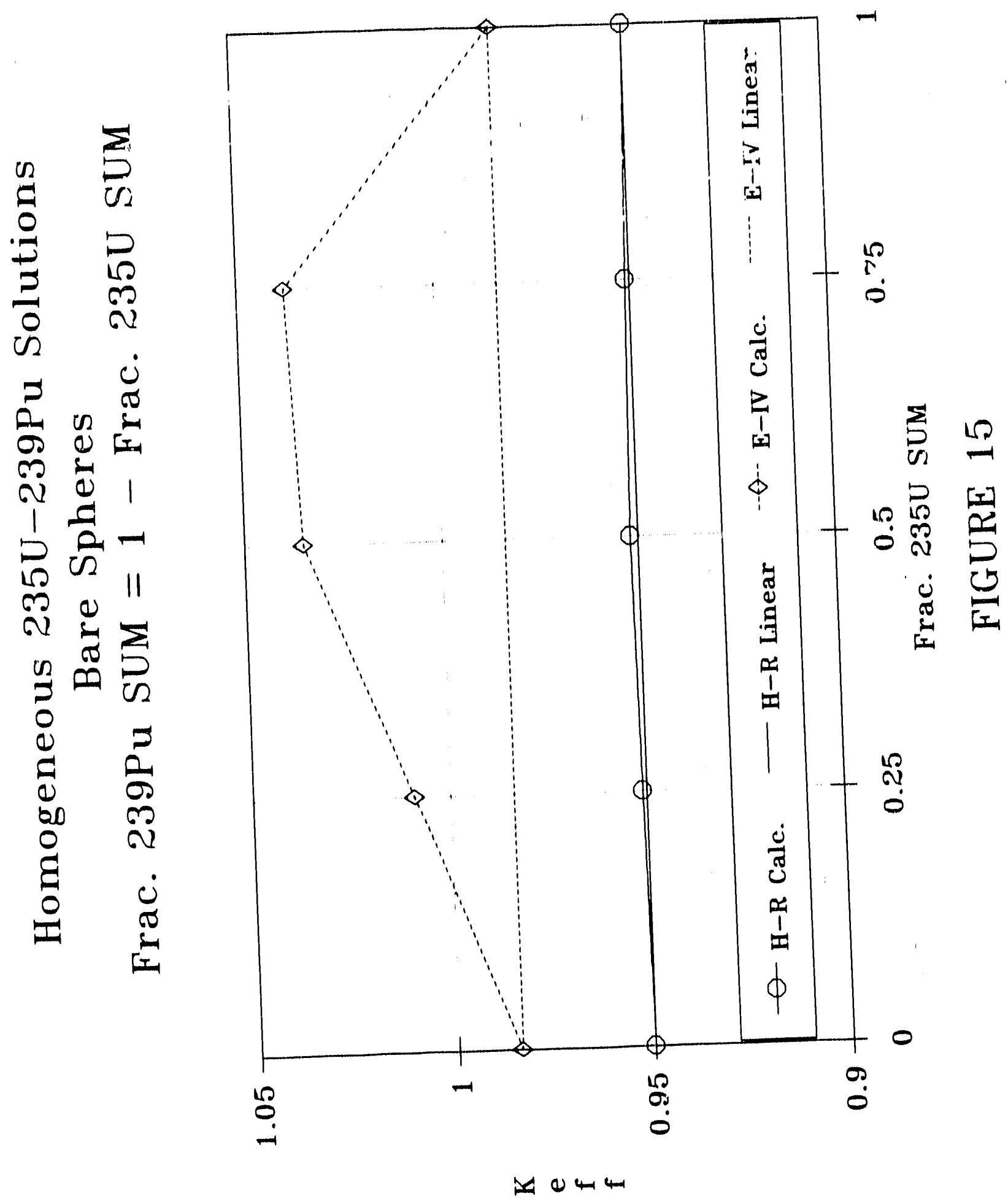




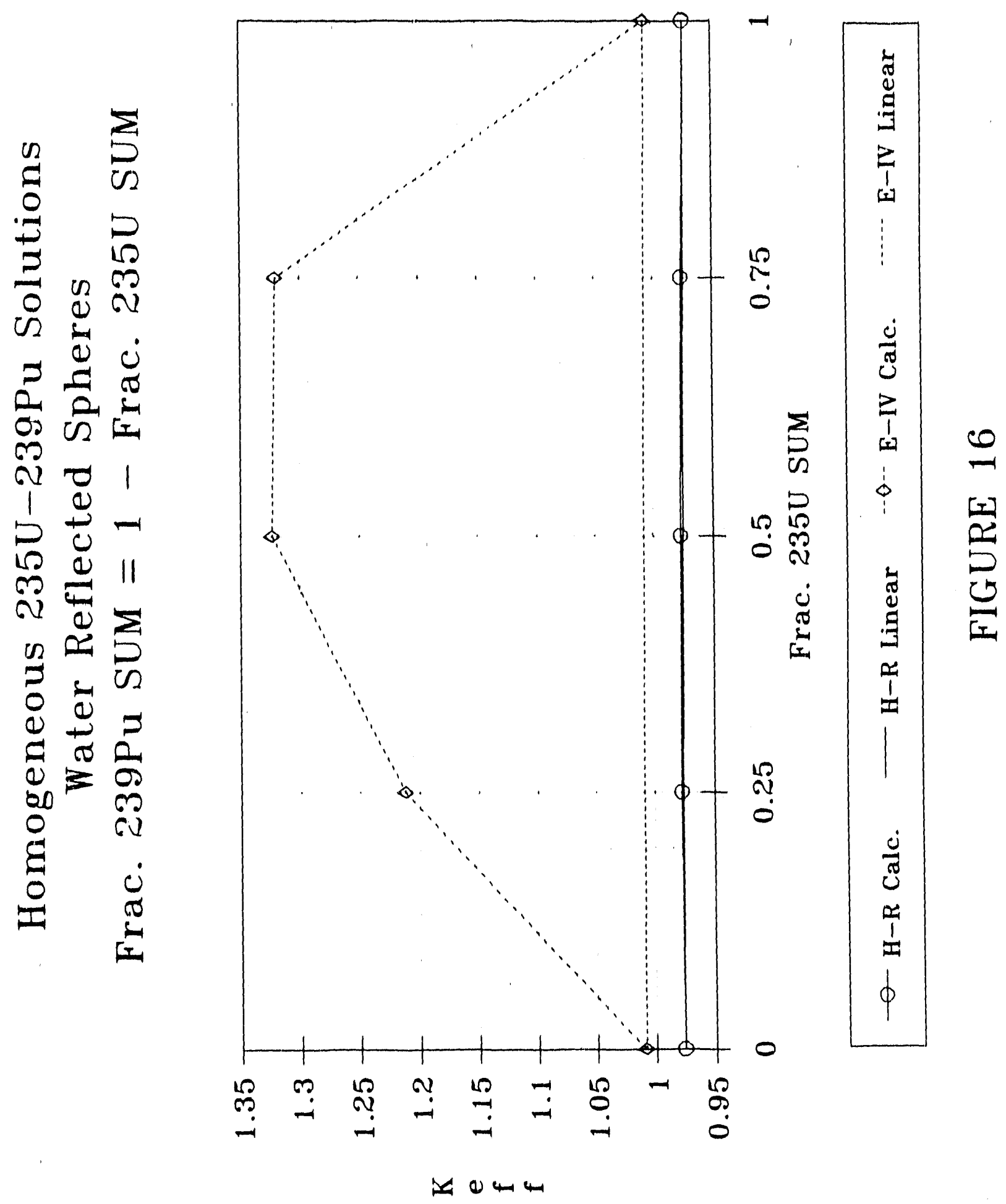




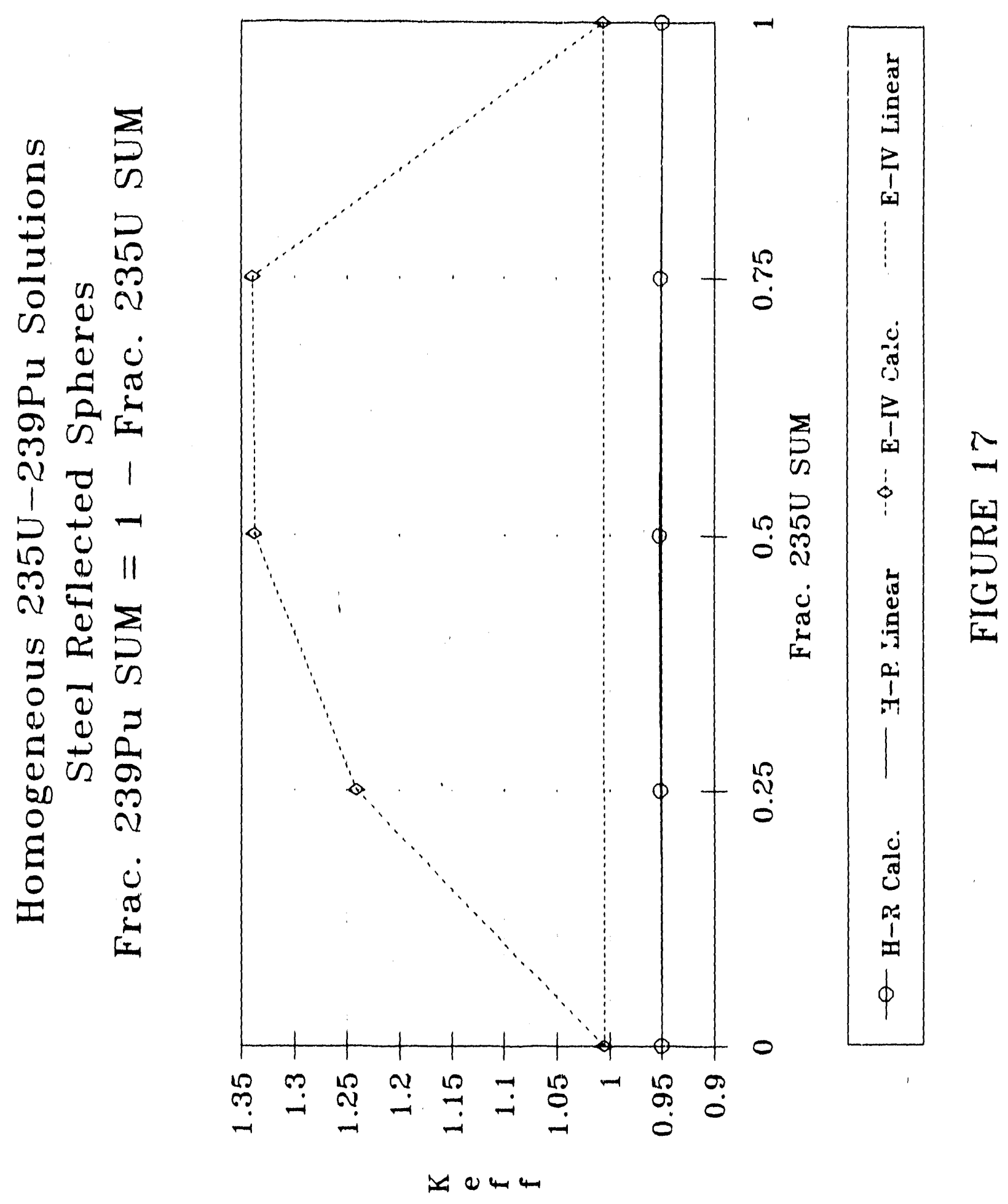


Two effects are occurring that affect the fissions $\frac{1}{3} g$ these very thermal spectrum cases. First, the $\mathrm{H} /{ }^{23} \mathrm{U}$ and $\mathrm{H} /{ }^{239} \mathrm{Pu}$ values are no longer at optimum values in the mixtures. second, the volume of the sphere changes which affects the size of the asymptotic spectrum region in the center of the sphere. This change in size has the effect of increasing the fissions in the ${ }^{2}{ }^{\mathrm{Pu}} \mathrm{Pu}$ me than decreasing the fissions in $23 \mathrm{U}_{\mathrm{U}}$. Total fissions are increased slightly for Hansen-Roach cross sections and more significantly for ENDF/B-IV cross sections.

The conclusions to be drawn from these homogeneous and heterogeneous $235 \mathrm{U}-239 \mathrm{Pu}$ metal and solution mixtures is that the Rule-of-Fractions works when the spectrum changes result in fewer fissions than for a weighted average of the suMs that define the straight $1: \mathrm{me}$, and does not work when the spectrum changes result in greater fissions than for the weighted average of the SUMs that define the straight line. All of the homogeneous metal mixtures fall in the first category, and all of the heterogeneous metal mixtures and homogeneous solution mixtures fall in the second category. It would be prudent to check any real-world mixture by analysis before using the Rule-of-Fractions.

\section{FI8BIONABLE-FI88IONABLE XIXTURES}

The two fissionable isotopes considered were ${ }^{238} \mathrm{Pu}$ and $240 \mathrm{Pu}$ which are both fast fissioning isotopes. The Hansen-Roach cross sections for ${ }^{2} \mathrm{Pu}$ were not part of the original Hansen-Roach cross sections. These cross sections (in Hansen-Roach form) were derived from Persimmon Bomb Test Data 12 by LANL and originally sent to H. K. Clark at SRS. The calculated critical mass of 238 Pu from these cross sections does not reproduce values in standards and other papers 13 . For the purposes of this study the normalization is not important so, $78^{n g}$ as it is consistent. The single Unit Masses for $238 \mathrm{Pu}$ and $248 \mathrm{Pu}$ were described in section $V$ and define the normalization for these calculations.

only homogeneous and heterogeneous mixtures of metal single Unit Masses were considered in this study because both isotopes show maximum reactivity in the metal form. The presence of water literally drives reactivity to very small values because few fissions occur in the thermal region for these isotopes.

Results for homogeneous mixtures of $238 \mathrm{Pu}$ and $240^{\mathrm{Pu}}$ metal are shown in Table VIII and Figures 18,19 , and 20 . In all of these cases the Rule-Of-Fractions appears to work well. The ENDF/B-IV results showed a greater variation in $k_{e f f}$ values than Hansen-Roach results. The results stem primarily from the volumetric changes produced in the metal mixes. The $238 \mathrm{Pu}$ sUM is about $25 \%$ of the $240 \mathrm{Pu}$ sUM. This results from the fisgign cross section for $238 \mathrm{Pu}$ being significantly bigger than for $248 \mathrm{Pu}$ at high energy. Mixing a large volume of ${ }^{24} \mathrm{Pu}$ with the $238 \mathrm{Pu}$ dilutes the mixture so that the ${ }^{238} \mathrm{Pu}$ is less effective as a fissioning nuclide. The result in all cases is a decrease in Keff that confirms the Rule-of-Fractions. 
TABLE VIII

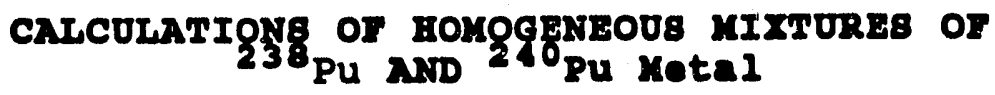

0.25238 Pu 80X $+0.75240 P^{2}$ 80X

Reflector Density (cm/cc) Wt.t238Pu Wt. $240 \mathrm{Pu}$ Radius (Cm)

Bare

Water

Steel
19.886

19.890

19.890
8.600

6.250

6.250
91.400

93.750

93.750
6.630

5.769

5.242
Reflector Volume (I) Bare Water Steel

1.2206
0.8044
0.6033

0.6033

Mass $(\mathrm{Ka})$
24.27
16.00
12.00

$$
S_{\infty} P_{1}
$$

$\frac{\text { Keff } H-8}{0.944}$

0.858

0.900
$S_{\infty} P_{1}$

Keff $\mathrm{E}-\mathrm{IV}$

0.926

0.871

0.815

\section{$0.5238 P u$ 8UY $+0.5210 P_{Y}$ 80Y}

Reflector Density (am/cc) Wt.f 238Pu Wt.\% 240Pu Radius (cm)
Bare
19.864
22.014
77.986
6.108
water
19.873
16.667
83.333
5.243
steel
19.873
16.667
83.333
4.764

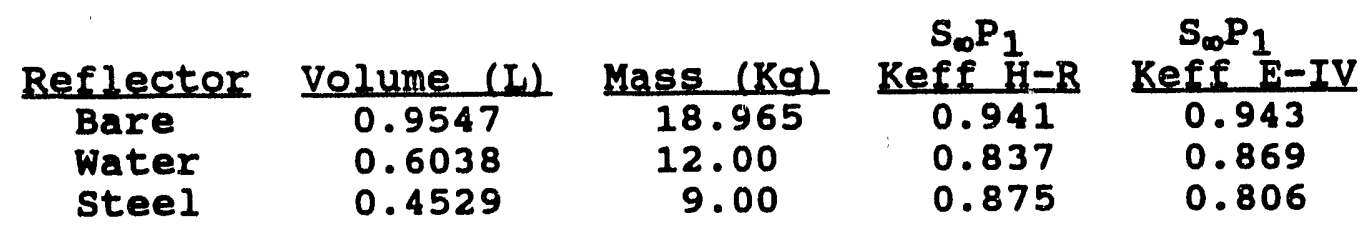

\section{$0.75238 \mathrm{Pu}$ 80X $+0.2524 .0 \mathrm{Pu}$ 80X}

Reflector Density (am/cc) Wt. 238Pu Wt.\% 240Pu Radius (Cm)
Bare
19.826
45.854
54.146
5.479
Water
19.840
37.500
62.500
4.583
Steel
19.840
37.500
62.500
4.164

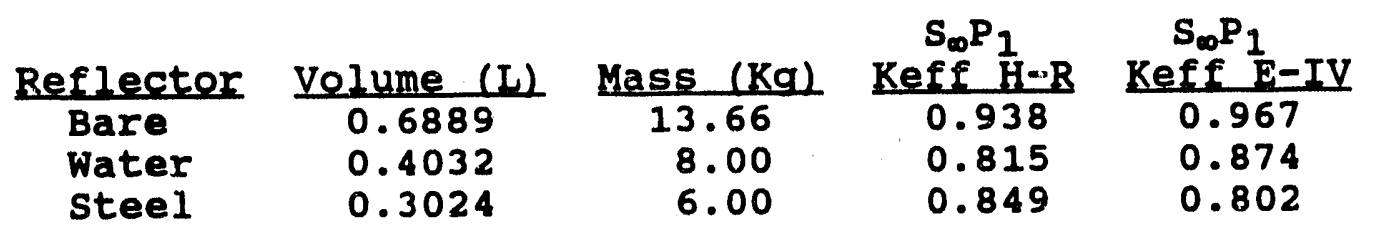

\footnotetext{
Water reflector thickness $-30.48 \mathrm{~cm}$.

steel reflector thickness $-25.4 \mathrm{~cm}$.

H-R - Hansen-Roach Cross Sections

E-IV - ENDF/B-IV Cross sections
} 


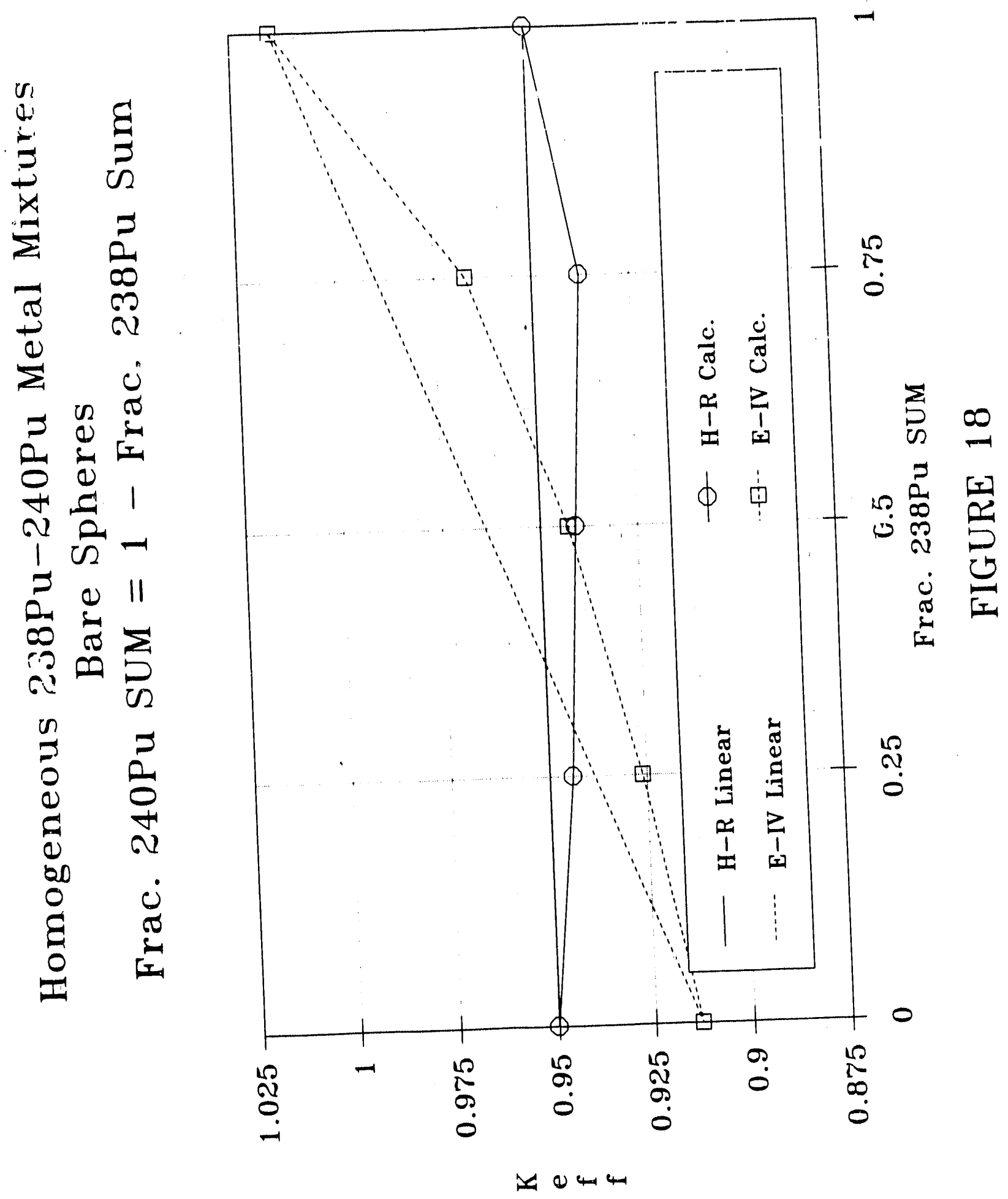


WBRC-TR-9 A-569

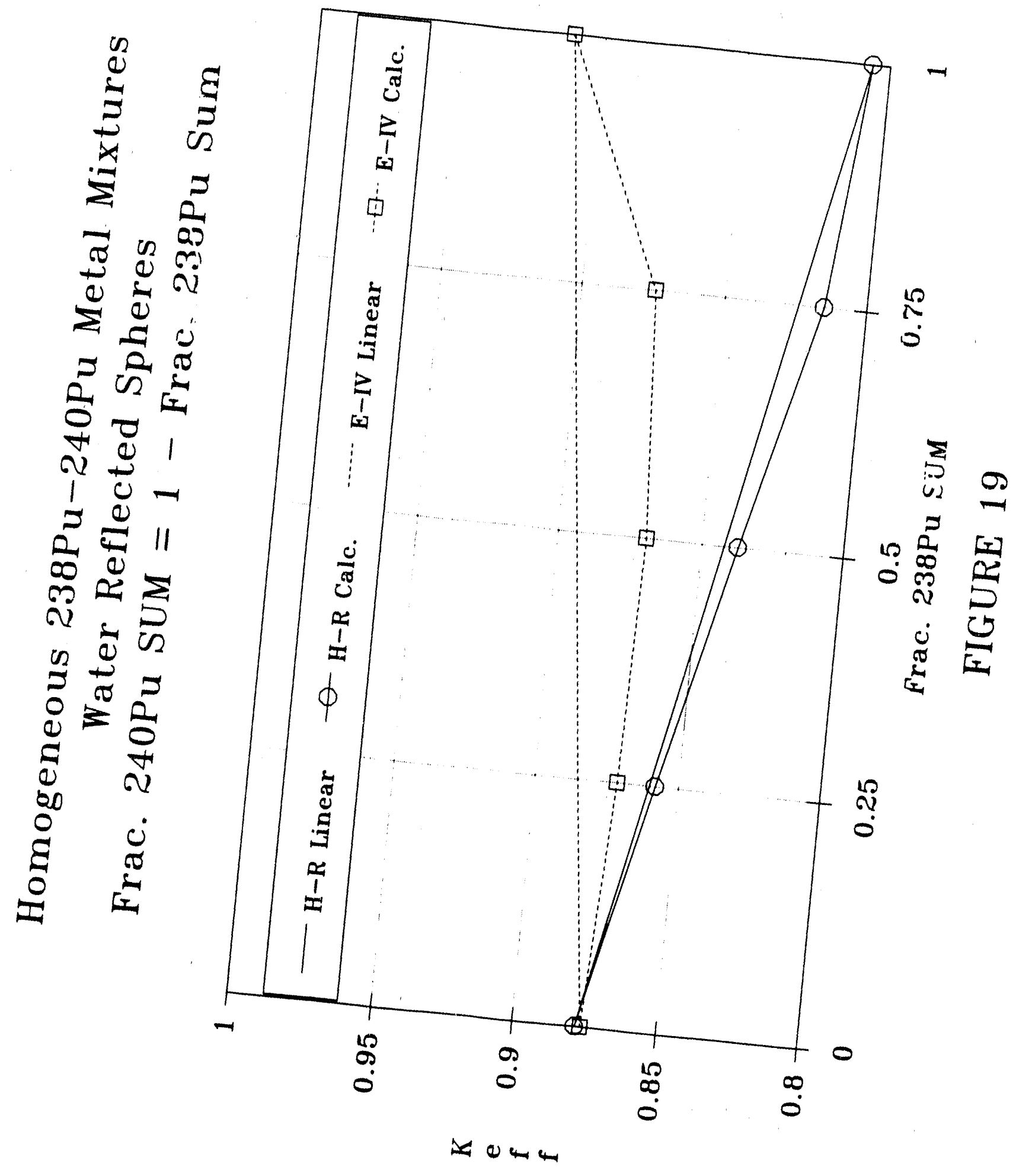




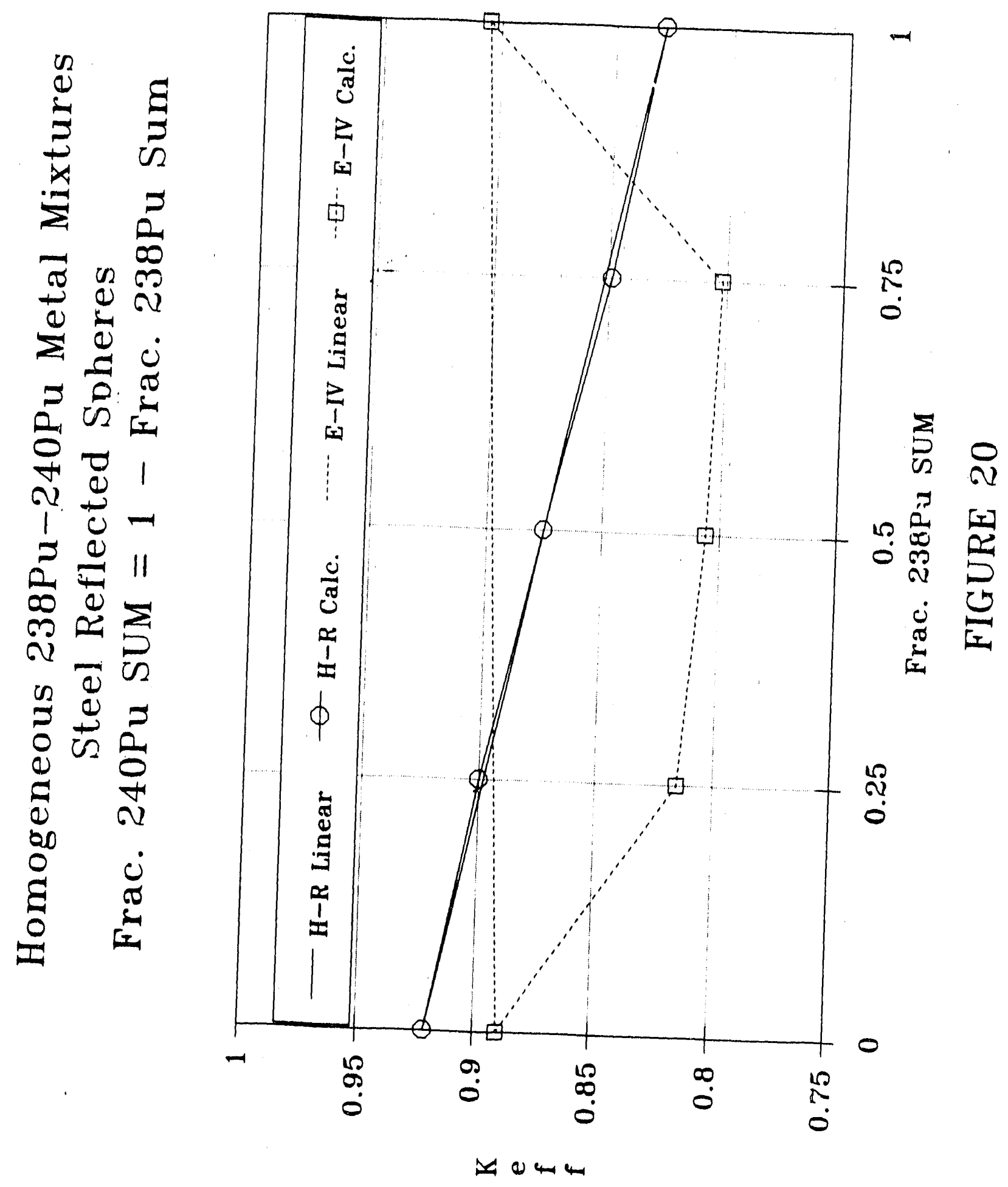


calculated results for heterogeneous ball-shell arrangements of $238 \mathrm{Pu}$ and $240 \mathrm{Pu}$ metal are shown in Table IX and Figures 21 , 22 , and 23 . These results are characterized by satisfying the Rule-Of-Fractions when ${ }^{24} \mathrm{Pu}_{3} \mathrm{~s}$ in the ball, and not satisfying the Rule-of-Fractions when $238 \mathrm{Pu}$ is in the ball. These effects arise becauge $238 \mathrm{Pu}$ has a higher fast fission cross section than $24 \mathrm{Pu}_{\mathrm{Pu}}$ and $240 \mathrm{Py}$ has a higher fast scattering cross section than $238 \mathrm{Pu}$. When $240 \mathrm{Pu}$ is in the ball it is surrounded by much less mass of a poorer reflector than in single unit form, even though that reflector has a very high fission cross section. When $238 \mathrm{Pu}$ is in the ball it is surrounded by a much bigger mass of a better reflector than in single unit form, and that reflector has a moderate fission cross section. The reflector surrounding the unit does not seem to play much role, as indicated by the shapes of all the curves being almost identical.

The conclusions to be drawn from the above results appear to be the following:

- the Rule-of-Fractions appears to hold for homogeneous mixtures of two pure fissionable nuclides.

- the Rule-of-Fractions appears to be valid for heterogeneous arrangements of two fissionable nuclides when the nuclide having the lower fission cross section is in the ball region of a ball-shell arrangement.

These conditions are not only hard to apply for any general application, but are restricted to two-nuclide mixtures.

\section{FIB8ILE-FIB8IONABLF KIXTUREA}

There are four possible combinations of the two fissile and two fissionable isotopes under consideration. For this study only two combinations were examined, and were chosen to prevent too great a disparity between masses of fissile and fissionable single Unit Masses. A large disparity in single Unit Masses seemed to play a very large role in the $238 \mathrm{Pu}-{ }^{2} 4 \mathrm{O}_{\mathrm{Pu}}$ mixtures in the previous section. It is obvious that a combination of $235 \mathrm{U}$ and $238 \mathrm{Pu}$ would represent a very large mass difference betweęn single units, as also would be the case for combinations of $239 \mathrm{Pu}$ and $240 \mathrm{Pu}$. Hompgeneous and heterogeneous mixtures of $235 \mathrm{U}$ and $240^{\mathrm{Pu}}$, and of $238_{\mathrm{Pu}}$ and ${ }^{239} \mathrm{Pu}$ were studied.

The mixtures were combined in quarter unit increments as in the previous ${ }_{2}$ gsses. Calculated results for homogeneous mixtures of $235 \mathrm{U}$ and $240 \mathrm{Pu}$ metal units are shown in Table $X$ and Figures 24,25 , and 26. These results indicate that the Rule-ofFractions is not valid for any mixture or reflector. The spectral effects that lead to reduced margins are more complex than in previous cases when homogeneous mixtures increased the margins. The spectral effects arise from differences in $v \Sigma_{f} / \Sigma_{a}$, $\Sigma_{s} / \Sigma_{a}$, and reflector effects between the two isotopes. These differences are summarized in Table XI. 
TABLE IX

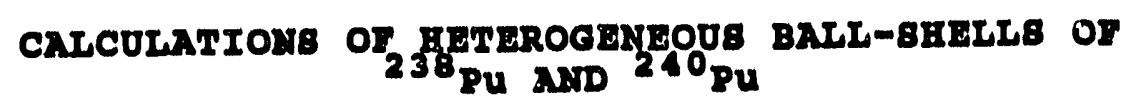

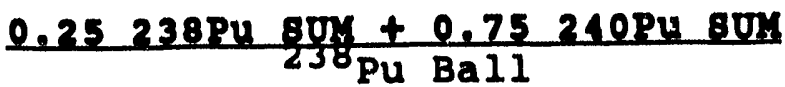

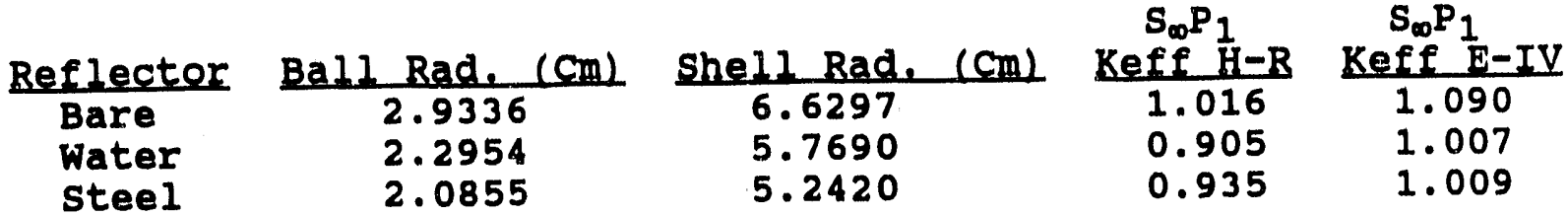

\section{$240^{\mathrm{Pu} \mathrm{Ball}}$}

Reflector

Bare

Water

Steel

2.0855

0.935

1.009

\begin{tabular}{cccccc} 
Reflector & Ball Rad. $(\mathrm{Cm})$ & Shell Rad. $(\mathrm{Cm})$ & $\begin{array}{c}\mathrm{S}_{\infty} \mathrm{P}_{1} \\
\text { Keff H-R }\end{array}$ & $\begin{array}{c}\mathrm{S}_{\infty} \mathrm{P}_{1} \\
\text { Keff } \mathrm{E}-I V\end{array}$ \\
\cline { 2 - 2 } & 6.4324 & 6.6297 & 0.912 & 0.876 \\
Water & 5.6457 & 5.7690 & 0.841 & 0.847 \\
Steel & 5.1294 & 5.2420 & 0.882 & 0.854
\end{tabular}

\section{$\frac{0.5238 \mathrm{Pu} 80 \mathrm{y}+0.5240 \mathrm{Pu} 80 \mathrm{x}}{230 \mathrm{Pu} \mathrm{Ball}}$}

Reflector

Bare

Water

steel

$S_{\infty} P_{1}$

$$
6.1084
$$

5.2430

1.037

0.910

0.934

$S_{\infty} P_{1}$
Keff $E-I V$
1.113
1.013
1.010

$240_{\mathrm{Pu} \mathrm{Ball}}$

Reflector Bare

water

2.8920

4.7640

1.010

Steel

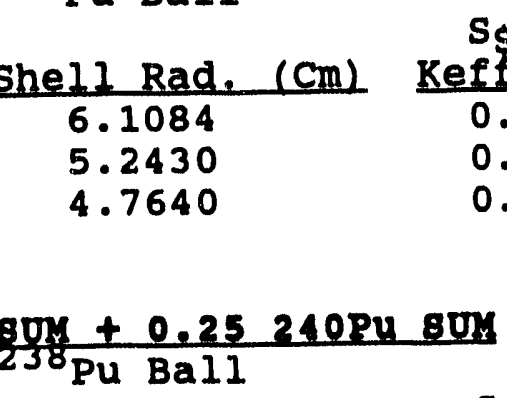

\begin{tabular}{cccccc} 
Reflector & Ball Rad, (cm) & Shell Rad._(Cm) & $\begin{array}{c}S_{\infty} P_{1} \\
\text { Keff H }-R\end{array}$ & $\begin{array}{c}S_{\infty} P_{1} \\
\text { Keff E-IV }\end{array}$ \\
\cline { 2 - 2 } & 4.2309 & 5.4787 & 1.020 & 1.094 \\
Water & 3.3105 & 4.5830 & 0.886 & 0.990 \\
Steel & 3.0078 & 4.1640 & 0.908 & 0.986
\end{tabular}

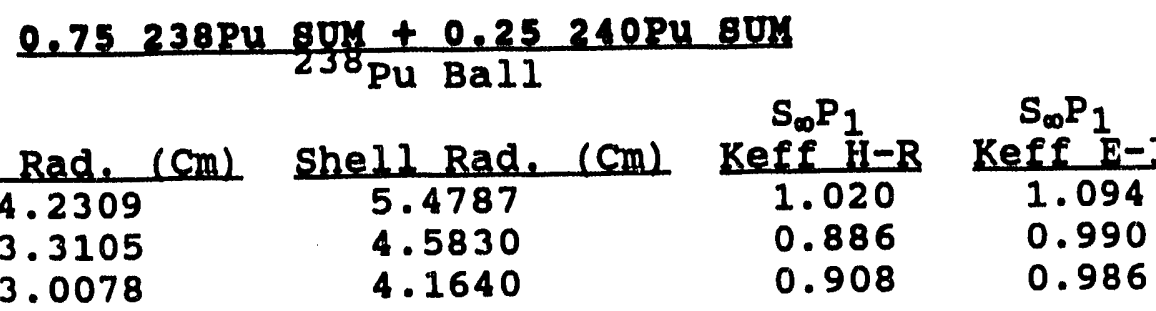

$24{ }^{\circ} \mathrm{Pu} \mathrm{Ball}$

Reflector Ball Fad. (Cm)

Bare

Water

steel
4.4600

3.9145

3.5566
Shell Rad. (Cm)

$$
S_{\infty} P_{1}
$$

5.4784

4.5830

4.1640

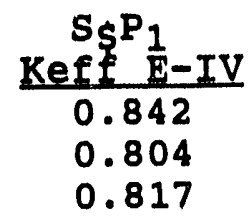

0.804 ft $\mathrm{H}-\mathrm{R}$

0.798

0.841 


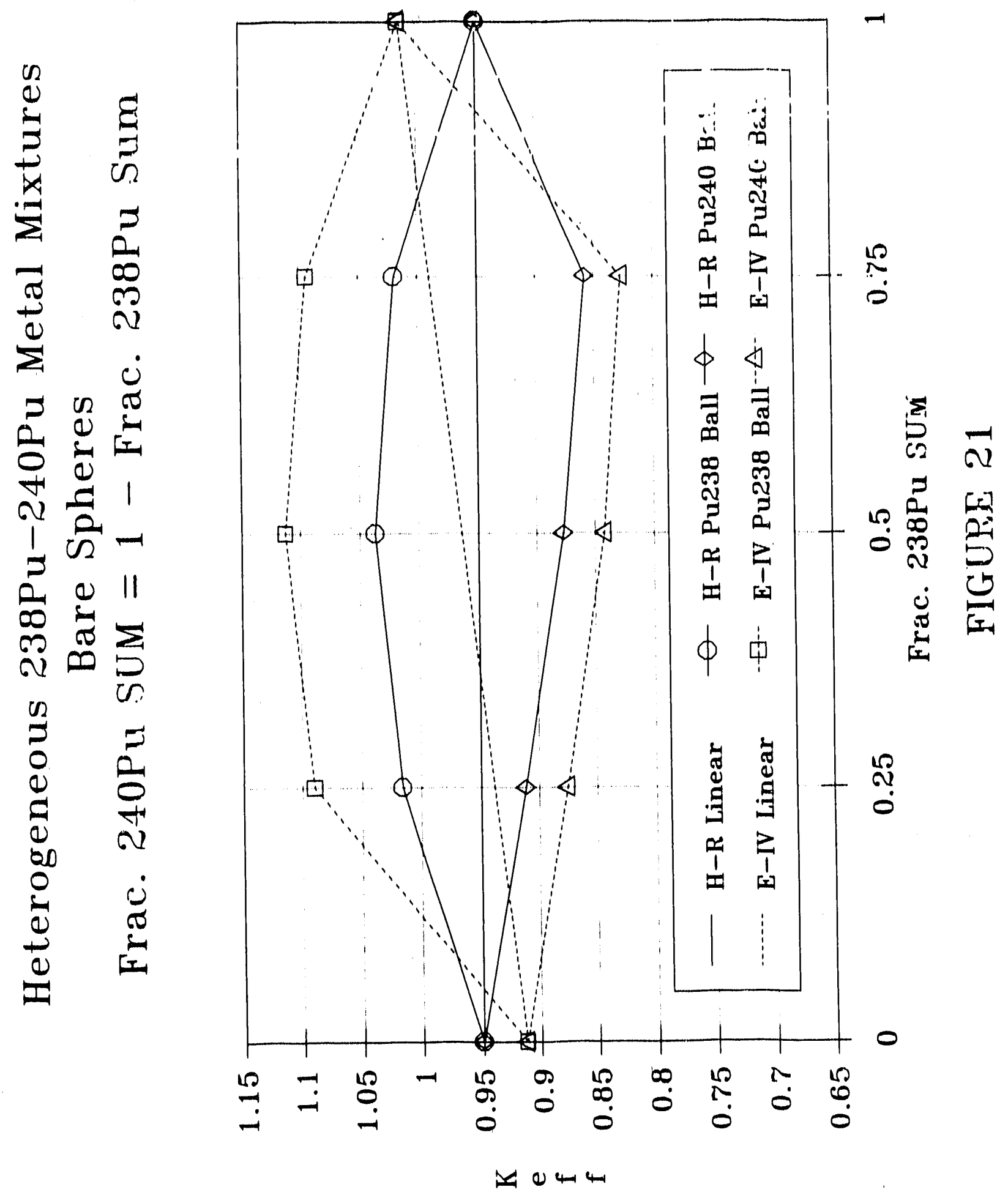



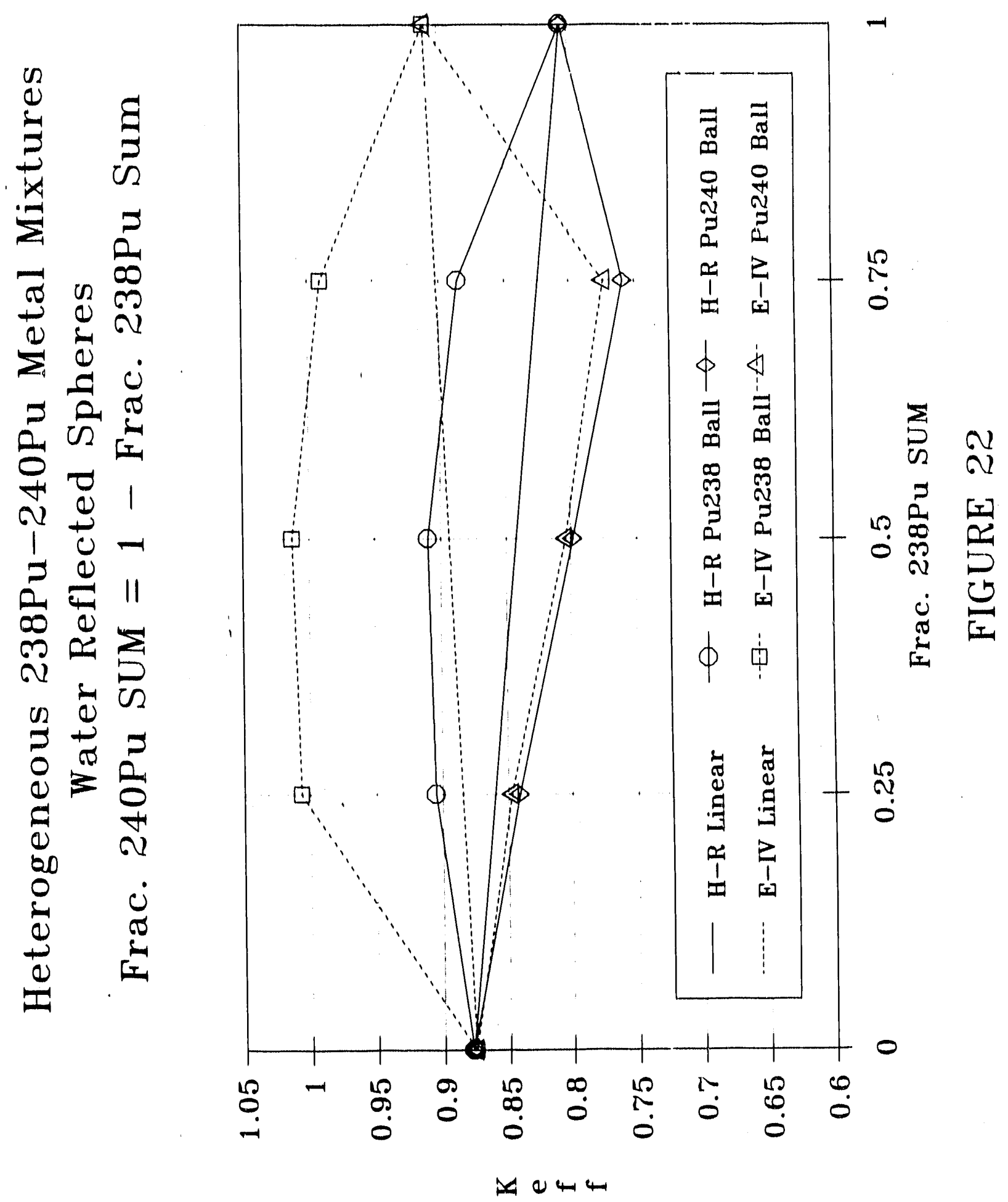

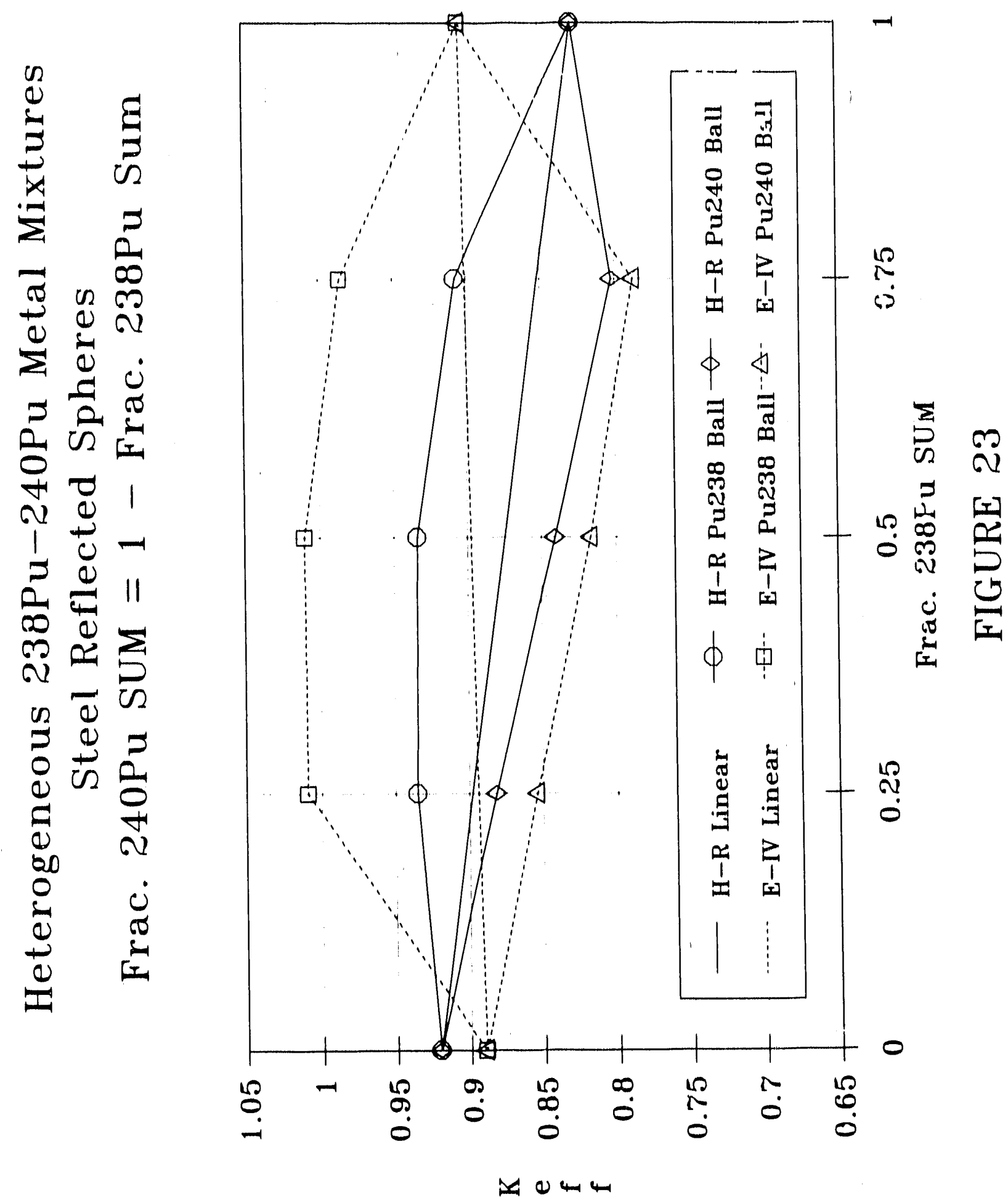
TABLE X

CALCOLATIOYYS OF HOYOQEYEOOS MIXTORES OF

\section{$2.25235080 x+0.25210 P^{2}+0 x$}

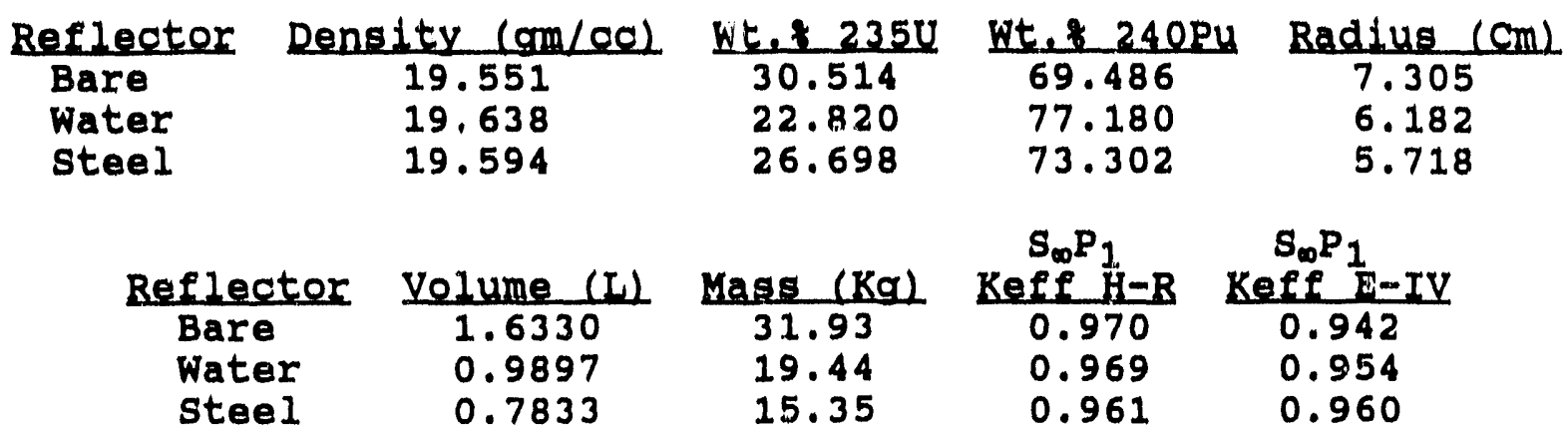

\subsection{0 +0.5240 Pu 80Y}

\begin{tabular}{ccccc} 
Reflector & Density $(\mathrm{gm} / \mathrm{CC})$ & Wt.7235U & Wt.f 240Pu & Radius $(\mathrm{Cm})$ \\
\cline { 2 - 4 } & 19.259 & 56.849 & 43.151 & 7.518 \\
Water & 19.367 & 47.006 & 52.994 & 6.150 \\
Steel & 19.310 & 52.214 & 47.786 & 5.789
\end{tabular}

\begin{tabular}{ccccc} 
Reflector & Volume $(L)$ & Kass $(K g)$ & $S_{\infty} P_{1}$ & $S_{\infty} P_{1}$ \\
\cline { 5 - 6 } Bare & 1.7797 & 34.275 & 0.969 & 0.954 \\
Water & 0.9743 & 18.870 & 0.958 & 1.084 \\
Steel & 0.8128 & 15.695 & 0.967 & 0.979
\end{tabular}

\section{$0.75235080 x+0.25240 P 480 x$}

Reflector Density (cm/cc) Wt.t 235U Wt.t 240Pu Radius (cm)

\begin{tabular}{|c|c|c|c|}
\hline $\begin{array}{l}\text { Bare } \\
\text { Water } \\
\text { Steel }\end{array}$ & $\begin{array}{l}19.012 \\
19.088 \\
19.046\end{array}$ & $\begin{array}{l}79.807 \\
72.685 \\
76.625\end{array}$ & $\begin{array}{l}20.193 \\
27.315 \\
23.375\end{array}$ \\
\hline
\end{tabular}

Beflector Volume (W) Mass (Kg)

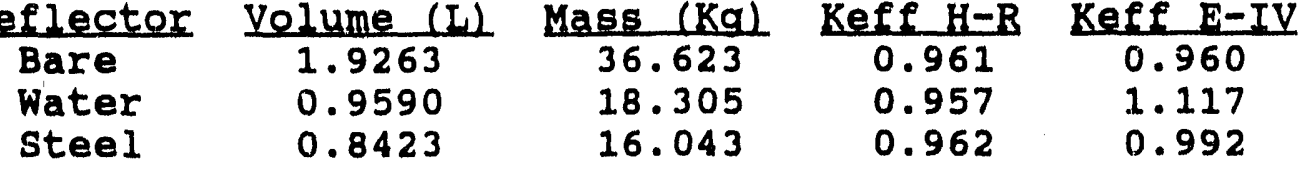

Water reflector thickness $-30.48 \mathrm{~cm}$.

steel reflector thickness $-25.4 \mathrm{~cm}$.

H-R - Hansen-Roach Cross Sections

E-IV - ENDF/B-IV Cross Sections 

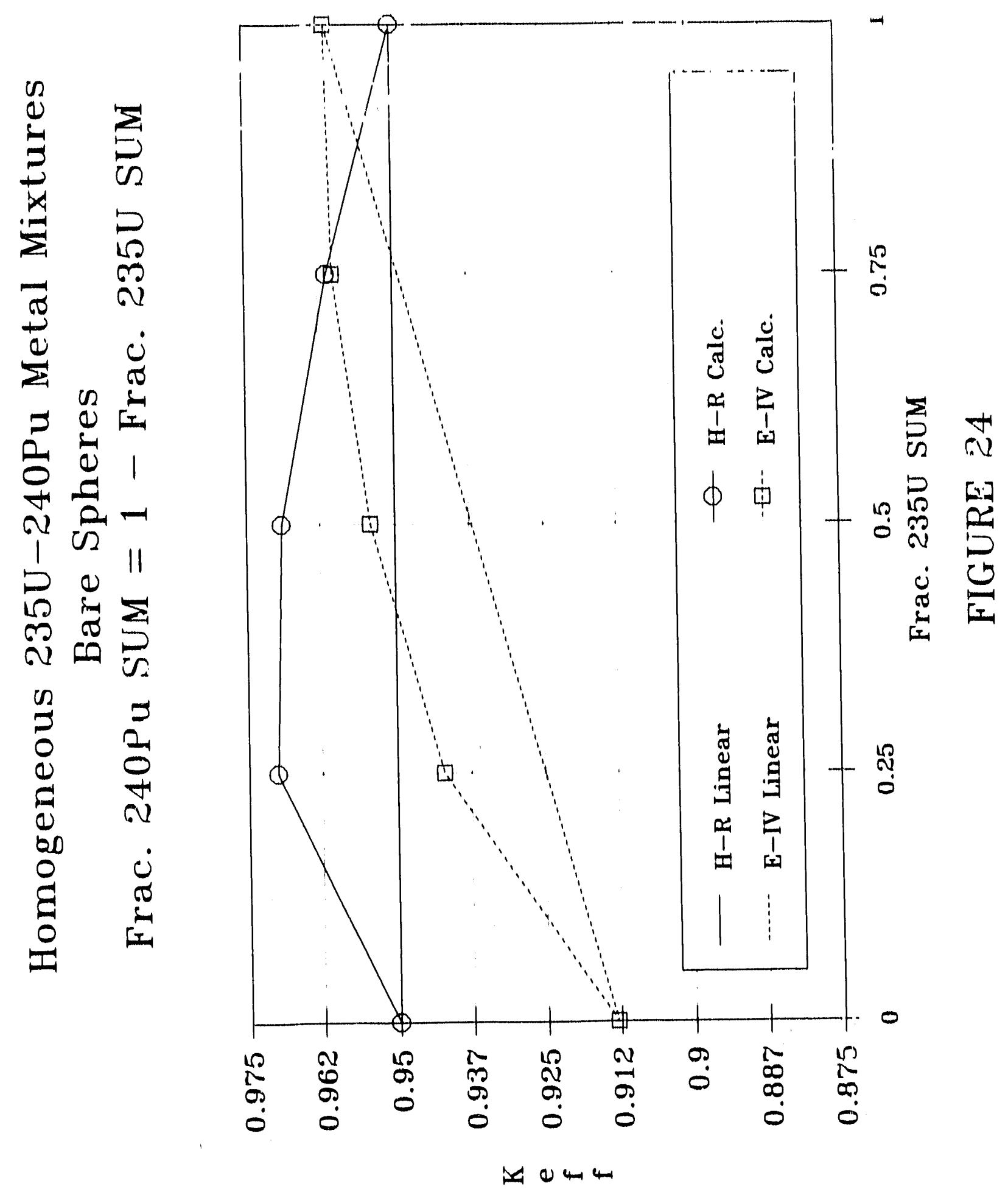


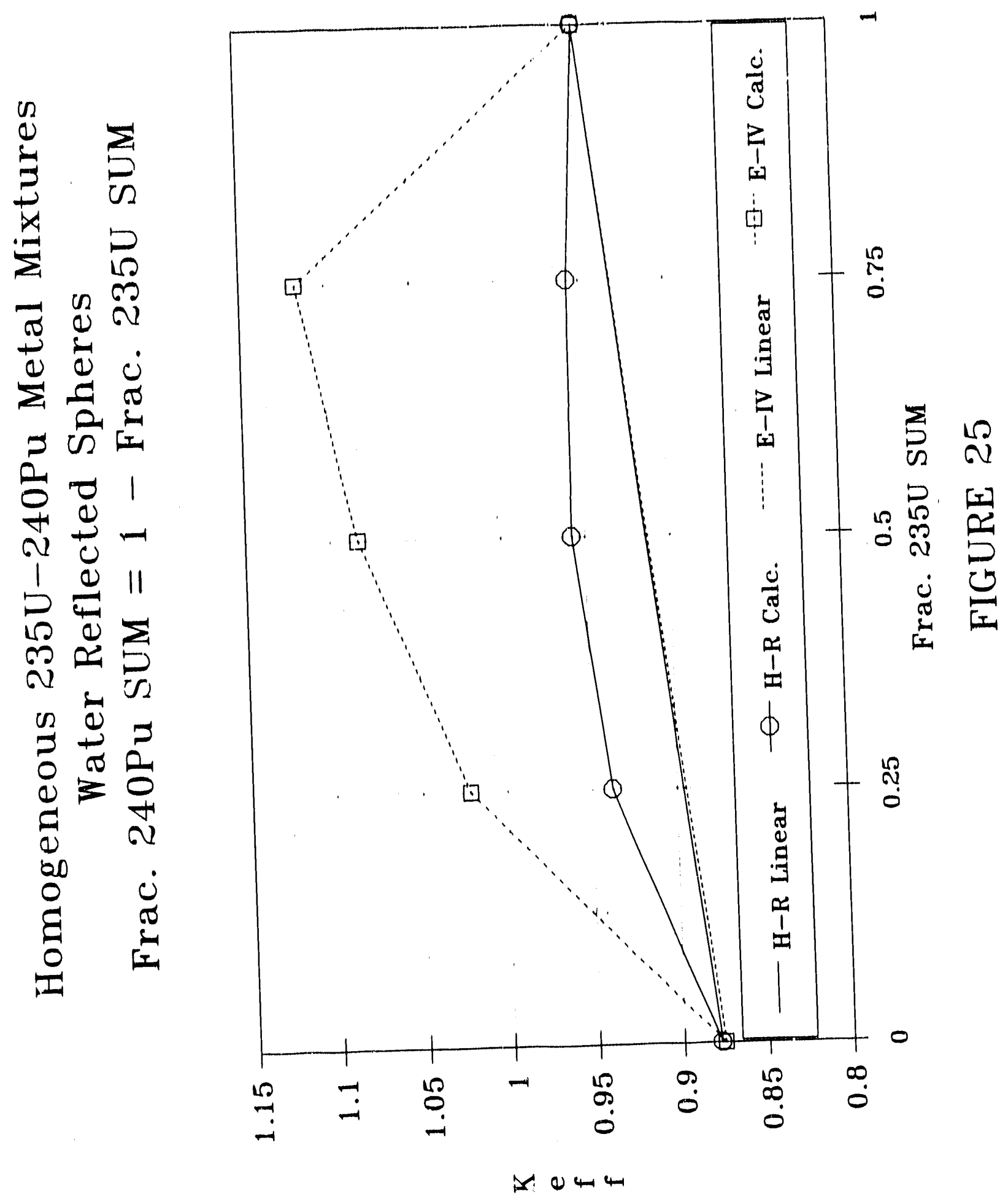



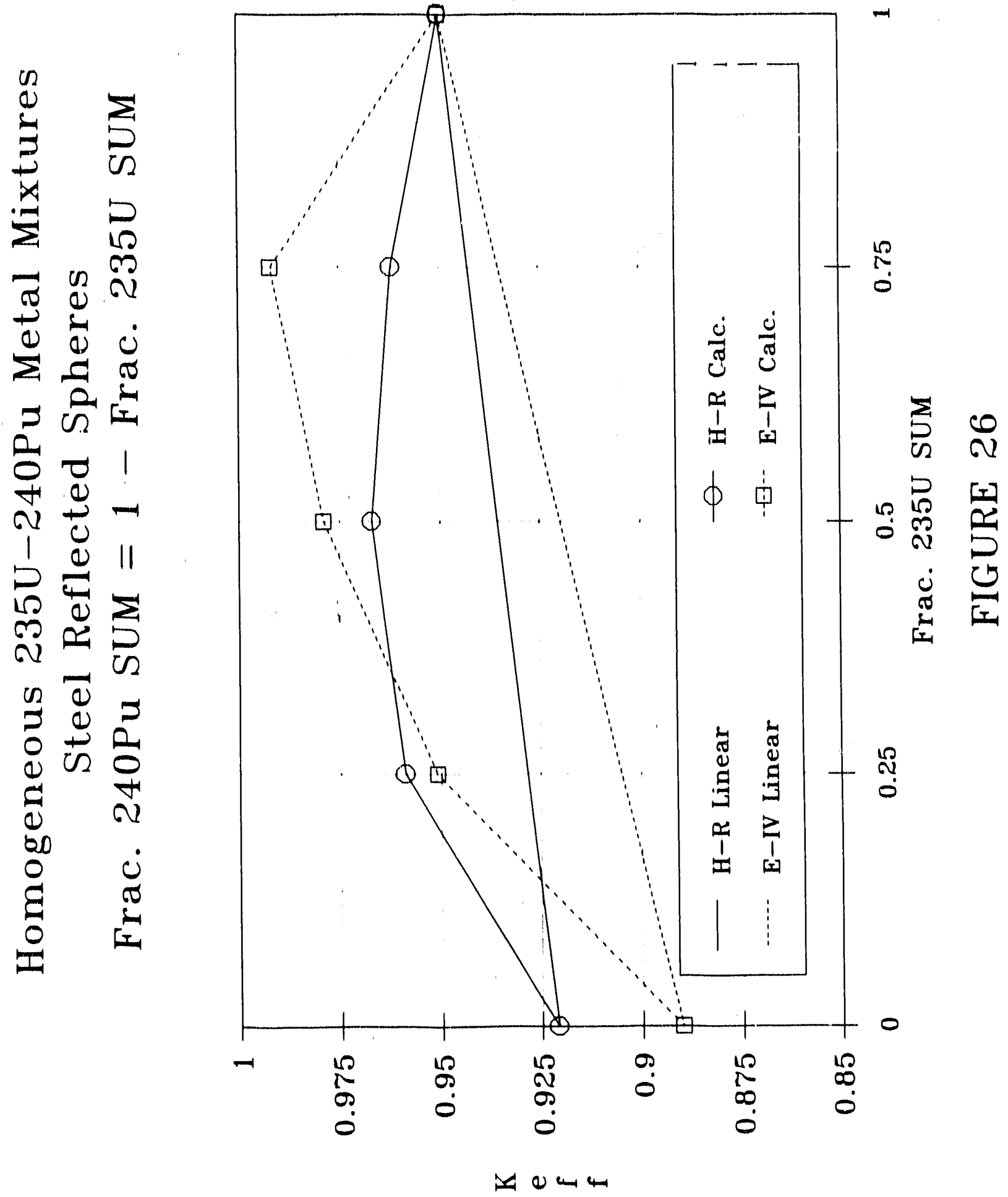
TABLE XI

HANSEN-ROACH CROSS SECTION RATIOS FOR ${ }^{235} \mathrm{U}$ AND ${ }^{240} \mathrm{PU}$

\begin{tabular}{|c|c|c|c|c|}
\hline \multirow{2}{*}{ Energy Region } & \multicolumn{2}{|c|}{$v \Sigma_{\mathrm{f}} / \Sigma_{\mathrm{a}}$} & \multicolumn{2}{c|}{$\Sigma_{\mathrm{s}} / \Sigma_{\mathrm{a}}$} \\
\cline { 2 - 5 } & $235_{\mathrm{U}}$ & $240_{\mathrm{Pu}}$ & $235_{\mathrm{U}}$ & $240_{\mathrm{Pu}}$ \\
\hline High: $>1 \mathrm{Mev}$ & 2.32 & 3.25 & 2.52 & 1.78 \\
\hline Intermediate: $10 \mathrm{ev}-1 \mathrm{Mev}$ & 2.0 & 0.21 & 0.2 & 0.3 \\
\hline Thermal: < $10 \mathrm{ev}$ & 2.1 & $<0.001$ & 0.1 & 0.3 \\
\hline
\end{tabular}

For the bare spheres, the spectrum peaks in the high energy region. Here the admixed ${ }^{2}{ }^{2} \mathrm{U}$ provides a better ${ }_{4}$ feflector than $\mathrm{Pu}$, and thus increasing the net essentially increases the of the asymptotic spectrum region in the center, increasing size importance, hence yielding more net fissions.

For the water reflected spheres, the major effect comes from 235ombination of increased intermediate and thermal fissions in for the bare spheres. The ENDF/B-IV data shows a markedly larger
for effect here than Hansen-Roach data. This is probably due to the better treatment of water scattering in ENDF/B-IV.

For the steel reflected spheres, the major effects that increase fission arise from the same source as for the bare spheres, and the magnitude of the $K_{e f f}$ change is larger for both sets of cross sections.

Calculated results for homogeneous mixtures of ${ }^{238} \mathrm{Pu}$ and $239 \mathrm{Pu}$ metal units are shown in Table XII and Figures 27,28 , and 29. Here maintaining Rule-of-Fractions margins seems to depend on the reflector.

The bare sphere mixtures display increased margin for both sets of cross sections thus satisfying the Rule-of-Fractions.

The water reflected spheres show a net: increase in $f \frac{j}{2} \xi 9$ ions that result primarily from increased thermal fissions in ${ }^{239} \mathrm{Pu}$
and intermediate fissions in ${ }^{38} \mathrm{Pu}$.

The steel reflected spheres show a smaller increase in margin than the bare spheres, and an almost exact preservation of the Rule-of-Fractions margins with Hansen-Roach cross sections. Figure 29 shows resuits that almost exactly agree with the Ruleof-Fractions, certainly better than any other case considered.

overall the homogeneous metal mixture cases do not confirm the margins of the Rule-of-Fractions. 
TABLE XII

\section{CALCOLATIOSY OF HOKOGgNEOU8 MIXTUREB OF}

\subsection{Pu 80x $+0.75238 \mathrm{Py}$ 80X}

\begin{tabular}{ccccc} 
Reflectior & Density (gm/cc) & Wt.t 238Pu & Wt.t 239Pu & Radius (Cm) \\
\cline { 2 - 3 } & 19.760 & 75.158 & 24.842 & 4.652 \\
Water & 19.762 & 72.438 & 27.562 & 3.685 \\
Steel & 19.765 & 67.873 & 32.127 & 3.421
\end{tabular}

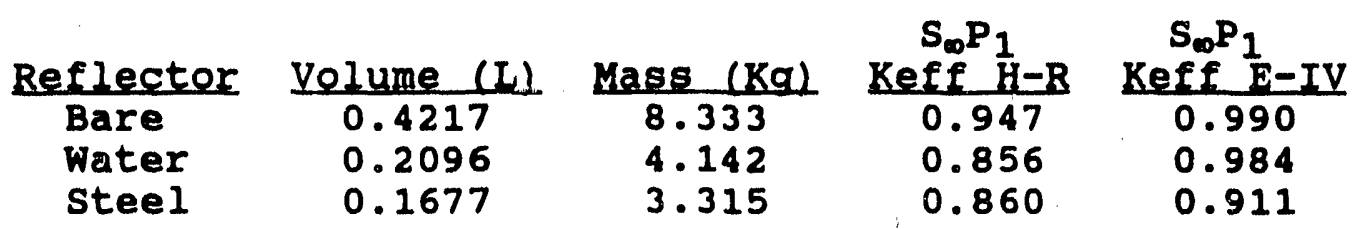

\section{$0.3239 \mathrm{Pu} 8 \mathrm{WY}_{Y}+0.5238 \mathrm{Pu}$ 8WY}

\begin{tabular}{|c|c|c|c|c|}
\hline $\begin{array}{l}\text { Bare } \\
\text { Water } \\
\text { Steel }\end{array}$ & $\begin{array}{l}19.780 \\
19.783 \\
19.787\end{array}$ & $\begin{array}{l}50.210 \\
46.696 \\
41.322\end{array}$ & $\begin{array}{l}49.790 \\
53.304 \\
58.678\end{array}$ & 4.647 \\
\hline$e+1+e c$ & Volume (L) & lass (Ka) & $\begin{array}{c}S_{\infty} P_{1} \\
\text { Keff } H-R\end{array}$ & $\begin{array}{l}S_{\infty} P_{1} \\
\text { Keff } E-J\end{array}$ \\
\hline $\begin{array}{l}\text { Bare } \\
\text { Water } \\
\text { Steel }\end{array}$ & $\begin{array}{l}0.4204 \\
0.2165 \\
0.1835\end{array}$ & $\begin{array}{l}8.315 \\
4.283 \\
3.630\end{array}$ & $\begin{array}{l}0.947 \\
0.890 \\
0.890\end{array}$ & $\begin{array}{l}0.969 \\
1.015 \\
0.925\end{array}$ \\
\hline
\end{tabular}

\section{$0.75239 P u$ 80Y $+0.25238 P u$ 80XY}

Reflector Density (am/CG) Wt, 238Pu Wt, $239 \mathrm{Pu}$ Radius (Cm)

\begin{tabular}{|c|c|c|c|c|}
\hline $\begin{array}{l}\text { Bare } \\
\text { Water } \\
\text { Steel }\end{array}$ & $\begin{array}{l}19.800 \\
19.802 \\
19.805\end{array}$ & $\begin{array}{l}25.158 \\
22.601 \\
19.011\end{array}$ & $\begin{array}{l}74.842 \\
77.397 \\
80.989\end{array}$ & $\begin{array}{l}4.642 \\
3.764 \\
3.623\end{array}$ \\
\hline Reflector & Volume (L) & Mass $(\mathrm{Kg})$ & $\begin{array}{l}S_{\infty \infty} P_{1} \\
\text { Keff } H-B\end{array}$ & $\begin{array}{c}S_{\infty 0} P_{1} \\
\text { Keff } E-\end{array}$ \\
\hline $\begin{array}{l}\text { Bare } \\
\text { Water } \\
\text { Steel }\end{array}$ & $\begin{array}{l}0.4191 \\
0.2234 \\
0.1992\end{array}$ & $\begin{array}{l}8.2975 \\
4.4245 \\
3.9450\end{array}$ & $\begin{array}{l}0.947 \\
0.920 \\
0.920\end{array}$ & $\begin{array}{l}0.953 \\
1.038 \\
0.943\end{array}$ \\
\hline
\end{tabular}

Water reflector thickness $-30.48 \mathrm{~cm}$.

steel reflector thickness $-25.4 \mathrm{~cm}$.

H-R - Hansen-Roach Cross Sections

E-IV - ENDF/B-IV Cross Sections 


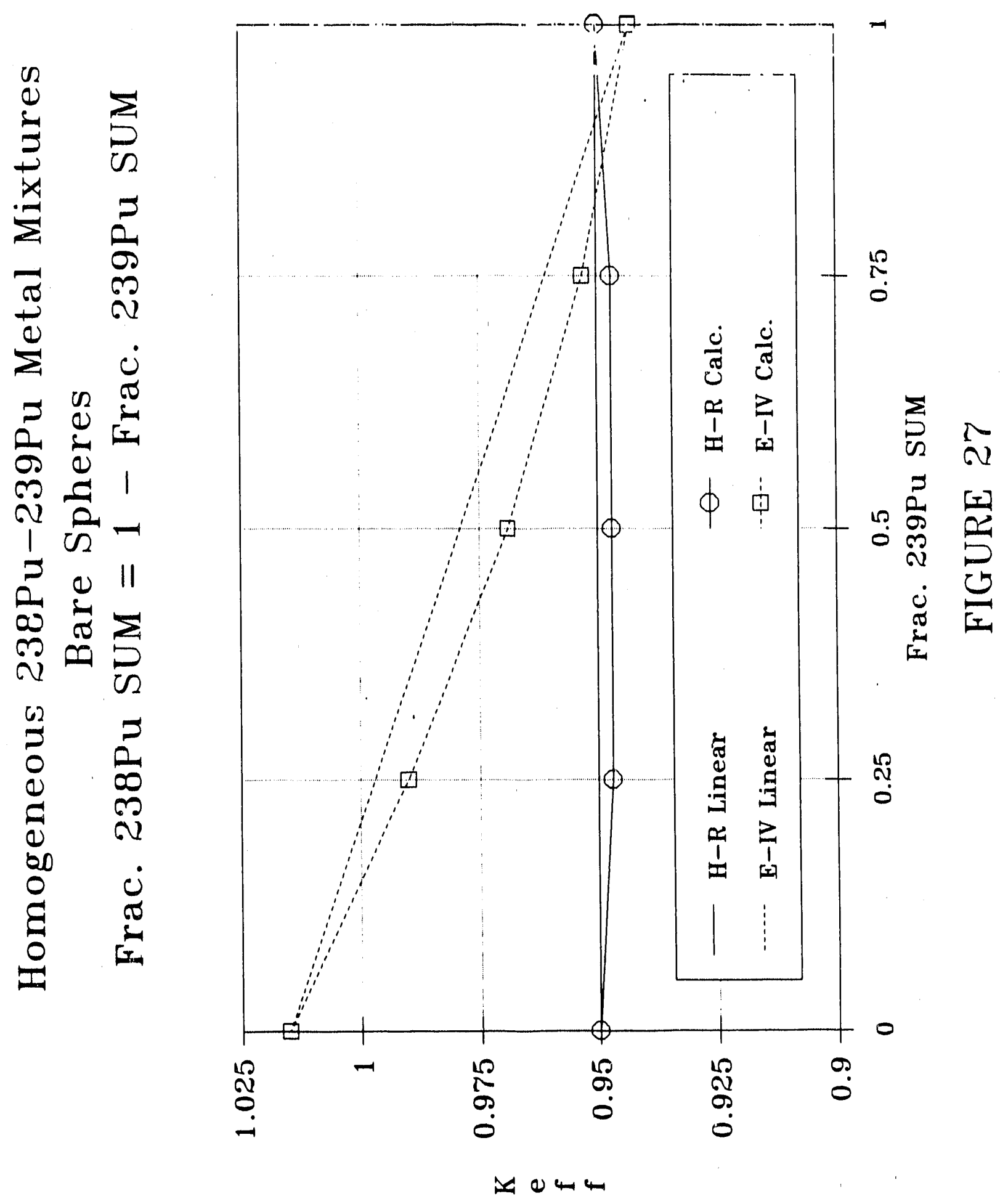


WBRC-TR-91-569

52

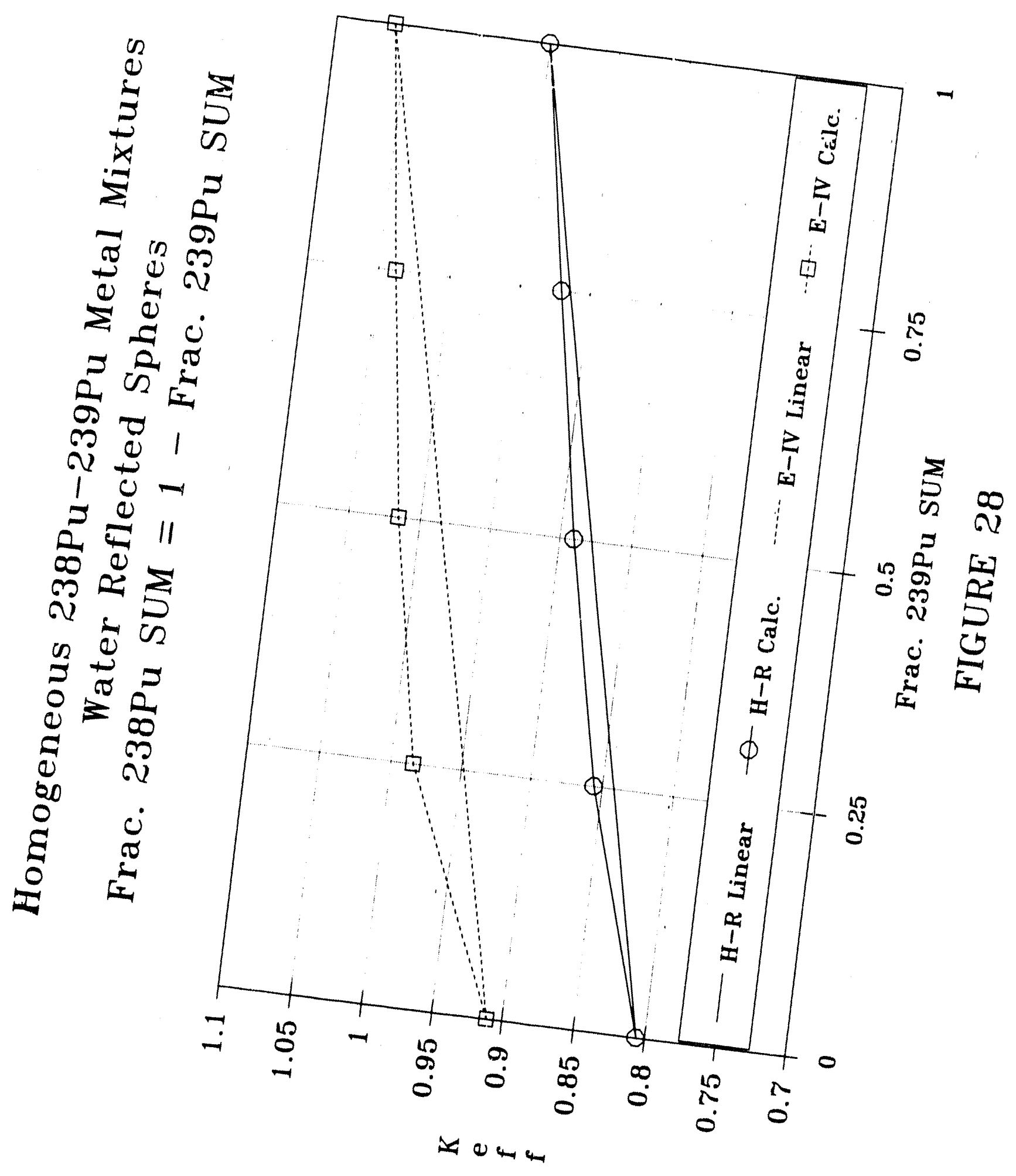




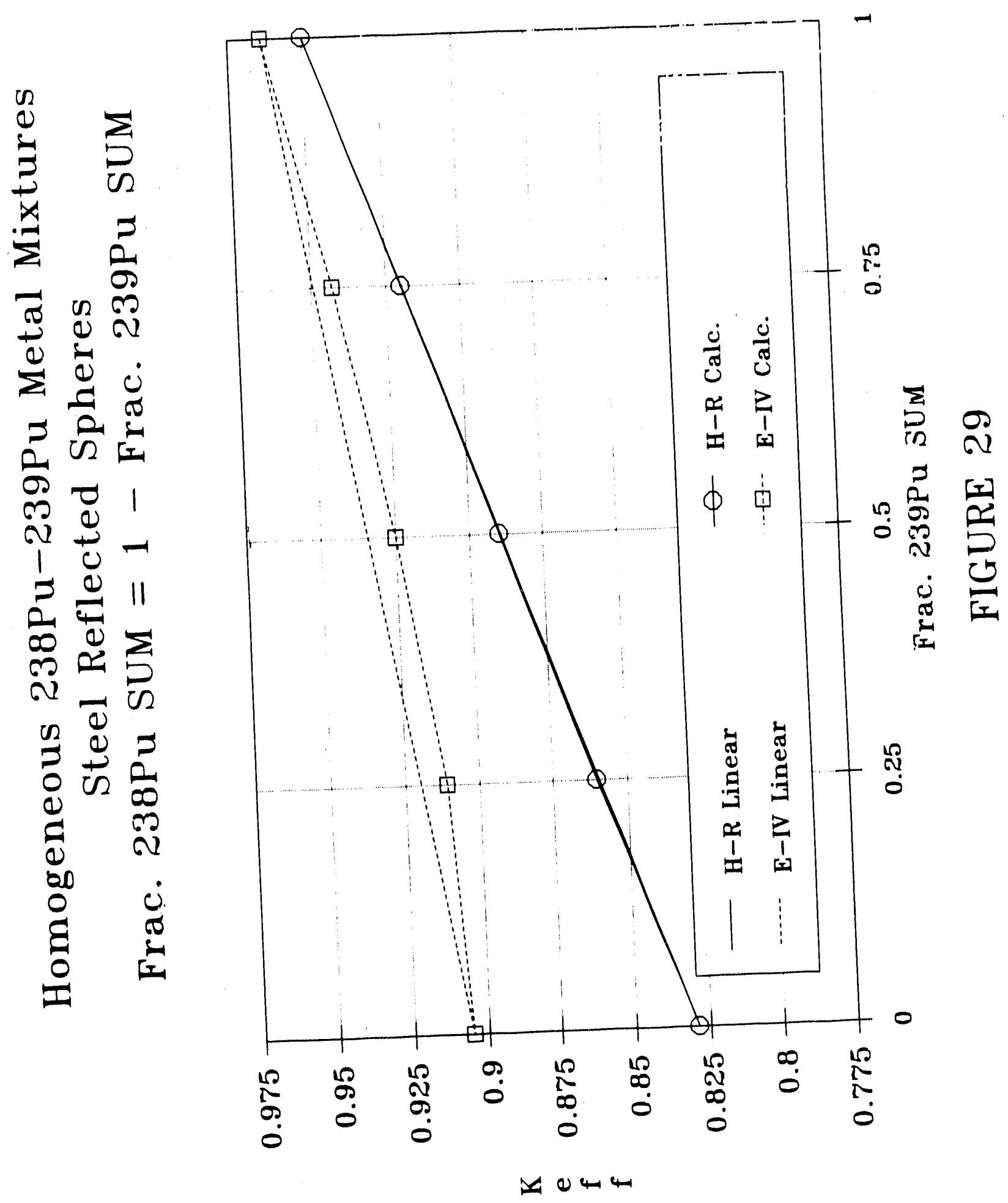


The next cases considered were heterogeneous ball-shell geometries using the fissile-fissionable metals.

Calculated results for heterogeneous mixtures of $235 \mathrm{U}$ and $240 \mathrm{Pu}$ metal are shown in Table XIT $\frac{1}{3} 5$ and Figures $30,31,2$ and 32 . Calculations were performed with $235 \mathrm{U}$ in the ball and $240 \mathrm{Pu}$ in the shell, and also with the isotopes reversed in the same geometry. The results of these calculations showed a wide variation.

Results for bare spheres are shown in Figure 30 . The Hansen-Roach cross sections show Rufe-Of-Fraction margins are not preserved for the geometry with a $24 \mathrm{O}_{\mathrm{Pu}}$ ball and $235 \mathrm{U}$ shell, but ENDF/B-IV cross sections show that the Rule-of-Fractions does maintain the margin. The cross section ratios in Table XI show that the Hansen-Roach result arises from having a higher fissioning metal in the ball and a better reflecting material in the shell. The ENDF/B-IV result arises because those cross sections shpw a much lower $\Sigma_{g} / \Sigma_{a}$ ratio for $235_{U}$ and a slightly lower $\nu \Sigma_{f} / \Sigma_{a}$ for $240_{\mathrm{Pu}}$ giving on balance a reduction in total fissions.

Results for water reflected spheres are shown in Figure 31 , and demonstrate that the Rule-Of-Frgetions marging 3 are not preserved for the geometry with a $248_{\mathrm{Pu}}$ ball and $235_{\mathrm{U}}$ shell. The Hansen-Roach results for the bare spheres is preserved, but the magnitude is larger because of significantly more fissions in the outer part of the shell from thermalized neutrons. The ENDF/B-IV results now also show the Rule-of-Fractions margins are not preserved which results from increased fissions in the shell from thermalized neutrons. The magnitude of the shift in ENDF/B-IV results from the bare sphere results is surprisingly large, and probably results from the better treatment of water scattering.

Results for steel reflected spheres are shown in Figure 32 , and demonstrate that Rule-of-Fractions margins are not preserved irrespective of which isotope is in the ball or shell. The spectrum change that produces this arise from the scattered neutrons from the steel reflector producing a very large increase in fissions in the $235 \mathrm{U}$ shell. Second, fewer neutrons are removed from the high energy region by scattering or leakage before fissioning, hence the overall magnitude of change is much larger.

The seçnd set of heterogeneous ball-shell spheres were for $238 \mathrm{Pu}$ and ${ }^{2}{ }^{\mathrm{Pu}} \mathrm{Pu}$ mal arrangements. Results of these calculations are shown in Table XIV and Figures 33,34 and 35 . The results for these cases appear to be strongly affected by the quality of the ${ }^{2}{ }^{3} \mathrm{Pu}$ cross sections which for the Hansen-Roach set are not the best.

Results for the bare sphere arrangements are shown in Figure 33. Here ENDF $/ B-I V$ shows the Rule-Of 5 ractions margins are not preserved for $238 \mathrm{Pu}$ in the ball and $239 \mathrm{Pu}$ in the shell. The 
TABLE XIII

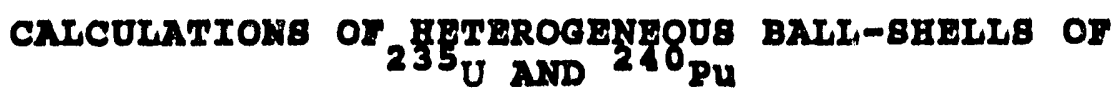

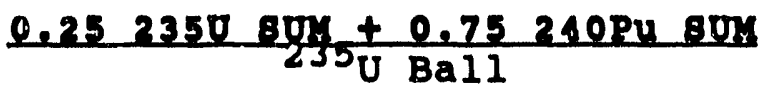

\begin{tabular}{|c|c|c|c|c|}
\hline $\begin{array}{l}\text { eflector } \\
\text { Bare } \\
\text { Water } \\
\text { Steel }\end{array}$ & $\begin{array}{c}\text { Bald Rad. C Cm } \\
4.9828 \\
3.8331 \\
3.7333\end{array}$ & $\begin{array}{c}\text { She11 Rad. (Cm } \\
7.3053 \\
6.1821 \\
5.7180\end{array}$ & $\begin{array}{c}\text { Keff } \bar{H}-\mathrm{R} \\
0.939 \\
0.866 \\
0.935\end{array}$ & $\begin{array}{l}\text { Keff E-IV } \\
0.923 \\
0.934 \\
1.024\end{array}$ \\
\hline
\end{tabular}

$$
240_{\mathrm{Pu} \mathrm{Ball}}
$$

Reflector Bare Water steel

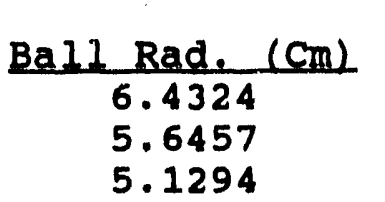

She11 Rad. (Cm)

$$
\begin{aligned}
& 7.3053 \\
& 6.1821 \\
& 5.7180
\end{aligned}
$$

$S_{\infty} P_{1}$

0.969

0.992

0.941
$S_{\infty} P_{1}$ $\mathrm{E}-\mathrm{IV}$ 0.931

1.121

1.020

\section{$\frac{0.5235080 x+0.5240 P u \text { 80x }}{235 \mathrm{Ball}}$}

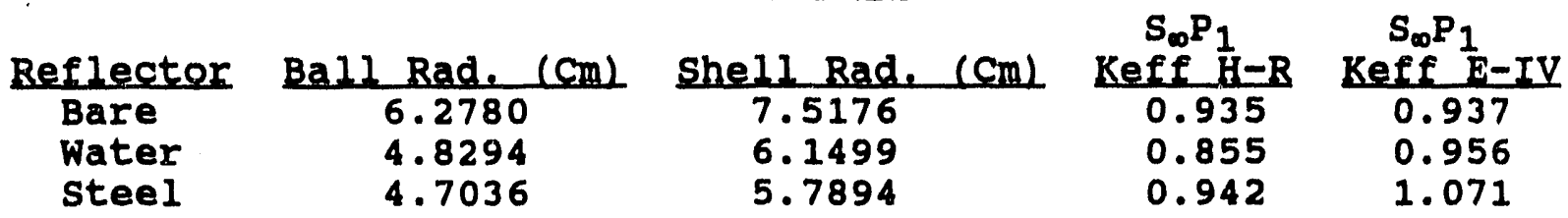

$$
240 \mathrm{Pu} \mathrm{Ball}
$$

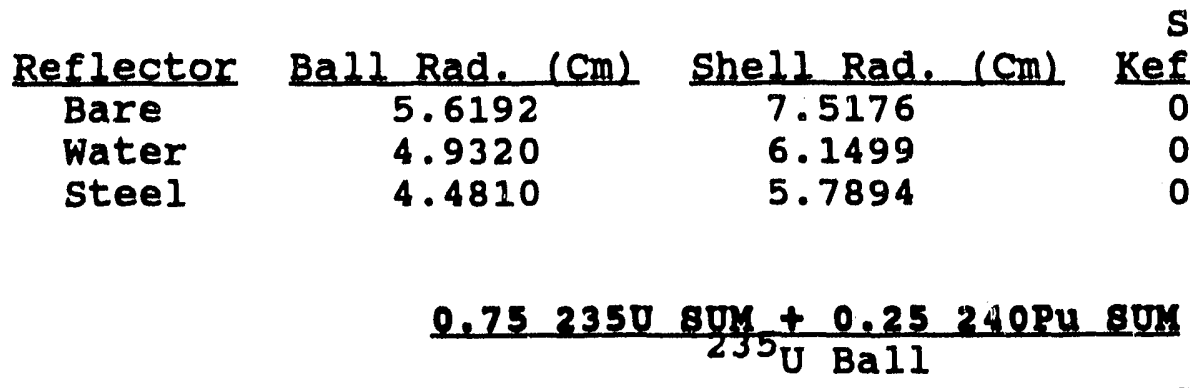

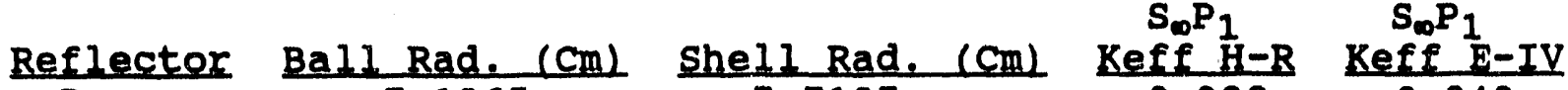

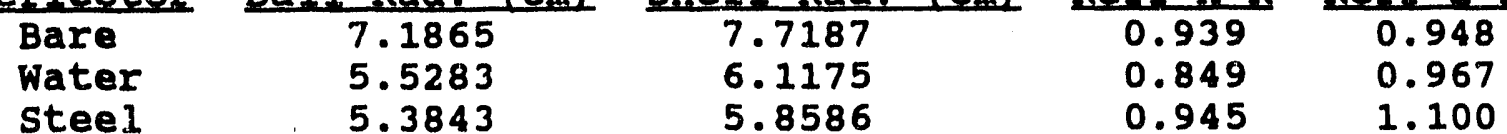

Steel $\quad 5.3843$

\section{$240 \mathrm{Pu} \mathrm{Ball}$}

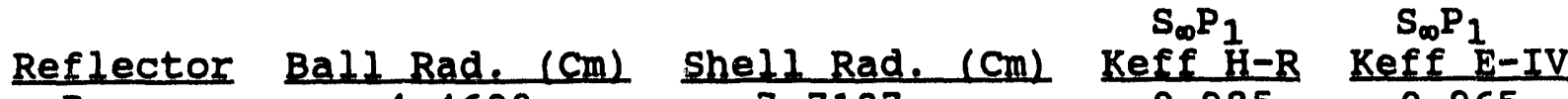
Bare

Water

4.4600

7.7187

6.1175

0.985

0.965

steel

3.5566

5.8586

0.988

1.144

0.968

1.107 

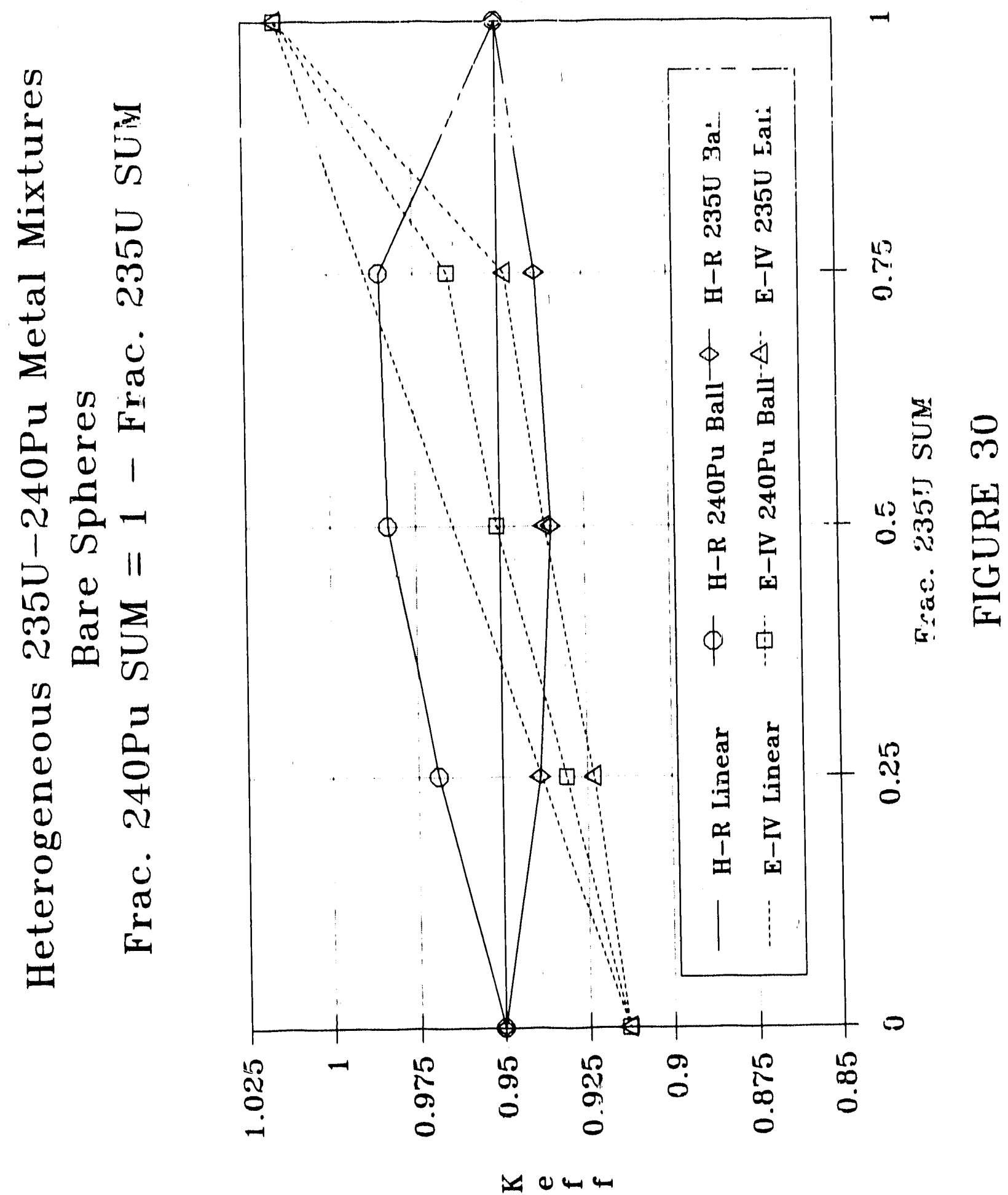


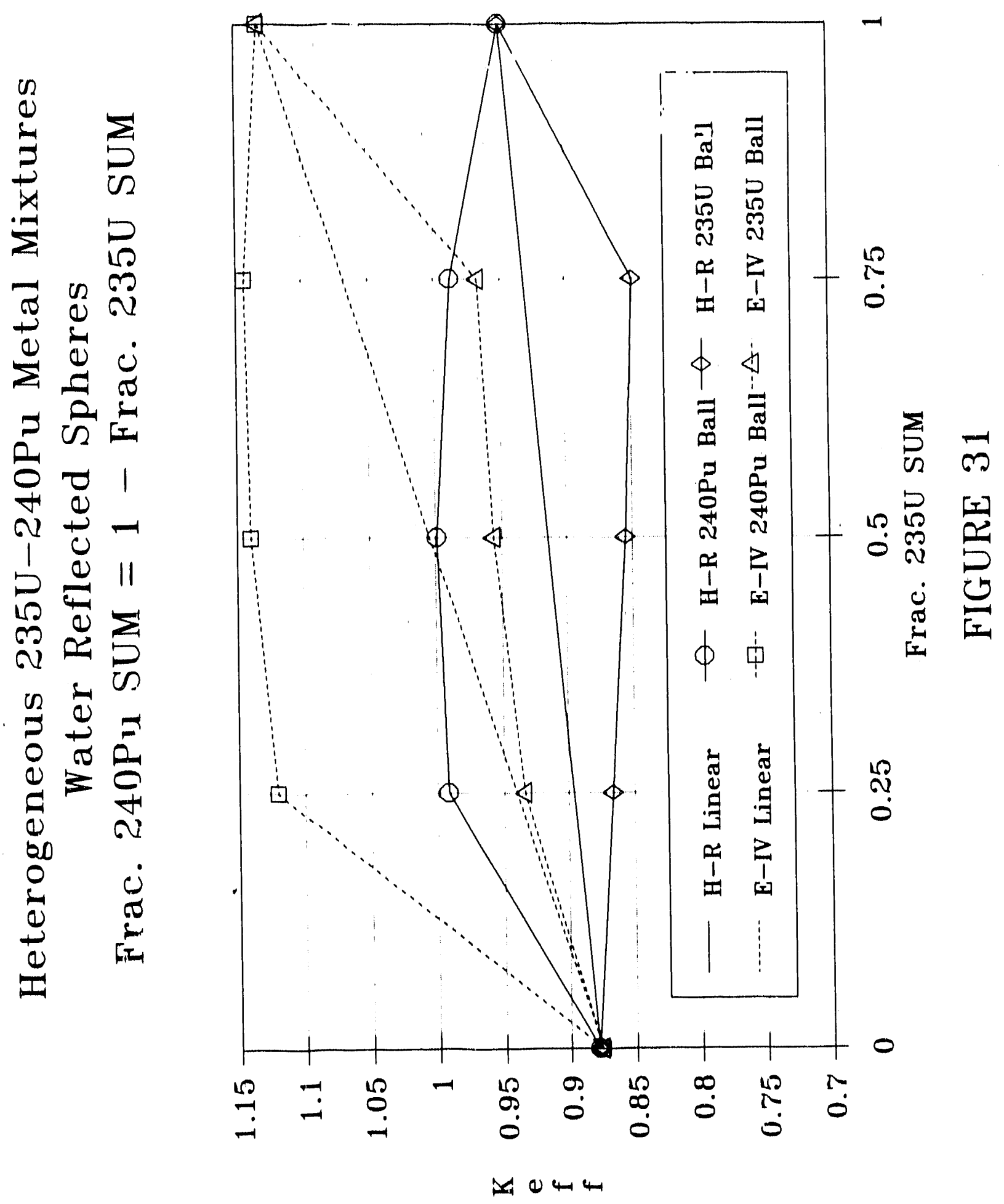



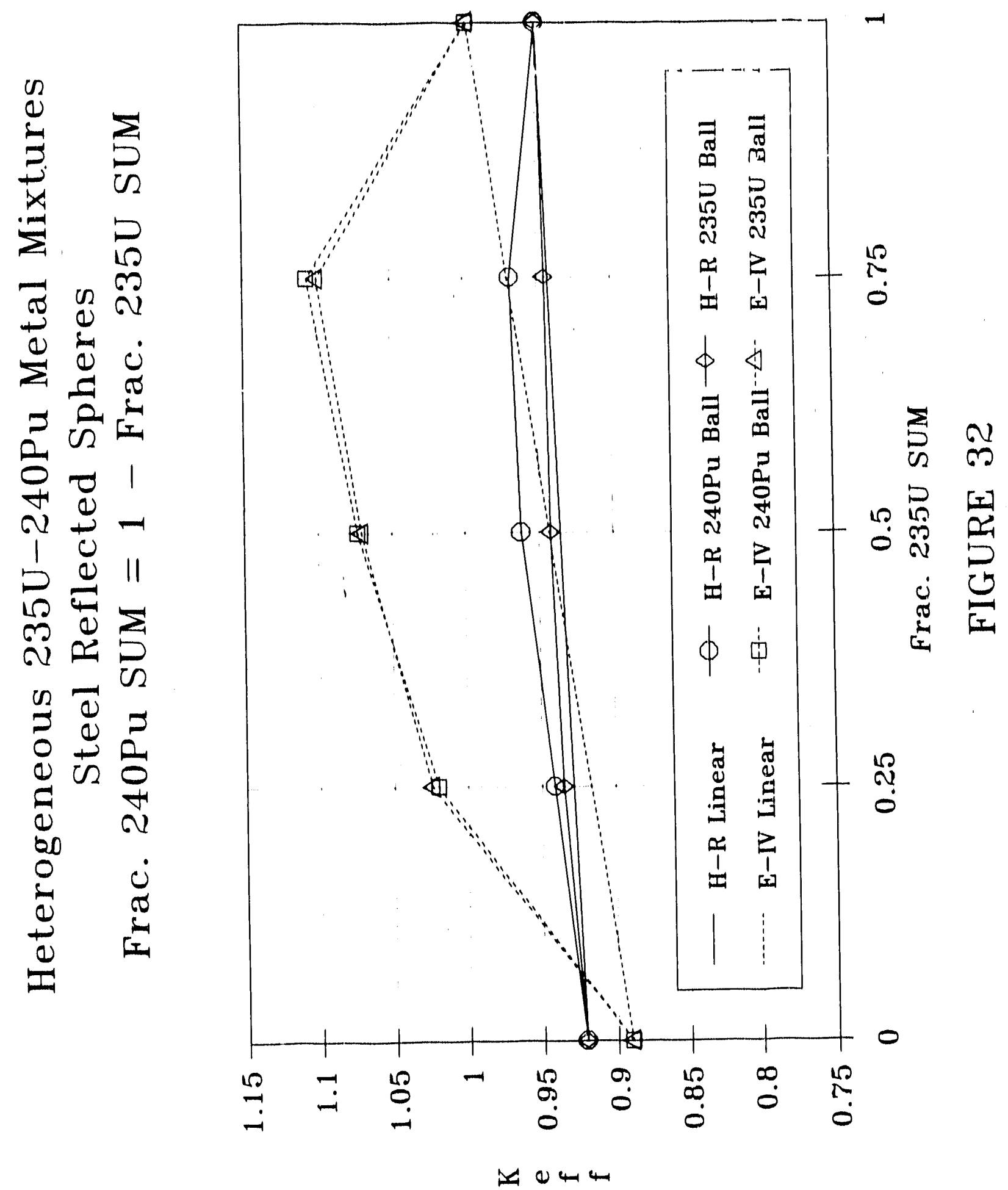
TABLE XIV

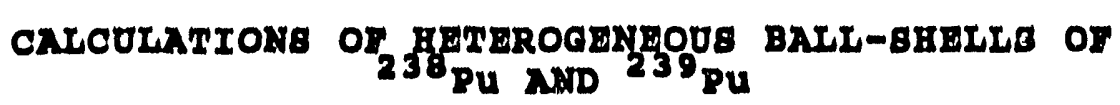

\section{$\frac{0.25238 \mathrm{Pu} 80 \mathrm{~g}+0.75239 \mathrm{Pu} \text { 80X }}{2{ }^{\mathrm{Pu}} \mathrm{Ba} 11}$}

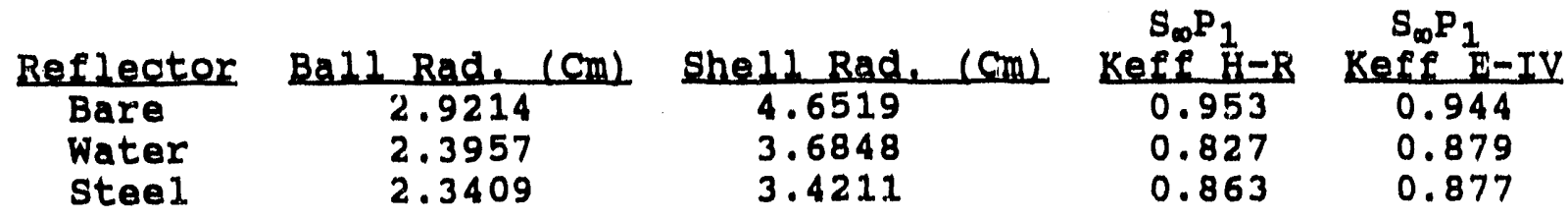

\section{$238 \mathrm{Pu} \mathrm{Ball}$}

Reflector Bare

Water

Steel

\begin{tabular}{cccc} 
Ball Rad. $(\mathrm{Cm})$ & Shell Rad, (Cm) & $\begin{array}{c}S_{\infty} P_{1} \\
\text { Keff } H-R\end{array}$ & $\begin{array}{c}S_{\infty} P_{1} \\
\text { Keff }\end{array}-I V$ \\
\hline 4.2309 & 4.6519 & 0.946 & 1.013 \\
3.3105 & 3.6848 & 0.888 & 1.035 \\
3.0078 & 3.4211 & 0.858 & 0.930
\end{tabular}

\section{$\frac{0.5238 \mathrm{Pu} 8 \mathrm{gWy}_{\mathrm{Y}}+0.5239 \mathrm{Pu} \text { 80u }}{\mathrm{Pu}}$}

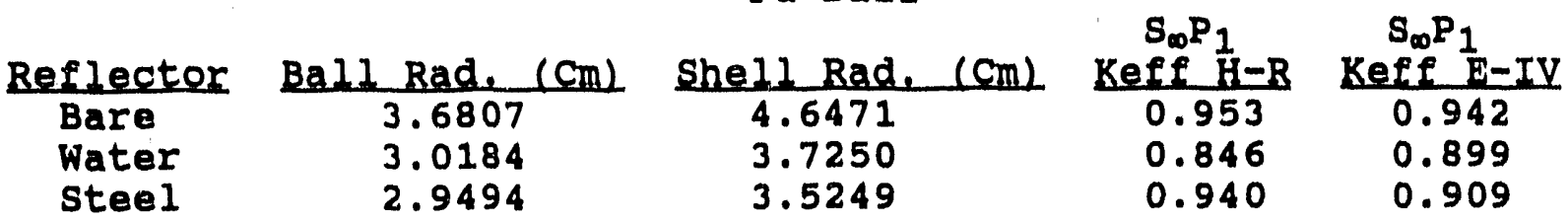

$$
238 \mathrm{Pu} \mathrm{Ball}
$$

Reflector

Water

Steel

Batl Rad. (Cm)

3.6961

2.8920

2.6276

$\frac{0.75238 \mathrm{Pu} 80 \mathrm{y}+0.25239 \mathrm{Pu} 80 \mathrm{YY}}{2{ }_{\mathrm{Pu} \mathrm{Ball}}}$

Reflector Bare

Water

Steel

Ball Rad. $(\mathrm{Cm})$
$\begin{aligned} & 4.2134 \\ & 3.4552 \\ & 3.3762\end{aligned}$

Shell Rad.

$\mathrm{S}_{\infty} \mathrm{P}_{1}$
4.6471
3.7250
3.5249
0.909
0.887

$S_{\infty} P_{1}$

0.943

$\operatorname{Seff}_{\infty} P_{1}-I V$
1.007
1.046
0.952




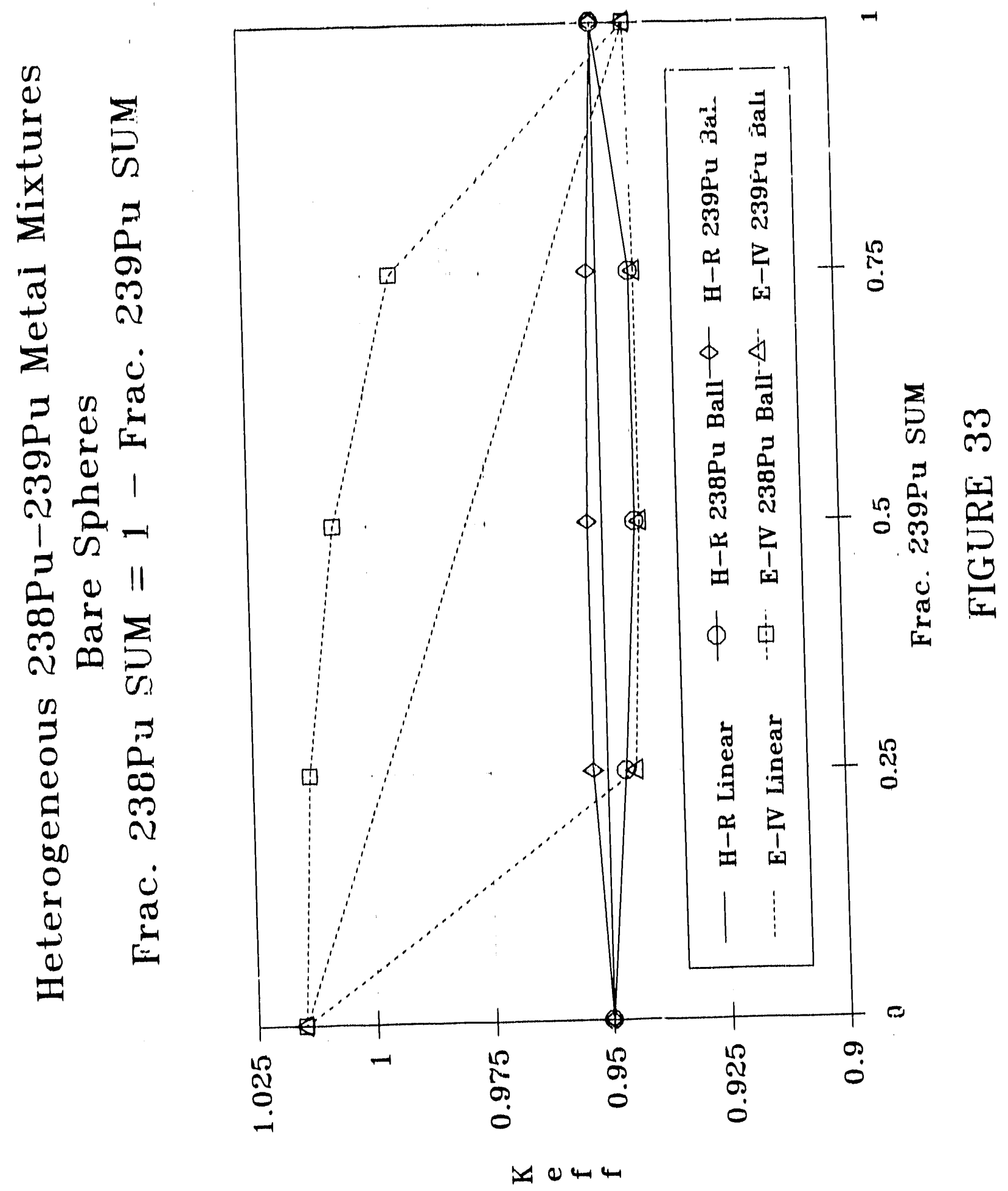



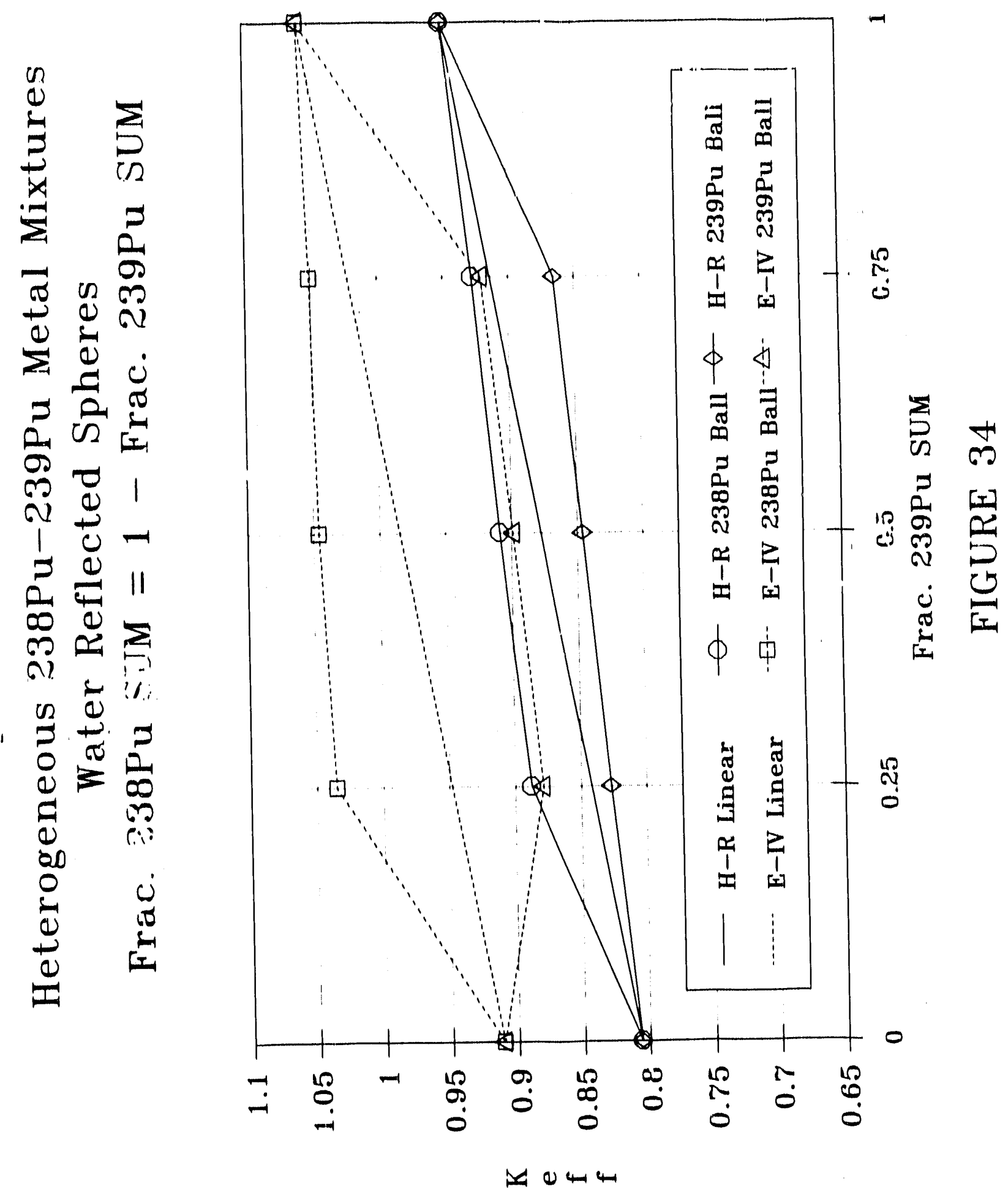

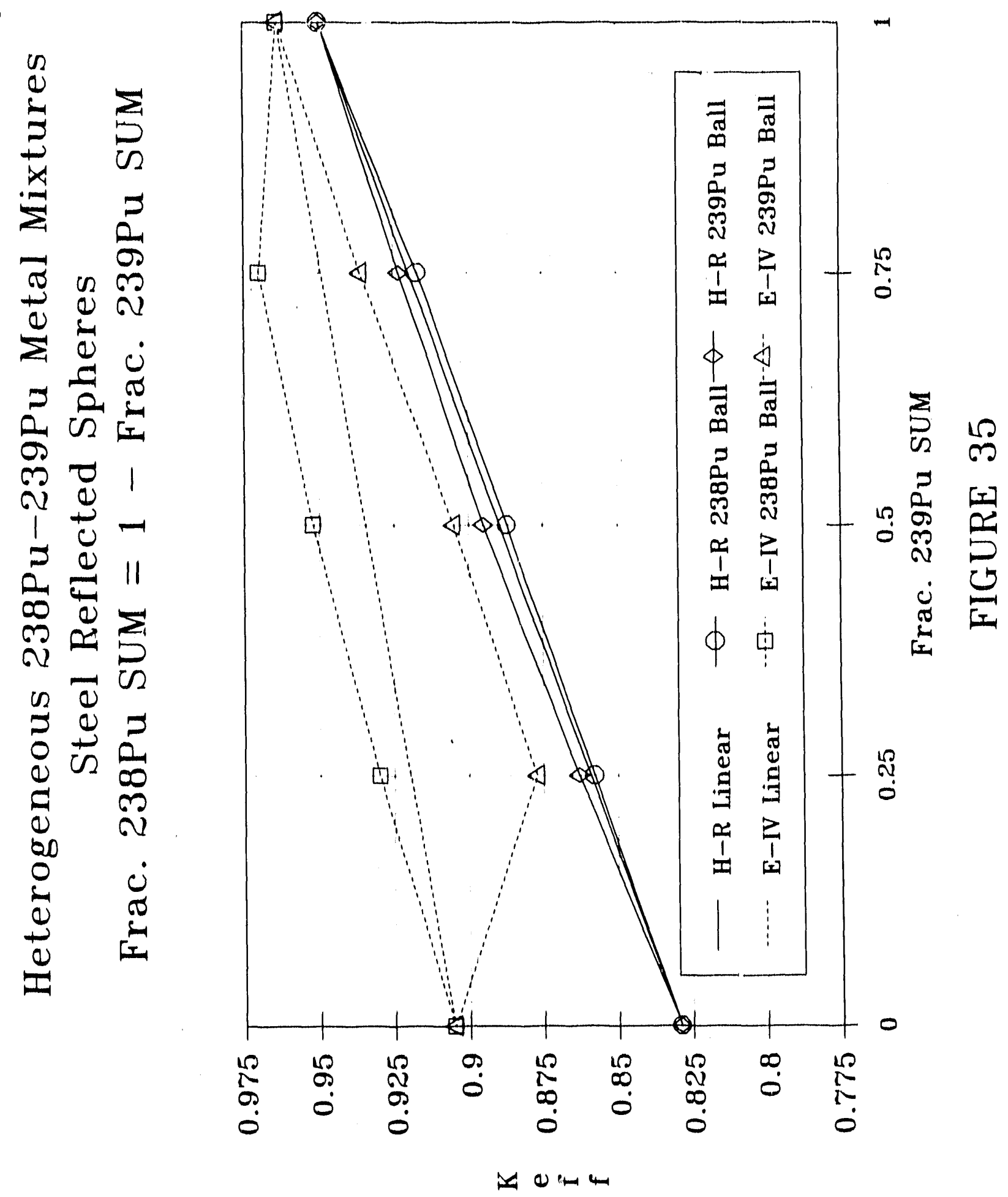
cross section meghanism for this is exactly the same as for the 235 $\mathrm{U}$ shell and $24 \mathrm{Pu}_{\mathrm{Pa}}$ ball substituting fissile for fissile and fissionable for fissionable. The Hansen-Roach cross sections for $238 \mathrm{Pu}$ display a somewhat different set of ratios in the high energy region. Table XV shows the comparative data for the two isotopes.

TABLE XV

Hansen-Roach Cross section Ratios for ${ }^{238} \mathrm{Pu}$ and ${ }^{239} \mathrm{Pu}$

\begin{tabular}{|c|c|c|c|c|}
\hline \multirow{2}{*}{ Energy Region } & \multicolumn{2}{|c|}{$\nu \Sigma_{\mathrm{f}} / \Sigma_{\mathrm{a}}$} & \multicolumn{2}{c|}{$\Sigma_{\mathrm{s}} / \Sigma_{\mathrm{a}}$} \\
\cline { 2 - 5 } & $238 \mathrm{Pu}$ & $239 \mathrm{Pu}$ & $238 \mathrm{Pu}$ & $23{ }^{23 \mathrm{Pu}}$ \\
\hline High: > 1 Mev & 3.0 & 3.1 & 2.1 & 1.25 \\
\hline Intermediate: 10 ev - 1 Mev & 0.5 & 2.2 & 0.2 & 0.3 \\
\hline Thermal: < 10 ev & $<0.002$ & 2.7 & 0.1 & 0.15 \\
\hline
\end{tabular}

Here ${ }^{233} \mathrm{Pu}$ is the best scatterer, but there is no essential difference in fissions between the nuclides. These cross sections make the geometry with a $239 \mathrm{Pu}$ ball produce more net fissions. What is most surprising is the relatively. large increase in Keff for the ENDF/B-IV cross sections.

$238 \mathrm{Pu}$ The calculated results for water reflected heterogeneous 34. These results return to those observed previously that a net increase in fissions occurs for the fissionable isotope in the ball. Heie both Hansen-Roach and ENDF/B-IV confirm the same result. The spectrum change that produces this result arises from the increase in thermal fissions in the shell outer regions. In addition the water reflects a significant number of the fast neutrons providing possible additional fissions.

The results for the steel reflected ${ }^{238} \mathrm{Pu}-239 \mathrm{Pu}$ metal ball shell arrangements are shown in Figure 35 . These results are similar to the bare sphere results except that the magnitude of the changes in $\mathrm{K}_{\text {eff }}$ are significantly lower. The difference from the bare sphere case appears to be that the steel reflector enhances the fissions in the $238 \mathrm{Pu}$ shell for the $239 \mathrm{Pu}$ ball case which raises the lower curve without changing the ${ }^{238} \mathrm{Pu}$ ball case very much.

The overall result of these heterogeneous fissilefissionable metal ball-shell cases is that little confirmation of the Rule-of-Fractions safety margins may be found.

The last cases examined were for homogenaous fissilefissionable solution spheres, except that in this case the most reactive fissionable solution is a metal sphere. A few calculations were done to assure that reactivity does decrease 
when a ${ }^{235} \mathrm{U}$ solution SUM is homogenized with a ${ }^{240} \mathrm{Pu}$ metal SUM. Results for these calculations are shown in Table XVI and Figures 36,37 , and 38. Calculations were only performed with HansenRoach cross sections.

The results of these calculations shoyed that in every case the loss of fissions in fast fissioning $240 \mathrm{Pu}$ decreased reactivity below a $K_{\text {eff }}$ of 0.25 . This results from the presence of water producing a dominant thermal spectrum.

The calculated results from all of the fissile-fissionable mixtures examined can be summarized as follows:

- Homogeneous metal mixtures of fissionable-fissile nuclides do not confirm the safety margins of the Rule-of-Fractions except for a few cases.

- Heterogeneous metal mixtures of flssionable-fissile nuclides do not confirm the safety margins of the Rule-of-Fractions.

- Homogeneous solution mixtures of fissionable-fissile nuclides confirm the safety margins of the Rule-Of-Fractions.

Overall there is no compelling reason to use the Rul--ofFractions with fissionable-fissile mixtures of nuclides.

\section{CONCLU8ION8}

The conclusion from the calculated examples in this study is that the Rule-of-Fractions cannot be relied on to preserve an acceptable margin of safety for any arbitrary combination of fissile and fissionable nuclides. However, for certain specific conditions the Rule-of-Fractions margin was preserved. The conditions under which it appears valid are:

- Homogeneous mixtures of fissile-firsile metals.

- Homogeneous mixtures of fissionabie-fissionable solutions.

- Homogeneous mixtures of fissile-fissionable solutions.

Even these conditions must be viewed with suspicion because this study examined only binary mixtures (two nuclides), and most circumstances of application of the Rule-of-Fractions can have more nuclides than two.

It should be noted that the calculated examples in this study represent pathological cases because such combinations of nuclides are not experienced in real world processing of fissile/fissionable mixtures of nuclides. These nuclides were chosen because of the quality of their cross section data and enabling various combinations of nuclides to be examined. In addition ball-shell arrangements of nuclides or stochiometric mixing of nuclides are rare events in real world handling of fissile/fissionable nuclides. These geometries and assumptions were made to enable well defined cases and ease in caicuiation. 
TABLE XVI

\section{CALCOLATYIONB OF HOYOGENEOUS MIXTURES OF $23^{3}$ N NW 24 PU BOLDTION BINGLE ONIT MAB8ES}

\section{$0.25235080 Y+0.75240$ Pu 80Y}

\begin{tabular}{|c|c|c|c|c|c|}
\hline $\begin{array}{l}\text { Reflector } \\
\text { Bare } \\
\text { Water } \\
\text { steel }\end{array}$ & $\begin{array}{c}\text { Density }(\mathrm{cm} / \mathrm{cc}) \\
3.3951 \\
3.9487 \\
4.1757\end{array}$ & $\begin{array}{c}\text { Wt. } t 235 \mathrm{U} \\
1.031 \\
1.001 \\
0.999\end{array}$ & $\begin{array}{l}\text { Wt. } 240 \text { Pu } \\
73.299 \\
70.059 \\
79.117\end{array}$ & $\begin{array}{l}\text { Wt. } \% 0 \\
22.800 \\
17.709 \\
17.659\end{array}$ & $\begin{array}{l}\text { Wt. } \% \text { H } \\
2.870 \\
2.231 \\
2.225\end{array}$ \\
\hline
\end{tabular}

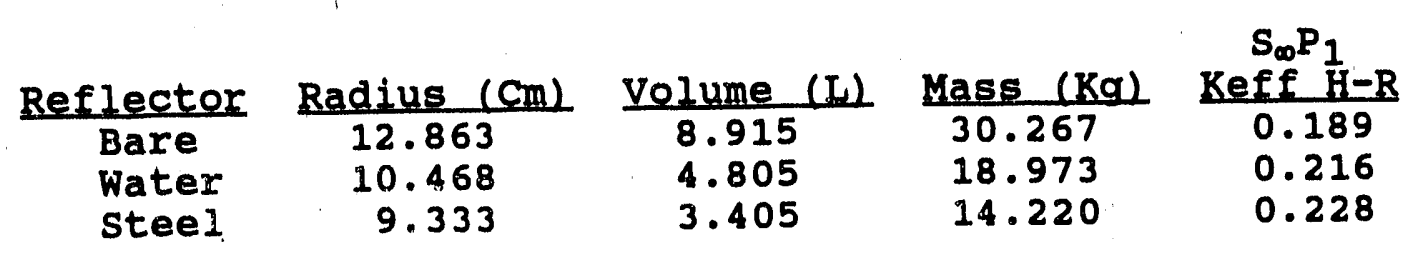

\section{$0.5235080 x+0.5240948 U_{x}$}

Reflector Density (am/cc) Wt. \& 235U Wt. \& 240Pu

$\begin{array}{llr}\text { Bare } & 1.8805 & 2.016 \\ \text { Water } & 2.2149 & 2.118 \\ \text { steel } & 2.2188 & 2.219\end{array}$

47.782

Wt. $\%$ O

Wt. 8 H

44.589

5.613

55.721

37.444

4.718

steel

2.2188

55.808

37.370

4.709

Reflector Radius (Cm) Volume (I) Mass (Ka)

$\begin{array}{lccc}\text { Bare } & 15.743 & 16.343 & 30.953 \\ \text { Water } & 12.460 & 8.103 & 17.947 \\ \text { Steel } & 11.308 & 6.057 & 13.439\end{array}$

$S_{\infty} P_{1}$

Keff $\mathrm{H}-\mathrm{R}$

0.124
0.130
0.140

\section{$0.75235080 x+0.25240$ Pu 80x}

Reflector Density (cm/cc) Wt. $235 \mathrm{U}$ Wt.z $240 \mathrm{Pu}$

$\begin{array}{lll}\text { Bare } & 1.3310 & 2.959 \\ \text { Water } & 1.4522 & 3.369 \\ \text { Steel } & 1.4536 & 3.365\end{array}$

23.372

29.551

$\frac{\text { Wt. } \% \text { O }}{65.433} \frac{\text { Wt. H H }}{8.236}$

59.574

7.506

Steel

1.4536

29.724

59.5127 .499

Reflector Radius (Cm) Volume (I) Mass (Ka)
Bare
water
17.837
14.064
12.763
23.772
11.651
8.708

31.640

16.920

12.659

$S_{\infty} P_{1}$

Keff H-R

0.193

0.191

0.184

\footnotetext{
water reflector thickness - $0.48 \mathrm{~cm}$. steel reflector thickness - $25.4 \mathrm{~cm}$. $H-R$ - Hansen-Roach Cross sections
} 


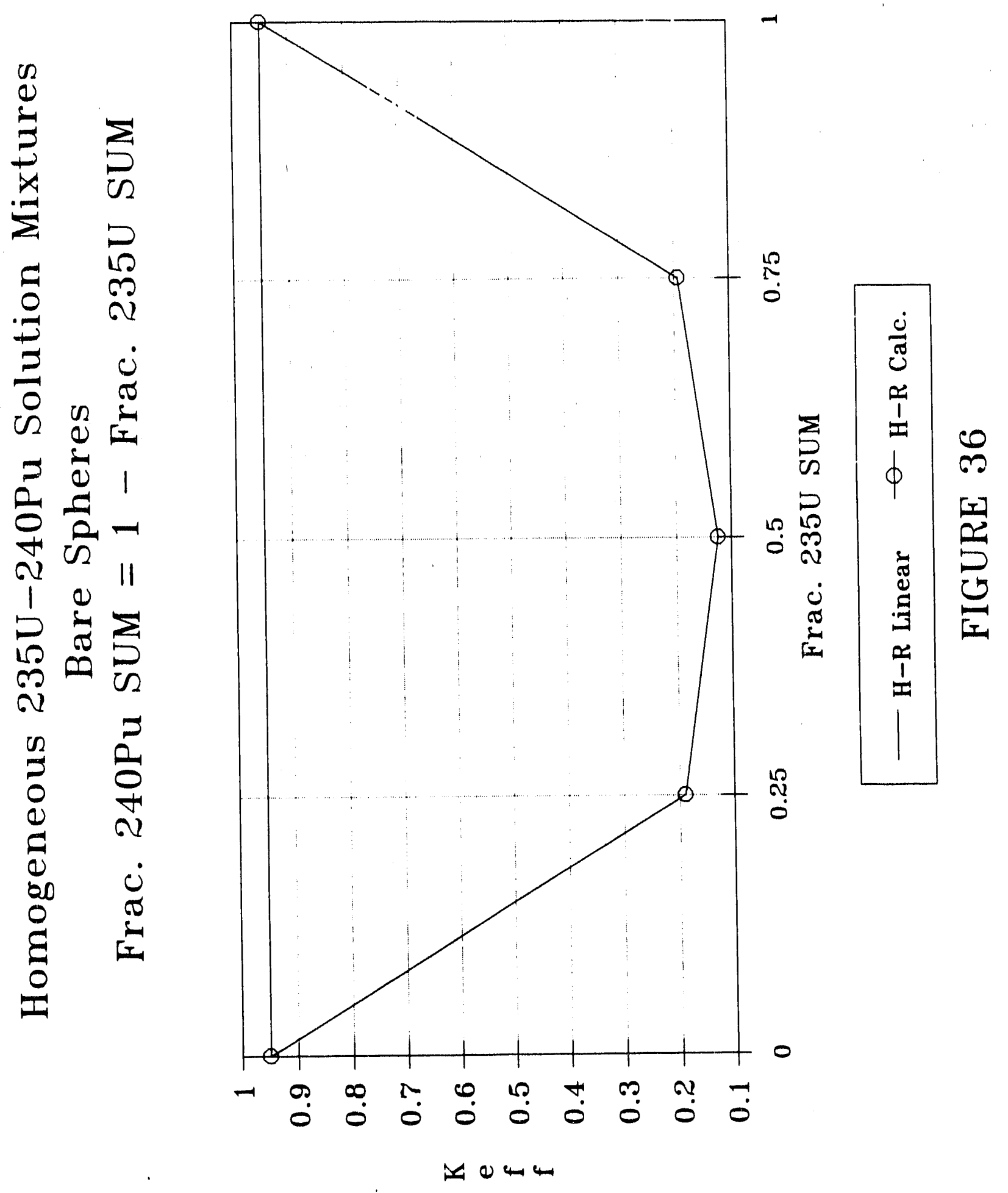



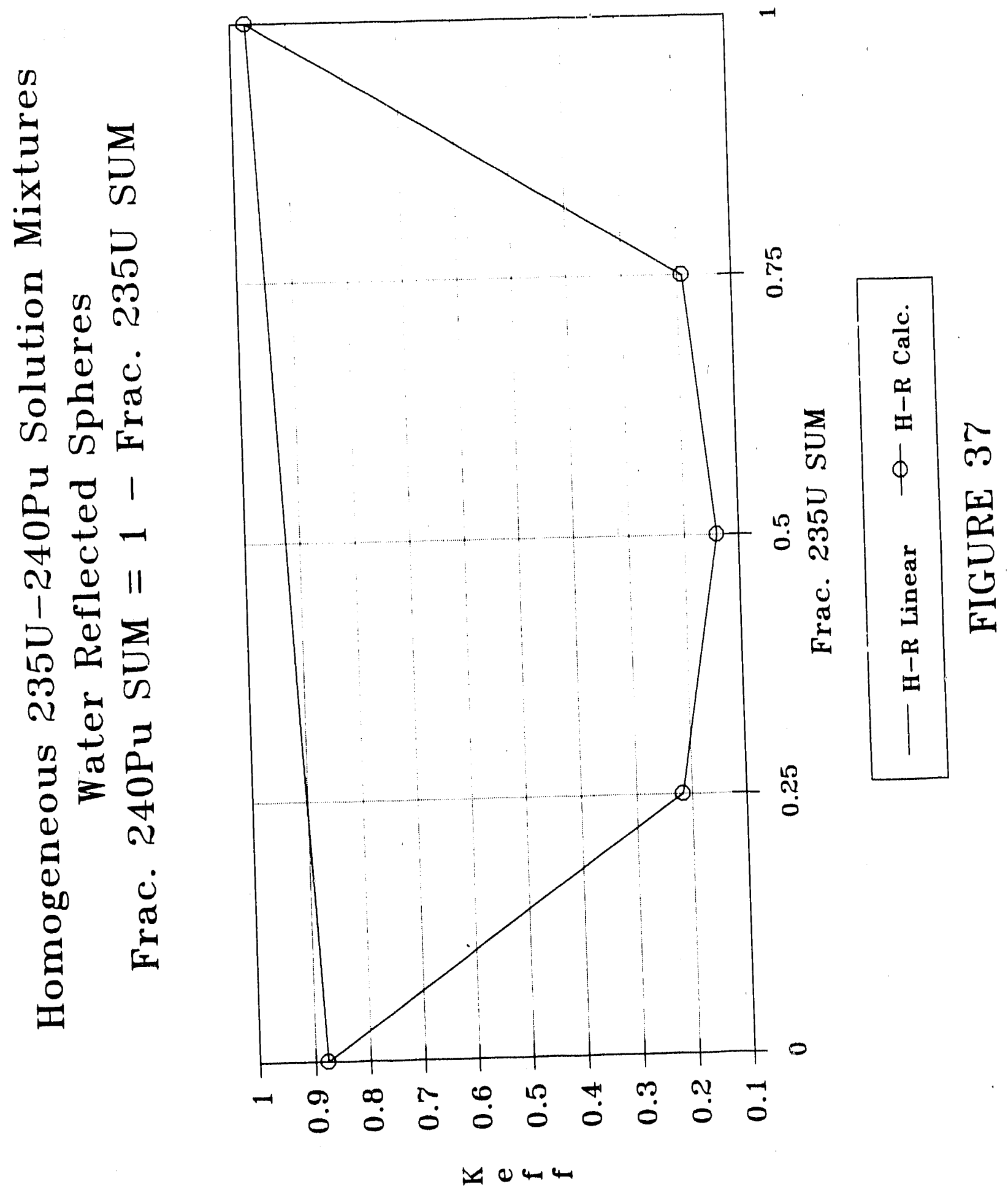

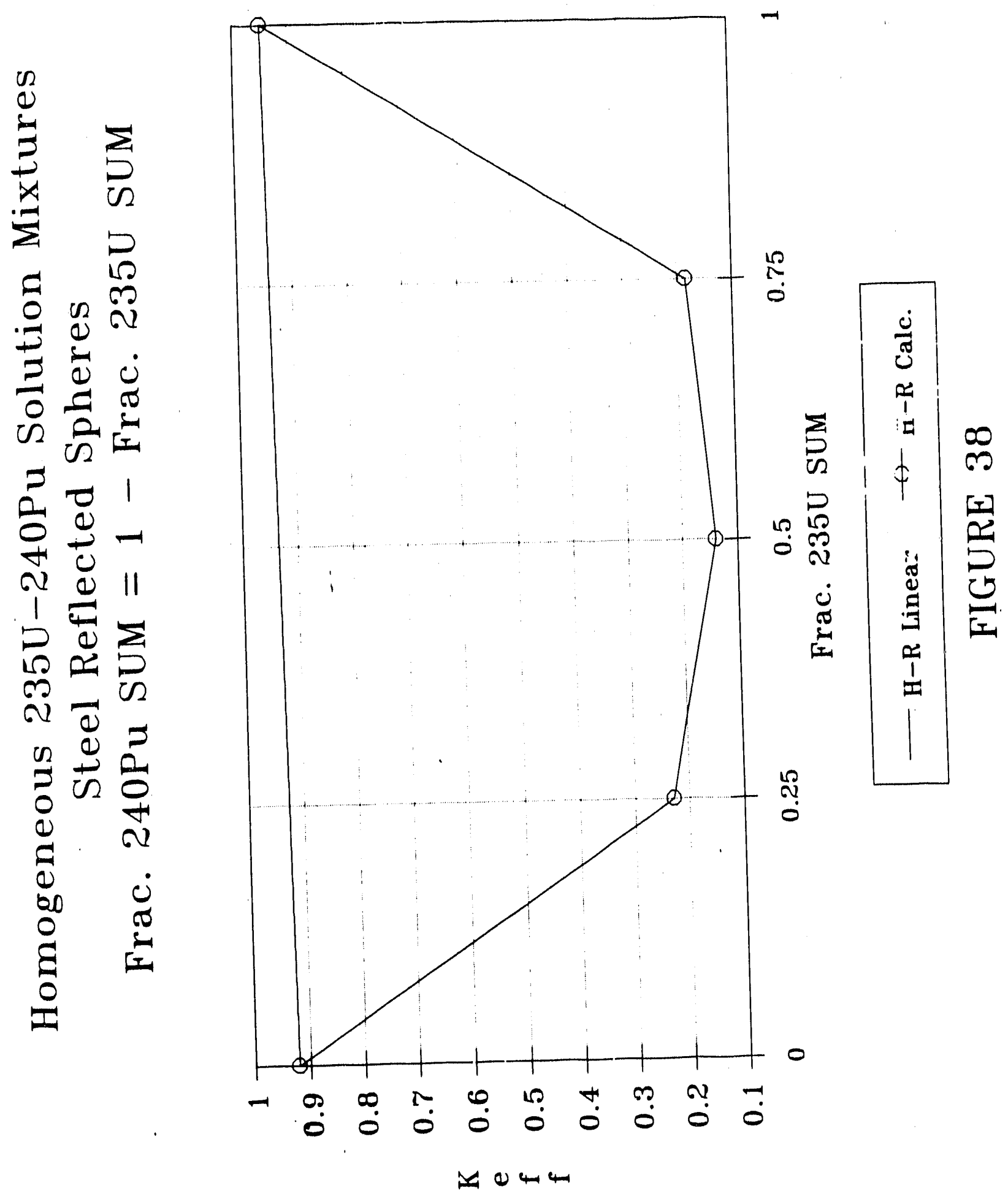
An application of the Rule-of-Fractions that was not examined in this study is illustrated in the shipping package in section II. Here geometry effects are important as well as mixtures of nuclides. The addition of the second parameter may well make the Rule-Of-Fractions valid over a wide range of applications. This requires justification which was not provided by this study.

The conclusion of this study is that the Rule-of-Fractions does not provide a generally applicable way of assuring a specified or desired margin of safety in Keff. Its use must be justified by computational or experimental results that demonstrate its applicability to the specific condition of use, and establish the range of parameters over which the rule may be applied.

\section{x. REFERELCER}

1. ANSI/ANS National standard, Nuclear criticality control of 8pecial Actinide Element, ANSI/ANS 8.15, American Nuclear Society, La Grange Park, IL (Reaffirmed October 30, 1987)

2. Bafety Analysis Roport For Packaging - sRs 9970 shipping package (U), Report to be issued, Westinghouse Savannah River Company, Aiken, sC.

3. BAVAMNAR RIVER IABORATORY - BRI CRITICALITY BAFETY MANOAL (0), Procedure Manual WSRC Q13.3, Westinghouse Savannah River Company, Aiken, SC.

4. ANSI/ANS National standard, Nuclear Criticality bafety In Operations With Fissile Materials outside Reactors, ANSI/ANS 8.1, American Nuclear Society, La Grange Park, IL (Reaffirmed November 30,1988 )

5. Operational safety Requirements, Beparations Area Operations, Building 221-F, Yow 8pecial Recovery (O), WSRC-RP-90-700, Westinghouse Savannah River Company, Aiken, SC (1990)

6. W. W. Engle, Jr., A Osers kanual for ANI8N, K-1693, Oak Ridge Gaseous Diffusion Plant, Oak Ridge, TN (1967)

also:

H. K. Clark, JosHon Nuclear Criticality Bafety Modules (U), DPSTM-86-700-3, section 1, E. I. du Pont de Nemours \& Company, Savannah River Laboratory, Aiken, SC (1986)

7. G. E. Hansen and W. H. Roach, Bix and sixteon Group Cross sections for Fast and Intermediate Critical Assemblies, LAMS-2543, Los Alamos Scientific Laboratory, Los Alamos, NM (1961)

8. O. Ozer and D. Garber, ENDF/B-IV Bummary Documentation, BNL17541 (ENDF-201), Brookhaven National Laboratory, Upton, NY (1973) 
9. H. K. Clark, JosHox wuelear Criticality Bafety Modules (U), DPSTM-86-700-3, Section 7, E. I. du Pont de Nemours \& Company, Savannah River Laboratory, Aiken, SC (1986)

10. H. K. Clark, JosHoA ruolear criticality sarety Modules (U), DPSTM-86-700-3, Section 3, E. I. du Pont de Nemours \& Company, Savannah River Laboratory, Aiken, SC (1986)

11. H. K. Clark, JosHon ruclear Criticality sarety Modulea (U), DPSTM-86-700-3, section 7, E. I. du Pont de Nemours \& Company, Savannah River Laboratory, Aiken, SC (1986)

12. W. F stubbins, et al., "The Neutron Production Cross Section of $238_{\mathrm{Pu}}$ in a Fast Spectrum", wuol. Bod. ENG., 25, 377 (1966)

13. H. K. Clark, "Subcritical Limits For special Fissile Actinides", Nuclear Technology, 48, 164 (1980) 

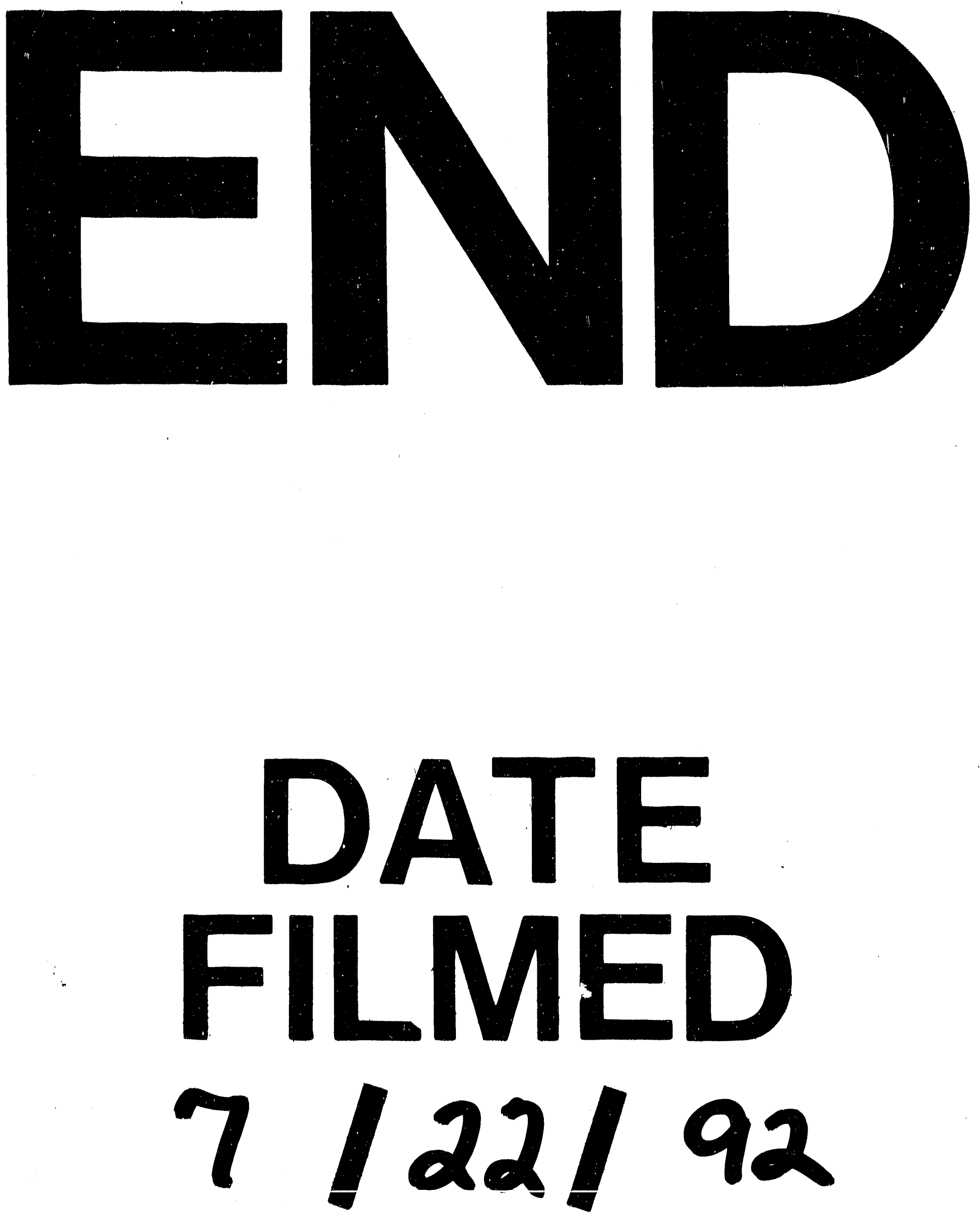
